\title{
jpen
}

AUTARQUIA ASSOCIADA À UNIVERSIDADE DE SÃO PAULO

\section{AVALIAÇÃO DE DOSE NOS SISTEMAS DE IRRADIAÇÃO DE BOLSAS DE SANGUE PARA ESTERILIZAÇÃO}

\author{
PAULO MÁRCIO DE OLIVEIRA
}

Dissertação apresentada como parte dos requisitos para obtenção do Grau de Mestre em Ciências na Área de Tecnologia Nuclear - Aplicações

Orientadora:

Profa. Dra. Letícia L. C. Rodrigues 


\title{
INSTITUTO DE PESQUISAS ENERGÉTICAS E NUCLEARES
}

Autarquia associada à Universidade de São Paulo

\section{AVALIAÇÃO DE DOSE NOS SISTEMAS DE IRRADIAÇÃO DE BOLSAS DE SANGUE PARA ESTERILIZAÇÃO}

\author{
PAULO MÁRCIO DE OLIVEIRA
}

\author{
Dissertação apresentada como parte dos \\ requisitos para obtenção do Grau de \\ Mestre em Ciências na Área de Tecnologia \\ Nuclear - Aplicações \\ Orientadora: \\ Profa. Dra. Letícia L. C. Rodrigues
}


À minha querida esposa, amiga e incentivadora, Danielle. Aos meus pais, Demétrio e Benedita, pela minha formação e personalidade. 


\section{AGRADECIMENTOS}

Agradeço, primeiramente, a Deus por tudo que tem me proporcionado nesta caminhada longa e cheia de percalços.

Ao Instituto de Pesquisas Energéticas e Nucleares - Comissão Nacional de Energia Nuclear de São Paulo (IPEN-CNEN/SP), na pessoa do Superintendente Dr. José Carlos Bressiani, pela oportunidade de realizar e concluir o curso de pós-graduação.

À minha orientadora, Profa. Dra. Letícia L. C. Rodrigues, pela oportunidade, orientação, paciência, compreensão, confiança e credibilidade. Por tudo o que me ensinou e pelas valiosas sugestões.

À Coordenação de Aperfeiçoamento de Pessoal de Nível Superior (CAPES), pelo apoio financeiro.

À Comissão Nacional de Energia Nuclear (CNEN), à Fundação de Amparo à Pesquisa do Estado de São Paulo (FAPESP) e ao Conselho Nacional de Desenvolvimento Científico e Tecnológico (CNPq) à Coordenação de Aperfeiçoamento de Pessoal de Nível Superior (CAPES).

A Universidade Federal de São Paulo (UNIFESP), ao Departamento de Diagnostico por Imagem (DDI) e ao Centro de Higiene das Radiações (CHR) pela oportunidade de realização da pesquisa em equipamentos da instituição.

Ao Hospital Santa Catarina pela oportunidade de realização da pesquisa com uso dos equipamentos da instituição.

À Profa. Dra. Linda Viola Ehlin Caldas, chefe da Gerência de Metrologia das Radiações (GMR) do IPEN, pela hospitalidade, paciência, pelos ensinamentos e por ser, sempre, prestativa e gentil. 
Ao Dr. Orlando Rodrigues Junior, pela reconstrução das imagens tridimensionais do simulador desenvolvido neste trabalho e pelo auxilio sempre que necessitei.

Ao Eng. Carlos G. da Silveira e à Enga . Elizabeth S. R. Somessari, do Centro de Tecnologia das Radiações (CTR) do IPEN, pelas irradiações das amostras nos irradiadores com fonte de ${ }^{60} \mathrm{Co}$ do Laboratório de Fontes Intensas de Radiação (LFIR) do IPEN, pelo esclarecimento de dúvidas, pela amizade e informações relevantes ao processo de irradiação das amostras.

À Dra. Regina Bitelli, pela oportunidade, assistência e pelas sugestões que acrescentou ao trabalho desenvolvido em colaboração com a UNIFESP.

À MSc. Bianca Maciel, pela paciência, compreensão e pela grande ajuda e disponibilidade que teve durante todo o desenvolvimento do trabalho na UNIFESP.

Ao MSc. Roberto Sakuraba, pela assistência e direcionamento no uso de equipamentos para aquisição de dados e pela disponibilidade de tempo que dedicou ao trabalho desenvolvido.

Ao Tecnólogo Benedito Herbert de Souza, pela disponibilidade de tempo concedida ao trabalho desenvolvido no Departamento de Diagnóstico por Imagem (DDI - UNIFESP) e pela amizade.

À toda a equipe da Gerência de Ensino (GE) do IPEN, na pessoa do Presidente da Comissão de Pós-graduação (CPG), Dr. Delvonei Alves de Andrade, pelos serviços prestados e pela gentileza.

À toda a equipe da Biblioteca do IPEN, "Terezine Arantes Ferraz", por sempre ter sido tão prestativa.

À minha querida esposa e amiga, Danielle da C. Silva, pelo amor, paciência, compreensão e por ter me incentivado de modo a não permitir que 
eu desistisse dos meus objetivos em momento algum. Sem dúvida, meus agradecimentos se estendem a toda a sua família, que muito me ajudou e incentivou.

Minhas queridas irmãs, Leila Patrícia de Oliveira e Alexandra Regis de Oliveira, pelo carinho, incentivo e por tudo que estão fazendo em favor de minha mãe que se encontra em estado, bastante, delicado.

Às senhoras, Maria Lourdes da Costa e Maria do Socorro da Costa, pelo incentivo, compreensão, pela amizade e pelo auxílio quando se fez necessária as suas intervenções.

À todos os membros da GMR do IPEN, pelo incentivo e amizade.

À todos os professores, amigos e colegas da pós-graduação, por todo o conhecimento transmitido, incentivo, companheirismo e amizade.

Enfim, a todos que contribuíram de alguma maneira para que o objetivo fosse atingido. 
"O sucesso nasce do querer, da determinação e persistência em se chegar a um objetivo. Mesmo não atingindo o alvo, quem busca e vence obstáculos, no mínimo fará coisas admiráveis." 


\title{
AVALIAÇÃO DE DOSE NOS SISTEMAS DE IRRADIAÇÃO DE BOLSAS DE SANGUE PARA ESTERILIZAÇÃO
}

\author{
PAULO MÁRCIO DE OLIVEIRA
}

\section{RESUMO}

O procedimento de esterilização do sangue é adotado para que sejam mínimas as condições necessárias de manifestação da doença do enxertoversus-hospedeiro associada à transfusão de sangue (DECHT), síndrome, geralmente fatal. Neste trabalho foi utilizada a solução Fricke gel desenvolvida no IPEN para a obtenção de um objeto simulador de bolsa de sangue empregada no processo de irradiação para esterilização de sangue em um irradiador Gammacell Elan. O objetivo desse trabalho é determinar a homogeneidade da dose aplicada no processo de esterilização de bolsas de sangue. Foram utilizadas as técnicas de Espectrofotometria de Absorção Óptica (EAO), Densitometria Óptica (DO), Termoluminescência (TL) e Ressonância Magnética por Imagem (RMI) e os softwares Numaris ${ }^{\circledR}$ versão 4 (Syngo-MR-A30) e MatLab ${ }^{\circledR}$ (versão 9.0) para a aquisição e reconstrução das imagens. O estudo foi realizado posicionando no canister do irradiador inicialmente uma bolsa e, posteriormente, duas bolsas e três bolsas e aplicando uma dose nominal de 25 Gy. O fabricante do irradiador Gammacell Elan recomenda que seja irradiado em cada procedimento o valor máximo de três bolsas de sangue. Os resultados obtidos indicam que o irradiador Gammacell Elan não demostrou homogeneidade na distribuição da dose. Irradiando uma bolsa de sangue foi obtida uma diferença de dose de 3,65 \%, enquanto para duas bolsas de sangue essa diferença caiu para 2,65 \% e quando posicionadas três bolsas de sangue a diferença de dose foi de 1,88 \%. O tempo de abertura de fechamento do equipamento de irradiação é responsável pela diferença de dose 3,17 \% acima da dose prevista à realização das irradiações de bolsas de sangue. Os resultados obtidos usando o filme radiocrômico Grafchromic MD-55 de dupla face aplicada à avaliação de dose no sistema de rotação de irradiação não apresentou resultados reproduzíveis. 


\title{
EVALUATION OF RADIATION DOSE IN SYSTEMS OF BLOOD BAG FOR STERILIZATION
}

\author{
PAULO MÁRCIO DE OLIVEIRA
}

\begin{abstract}
The blood sterilization procedure is adopted so that the necessary conditions of manifestation of graft-versus-host syndrome, disease associated with blood transfusion (AT-GVHD), usually a fatal disease, are minimal. In this work the Fricke gel solution developed in IPEN was used for obtaining a phantom of blood bag used in the irradiation process for sterilization of blood in a Gammacell irradiator Elan. The objective of this study was to evaluate the homogeneity of the applied radiation sterilization dose in the blood bags. Optical Absorption Spectroscopy (OAS), Optical Densitometry (OD), Thermoluminescence ( $\mathrm{TL}$ ) and Magnetic Resonance Imaging (MRI) technics and Numaris ${ }^{\circledR}$ software version 4 (Syngo-MR-A30) and MatLab ${ }^{\circledR}$ (version 9.0) softwares were used to images acquisition and reconstruction. The study was conducted positioning one bag in the canister irradiator initially and subsequently two and three bags together and applying a nominal dose of 25 Gy. The Elan Gammacell irradiator manufacturer recommends that the maximum values of three blood bags are irradiated in each procedure. The results indicate that the Gammacell irradiator Elan did not presents homogeneous dose distribution. Radiating a blood bag a dose difference of $3.65 \%$ was obtained, while for two bags of blood that difference dropped to $2.65 \%$ and when positioned three blood bags the difference in dose was $1.88 \%$. The opening and closing times of the irradiation source is responsible for an increasing in the planned irradiation dose of 3.17\%. The results obtained using radiochromic double-sided Grafchromic MD-55 film applied to dose evaluation in the rotation irradiation system did not present reproducible results.
\end{abstract}




\section{SUMÁRIO}

1. INTRODUÇÃO

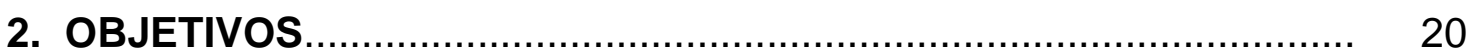

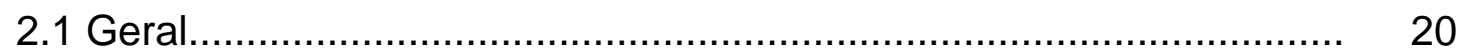

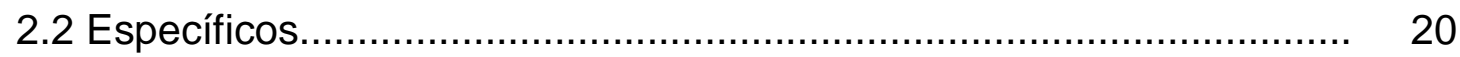

3. FUNDAMENTOS TEÓRICOS .......................................................... 21

3.1 Classificação da Radiação........................................................... 21

3.2 Interações de Fótons com a Matéria................................................. 22

3.2.1 Fótons Indiretamente Ionizantes............................................... 22

3.2.2 Espalhamento Rayleigh..................................................... 23

3.2.3 Efeito Fotoelétrico..................................................................... 24

3.2.4 Efeito Compton.................................................................. 25

3.2.5 Produção de Pares.............................................................. 26

3.2.6 Reações Fotonucleares......................................................... 27

3.2.7 Predominâncias Relativas de Efeitos: Fotoelétrico, Compton e Produção de Pares...................................................................... 28

3.3 Dosimetria das Radiações............................................................. 29

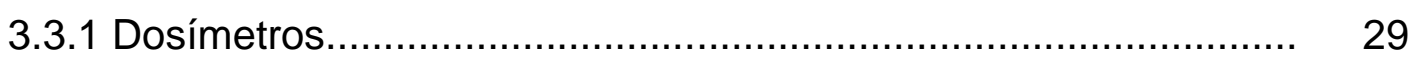

3.3.2 Propriedades dos Dosímetros.................................................. 31

3.3.3 Precisão e Exatidão.............................................................. 32

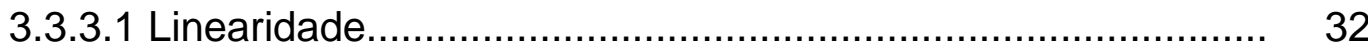

3.3.3.2 Sensibilidade............................................................. 33

3.3.3.3 Limites Inferior e Superior de Detecção................................. 33

3.3.3.3.1 Limite Inferior do Intervalo de Dose................................ 33

3.3.3.3.2 Limite Superior do Intervalo de Dose.............................. 34

3.3.3.4 Estabilidade ...................................................................... 35

3.3.3.4.1 Antes da Irradiação.................................................... 35

3.3.3.4.2 Depois da Irradiação.................................................... 35

3.3.3.5 Dependência com a Taxa de Dose..................................... $\quad 36$

3.3.3.6 Dependência Energética.................................................... 36

3.3.3.7 Dependência Direcional ou Angular.................................... 36

3.3.3.8 Resolução Espacial......................................................... 37 
3.3.3.9 Condição de Uso.

3.3.3.10 Homogeneidade do Lote................................................... 37

3.3.3.11 Fatores de Influência......................................................... 38

3.4.4 Dosimetria Química.............................................................. 38

3.4.5 O Dosímetro Fricke Gel.......................................................... 39

3.4.6 Ressonância Magnética por Imagem (RMI)............................... 40

3.4.6.1 Teoria Básica................................................................ 41

3.4.6.2 O Espaço K................................................................... 43

3.4.6.3 Relaxação Nuclear............................................................. 44

3.4.6.3.1 Tempo de Relaxação Longitudinal $\left(T_{1}\right)$........................ 45

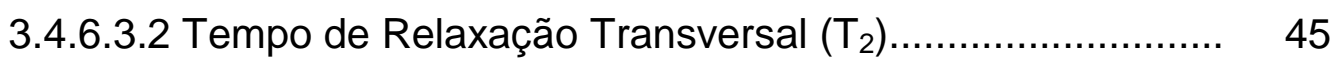

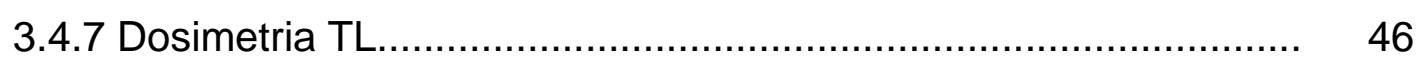

3.4.7.1 Termoluminescência.......................................................... 46

3.4.8 Filme Radiocrômico............................................................. 48

3.4.9 Absorção Óptica.................................................................... 49

4. MATERIAIS

4.1 Reagentes e Vidrarias......................................................... 50

4.2 Bolsas de Sangue de $300 \mathrm{~mL}$ para Transferência............................ 51

4.3 Filme Radiocrômico para Dosimetria de Fótons de Energia Alta Grafchromic MD-55 .......................................................... 52

4.4 Equipamentos de Medição........................................................ 54

4.5 Sistemas de Irradiação............................................................. 56

4.6 Dosímetros Termoluminescentes (DTLs) - LiF:Mg,Ti (TLD-100)....... 58

4.7 Densitômetro Óptico.................................................................. 59

4.8 Programas Computacionais........................................................ 60

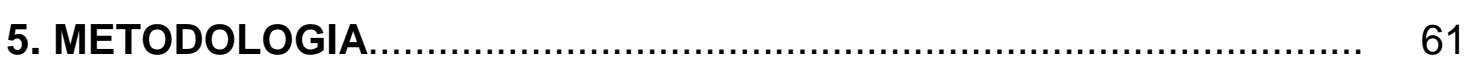

5.1 Preparação da Solução Fricke Gel................................................... 61

5.2 Bolsas de Sangue de $300 \mathrm{~mL}$ para Transferência............................. 62

5.3 Filme Radiocrômico para Dosimetria de Fótons de Energia Alta -

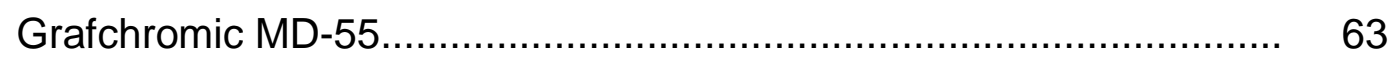

5.4 Dosímetros Termoluminescentes (DTLs) - LiF:Mg, Ti ....................... 63

5.5 Espectrofotometria............................................................... 64

5.6 Irradiação das Amostras.............................................................. 64 


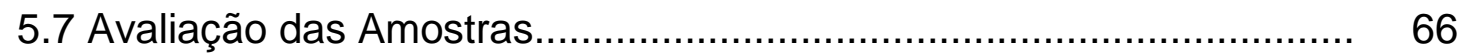

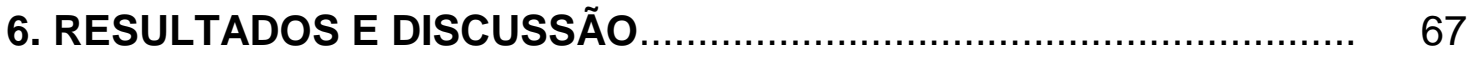

6.1 Espectro de Absorção Óptica da Solução Fricke Gel......................... 67

6.2 Resposta Espectrofotométrica da Solução Fricke Gel Irradiada no

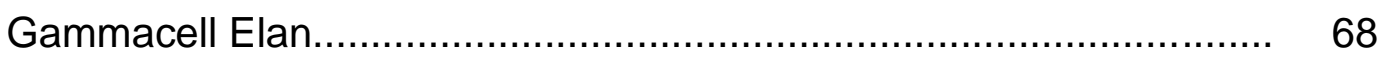

6.3 Resposta da Solução Fricke Gel Avaliada por Técnica de RMI......... 69

6.4 Bolsas de Sangue de $300 \mathrm{~mL}$ para Transferência.............................. 69

6.5 Imagens de Corte das Cubetas de $5 \mathrm{~mL}$ e das Bolsas de Sangue de $300 \mathrm{~mL}$ Geradas por RMI ......................................................... 74

6.6 Reconstrução da Imagem 3D das Bolsas de Sangue de $300 \mathrm{~mL}$

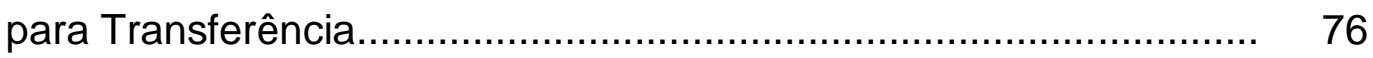

6.7 Filme Radiocrômico para Dosimetria de Fótons de Energia Alta Grafchromic MD-55 .................................................................. 78

6.8 Dosímetros Termoluminescentes (DTLs) - LiF:Mg,Ti ..................... 81

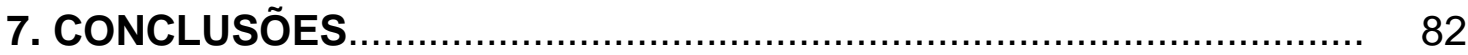

8. REFERÊNCIAS BIBLIOGRÁFICAS ......................................... 83 


\section{Lista de Figuras}

Figura 1. Representação do efeito fotoelétrico (TAHUATA, et. al., 2003).

Figura 2. Representação do efeito Compton (TAHUATA, et. al., 2003)

Figura 3. Representação da produção de pares (TAHUATA, et. al., 2003)

Figura 4. Regiões de predominância relativa das três principais formas de interação de fótons com a matéria (YOSHIMURA, 2009)

Figura 5. Respostas características de dois sistemas dosimétricos diferentes (IZEWSKA; RAJAN, 2005).

Figura 6. Ilustração de uma função dose-resposta duplamente estimada resultante de uma diminuição na sensibilidade de um dosímetro em doses altas (ATTIX, 1986).....

Figura 7. Magnetização longitudinal, $M_{z}$; Magnetização transversal, $M_{x y}$; Magnetização de equilíbrio, $M_{0}$ 42

Figura 8. Bolsa de sangue de $300 \mathrm{~mL}$ para transferência. 52

Figura 9. Equipamento de RMI modelo Siemens Magnetom Symphony Maestro Class (1,5 T)

Figura 10 (a) Irradiador Gammacell Elan; (b) Conjunto de suporte das fontes do Gammacell Elan

Figura 11 (a) Blindagem móvel e rotor do irradiador; (b) Posicionamento do canister no rotor

Figura 12. Equipamento sem proteção externa......................................... 59

Figura 13. Densitômetro Densoquick 2H............................................. 59

Figura 14. Cubetas preenchidas com Solução Fricke gel irradiadas e não irradiadas.

Figura 15. (a) Bolsa de sangue para transferência de $300 \mathrm{~mL}$ preenchida com solução Fricke gel; (b) Bolsa de sangue para transferência de 300 $\mathrm{mL}$ preenchida com solução Fricke gel irradiada posicionada no equipamento de RMI. 


\section{Lista de Figuras}

Figura 16. Espectro de absorção óptica da solução Fricke gel: irradiação gama com ${ }^{60} \mathrm{Co}$; (a) e irradiação gama com ${ }^{137} \mathrm{Cs}$; (b) para doses entre 0,6 e 45,0 Gy

Figura 17. Resposta espectrofotométrica da solução Fricke gel irradiada com ${ }^{137} \mathrm{Cs}$.

Figura 18. Curva de calibração da solução Fricke gel irradiada com ${ }^{137} \mathrm{Cs}$ : técnica de RMI.

Figura 19. Regiões selecionadas nas bolsas de sangue para estudo do sinal da RMI.

Figura 20. Relação entre as doses e as regiões selecionadas de uma bolsa de sangue irradiada com dose mínima de 25 Gy determinada pela Resolução RDC 57 de 2010 da ANVISA......

Figura 21. Relação entre as doses e as regiões selecionadas de duas bolsas de sangue irradiadas com dose mínima de 25 Gy determinada pela Resolução RDC 57 de 2010 da ANVISA......

Figura 22. Relação entre as doses e as regiões selecionadas nas bolsas de sangue periféricas quando foram posicionadas três bolsas irradiadas com dose mínima de 25 Gy determinada pela Resolução RDC 57 de 2010 da ANVISA.

Figura 23. Corte sagital de uma Imagem obtida por MRI de um das um conjunto de cubetas de $5 \mathrm{~mL}$ não irradiadas

Figura 24. Corte sagital de uma imagem obtida por MRI de um conjunto de cubetas de $5 \mathrm{~mL}$ irradiadas com doses de $20 \mathrm{~Gy}, 25$ Gy e 30 Gy.

Figura 25. Corte coronal de uma imagem obtida por MRI de um conjunto de três bolsas de sangue irradiadas com dose de $25 \mathrm{~Gy}$; (a) periférica 1; (b) intermediária; (c) periférica 2 


\section{Lista de Figuras}

Figura 26. (a) Imagem reconstruída da RMI no plano coronal da aquisição da bolsa de sangue não irradiada; (b) Imagem reconstruída da RMI no plano axial da aquisição da bolsa de sangue não irradiada; (c) Imagem reconstruída da RMI no plano coronal da aquisição da bolsa de sangue irradiada com dose de 25,0 Gy $\left({ }^{137} \mathrm{Cs}\right)$; (d) Imagem reconstruída da RMI no plano axial da aquisição da bolsa de sangue irradiadas com dose de 25,0 Gy $\left({ }^{137} \mathrm{Cs}\right)$

Figura 27. Resposta em função da dose do filme Grafchromic MD-55 irradiado com ${ }^{60} \mathrm{Co}$.

Figura 28. Resposta em função da dose do filme Grafchromic MD-55 irradiado com ${ }^{137} \mathrm{Cs}$

Figura 29. Curva de dose-resposta do filme Grafchromic MD-55 irradiado com ${ }^{60} \mathrm{Co}$ no irradiador Gammacell 220 (curve A); e com ${ }^{137} \mathrm{Cs}$ Gammacell Elan (curve B).....

Figura 30. Espectro de absorção óptica do filme Grafchromic MD-55 irradiado com fonte de ${ }^{137} \mathrm{Cs}$ em rotação com doses entre 1,0 e 40,0 Gy......

Figura 31. Curva de dose-resposta do filme Grafchromic MD-55 irradiado com ${ }^{137} \mathrm{Cs}$ analisado com técnica de espectrofotometria óptica...

Figura 32. Curva de dose-resposta dosímetros LiF:Mg,Ti (TLD-100)....... 


\section{Lista de Tabelas}

Tabela 1. Sistemas dosimétricos e exemplos de dosímetros utilizados (McLAUGHLIN, et. al.,1989); (GALANTE, 2003); (SEHESTED, 1970).

Tabela 2. Características do Grafchromic MD-55 descritas pelo fabricante.

Tabela 3. Parâmetros operacionais do espectrofotômetro marca SHIMADZU ${ }^{\circledR}$....

Tabela 4. Parâmetros operacionais do espectrofotômetro marca Agilent Technologies ${ }^{\circledR}$

Tabela 5. Parâmetros operacionais do equipamento de RMI marca Siemens ${ }^{\circledR}$..... 56

Tabela 6. Especificações técnicas do Densoquick $2 \mathrm{H}$.....

Tabela 7. Relação entre a intensidade do sinal avaliado por RMI e as regiões selecionadas nas bolsas de sangue para uma bolsa. 70

Tabela 8. Relação entre a intensidade do sinal avaliado por RMI e as regiões selecionadas nas bolsas de sangue para duas bolsas.

Tabela 9. Relação entre a intensidade do sinal avaliado por RMI e as regiões selecionadas nas bolsas de sangue para três bolsas (bolsa intermediária)

Tabela 10. Relação entre a intensidade do sinal avaliado por RMI e as regiões selecionadas nas duas bolsas de sangue periféricas quando foram posicionadas três bolsas 


\section{Lista de Siglas e Abreviaturas}

DECHT Doença do enxerto-versus-hospedeiro associada à transfusão de sangue

AT-GVHD Transfusion-associated graft-vs-host disease

EAO Espectrofotometria de Absorção Óptica

DO Densitometria Óptica

RMI Ressonância Magnética por Imagem

OAS Technical Optical Absorption Spectroscopy

OD Optics Densitometry

MRI Magnetic Resonance Imaging

EPR Ressonância Paramagnética Eletrônica

DTL Dosímetro Termoluminescente

IAEA International Atomic Energy Agency

A.O. Absorção Óptica

BOLD Blood Oxygen Level Dependent

fMRI functional Magnetic Resonance Imaging

SE Spin Eco

GRE Gradiente Eco

RF Radiofrequência

TR Tempo de Repetição

TE Tempo de Eco

UV Ultravioleta

OSL Luminescência Oticamente Estimulada

TI Tempo de Inversão

PMMA Polimetil Metacrilato

PVC Policloreto de Vinila

LDA Laboratório de Doses Altas

GMR Gerência de Metrologia das Radiações

CTR Centro de Tecnologia das Radiações

DDI Departamento de Diagnóstico por Imagem

CHR Coordenadoria de Higiene das Radiações

LMD Laboratório de Materiais Dosimétricos

IPEN Instituto de Pesquisas Energéticas e Nucleares 


\section{INTRODUÇÃO}

A irradiação de sangue é proposta para esterilizar e diminuir os riscos de uma possível contaminação numa transfusão. A doença do enxerto-versushospedeiro associada à transfusão de sangue (DECHT) é uma síndrome rara e geralmente fatal com mortalidade estimada entre 90 e 100\% dos casos registrados. A DECHT inicia através da reação imunológica entre linfócitos transplantados e tecidos de hospedeiro, e ocorre, por ataque imune das células T do doador às do hospedeiro, as quais diferem daquelas pelos antígenos de histocompatibilidade. Pode ocorrer em pacientes com imunossupressão, como por exemplo, pacientes transplantados, após a transfusão de hemocomponentes celulares. O desconhecimento da síndrome, o retardo no diagnóstico, o curso rápido e a ausência de resposta ao tratamento estão relacionados à má evolução do paciente. A melhor forma de abordagem da DEVH-AT é a prevenção através da irradiação gama dos hemocomponentes (LANDI; OLIVEIRA, 1999). A irradiação do sangue total e dos componentes celulares demonstrou ser um procedimento eficaz no processo de inativação dos linfócitos T, eliminando os riscos da DECHT. Pelo menos, 25,0 Gy devem ser liberados no plano médio do volume irradiado para garantir a completa inativação dessas células. O Conselho Europeu de saúde orienta que a irradiação deve ser de pelo menos 25,0 Gy, mas não mais do que $50 \mathrm{~Gy}$ (GOES et. al., 2008). As radiações $X$ e gama, ambas radiações ionizantes, quebram as moléculas de DNA dos linfócitos $T$ e previnem uma resposta imunológica contra o receptor.

No procedimento de esterilização de hemocomponentes do sangue são utilizados irradiadores constituídos de fontes de ${ }^{137} \mathrm{Cs}$ ou de ${ }^{60} \mathrm{Co}$ com atividades variando entre 22 e 89 TBq (600-2400 Ci). Os irradiadores podem apresentar um sistema pneumático constituído por um canister, um rotor e blindagem com abertura e fechamento em dois estágios. Um procedimento dosimétrico rigoroso se faz necessário, para o controle da dose liberada na bolsa.

A solução Fricke que tem sido utilizada como dosímetro de referência para determinação da taxa de dose em campos gama e pode ser usada 
também como dosímetro de rotina para a verificação da homogeneidade da dose.

$\mathrm{Na}$ dosimetria de doses altas há recomendação quanto ao uso de filmes radiocrômicos, como o Grafchromic MD-55 que apresenta dupla-face sensível à radiação ionizante. O Grafchromic MD-55, de acordo com o fabricante, é recomendado para uso em rotinas dosimétricas e não apresenta dependência energética para fótons de energia superior a 0,2 MeV. Sua leitura pode ser realizada utilizando densitômetros de transmissão, scanners de filme ou espectrofotômetros.

A técnica de dosimetria termoluminescente das radiações utilizando fluoreto de lítio (LiF:Mg,Ti) é largamente utilizada em dosimetria clínica de pacientes. Sua eficiência é cientificamente comprovada e o uso em rotinas de dosimetria clinica é recomendado por possuir número atômico aproximado ao do tecido humano.

No IPEN, os laboratórios de Materiais Dosimétricos (LMD) e de Doses Altas (LDA), possuem larga experiência no desenvolvimento e caracterização de materiais dosimétricos voltados para a dosimetria externa da radiação, utilizando as técnicas de espectrofotometria (EAO), termoluminescência ( $T L)$, luminescência termicamente estimulada $(\mathrm{OSL})$, ressonância paramagnética eletrônica (EPR) e imagem por ressonância magnética (RMI) (CAVINATO, 2009); (Silva, 2009); (GALANTE, 2003); (MIZUNO, 2007) (MANGUEIRA, 2009).

O laboratório de Dosimetria Química desenvolveu uma solução Fricke gel, preparada com gelatina suína 270 Bloom, encontrada no mercado nacional. O dosímetro Fricke gel, avaliado pela técnica de imageamento por ressonância nuclear, permite a obtenção de objetos simuladores de diferentes formas e tamanhos, bem como a avaliação da distribuição tridimensional da dose. Usaremos a solução Fricke gel para substituir o volume de $300 \mathrm{ML}$ ocupado pelo sangue nas bolsas para transferência, onde serão submetidas aos protocolos recomendados no processo de irradiação para a esterilização e inativação dos linfócitos T. Avaliaremos se ocorre homogeneidade na distribuição da dose e se o procedimento atende as normas vigentes para a esterilização do sangue e de seus hemocomponentes. 


\section{OBJETIVOS}

\subsection{Objetivo Geral}

Avaliar a homogeneidade e a distribuição dose aplicada em bolsas de sangue para esterilização, usando dosímetro Fricke gel.

\subsection{Objetivos Específicos}

- Desenvolver os objetos simuladores a partir de bolsas de sangue preenchidas com gel, utilizando como material geleificante gelatina animal 270 Bloom;

- Avaliar a distribuição da dose e efetuar a reconstrução da dose a partir dos resultados obtidos em pregando as técnicas de espectrofotometria e ressonância magnética por imagem (RMI);

- Comparar os resultados obtidos experimentalmente com os dados obtidos nas simulações computacionais e os dados do planejamento no processo de irradiação das bolsas de sangue.

- Avaliar as doses utilizando o protocolo para esterilização de bolsas de sangue com o filme radiocrômico Grafchromic MD-55 para verificar sua aplicabilidade na dosimetria de rotina do procedimento.

- Avaliar a dose de trânsito na abertura e fechamento do equipamento com técnica de dosimetria termoluminescente (DTL) utilizando o dosímetro de fluoreto de lítio (LiF:Mg,Ti) (TLD - 100). 


\section{FUNDAMENTOS TEÓRICOS}

\subsection{Classificação da Radiação}

A radiação é classificada em duas principais categorias, ionizante e não ionizante. A radiação ionizante pode ionizar a matéria de forma direta ou indireta, dependendo da sua capacidade de ionizar a matéria. O potencial de ionização dos átomos, (isto é, a energia mínima necessária para ionizar um átomo), varia de poucos elétrons-volt (eV) para elementos alcalinos a $24,5 \mathrm{eV}$ para o hélio, um gás nobre (PODGORSAK, 2005).

A radiação ionizante é constituída por fótons ou partículas capazes de determinar, direta ou indiretamente, a formação de íons. A radiação não ionizante, na interação com a matéria biológica não possui energia suficiente para provocar uma ionização, ou seja, não possui energia suficiente para ionizar os átomos ou moléculas com os quais interage.

A radiação diretamente ionizante abrange as partículas carregadas como elétrons, prótons, partículas alfa ( $\alpha$ ) e íons pesados. Estas partículas depositam energia no meio por interações Coulombianas diretas entre a partícula carregada diretamente ionizante e os elétrons orbitais dos átomos do meio.

A radiação indiretamente ionizante compreende os nêutrons (partículas sem carga que não estão sujeitos a interação Coulombiana) e os fótons (raios $X$ e radiação gama) Os fótons ou nêutrons depositam energia no meio material em duas etapas:

- Na primeira etapa, a partícula carregada é liberada no meio (os fótons liberam elétrons ou pósitrons e os nêutrons liberam prótons ou íons pesados);

- Na segunda etapa, as partículas carregadas liberadas depositam energia no meio por intermédio de interações Coulombianas diretas com elétrons orbitais dos átomos do meio. 
As duas radiações, diretamente ionizante e indiretamente ionizante, são utilizadas no tratamento de doenças, principalmente, mas não exclusivamente, para doenças malignas (PODGORSAK, 2005).

A radiação ionizante, além do uso em tratamento de doenças, também é utilizada para esterilização de materiais cirúrgicos, bolsas de sangue e seus hemocomponentes, polímeros para uso na indústria automobilística e irradiação de alimentos.

\subsection{Interações de Fótons com a Matéria}

\subsubsection{Fótons Indiretamente Ionizantes}

Dependendo da origem dos fótons indiretamente ionizantes, pode ocorrer um dos quatro processos de interação:

- Raios X característicos (discretos). As emissões dos fótons ocorrem por processos naturais que permitem a liberação de excesso de energia de um átomo durante a transição de elétrons para suas camadas mais internas;

- $\quad$ Bremsstrahlung ou raios $X$ de freamento (raios $X$ contínuos). Resulta na produção de fótons de energia alta. A variação das forças Coulombianas e da energia da aceleração dos elétrons vai determinar a energia dos fótons de raios $X$ emitidos por meio de interações elétron-núcleo. $A$ emissão total de raios $X$ contínuos por átomo é proporcional $a Z^{2}$, onde $Z$ é o numero atômico do absorvedor, e inversamente proporcional ao quadrado da massa da partícula incidente, que é $Z^{2} / \mathrm{m}^{2}$ (BUSHBERG, 2002).

- Radiação gama (discreta). Não é de natureza corpuscular e constitui-se numa onda eletromagnética emitida por meio de transições nucleares em decaimento gama até atingir o estado de energia mínima (estado fundamental do núcleo); 
- Radiação de aniquilação (discreta). Ocorre quando dois pósitrons perdem energia cinética ao interagir com elétrons. Nessa interação matéria em sua totalidade, é transformada em energia e são emitidos, normalmente, dois fótons em sentidos opostos, com energia de 0,511 MeV $\left(2 \times 0,511 \mathrm{MeV}=2 \mathrm{mc}^{2}\right)$ (PODGORSAK, 2005); (TAUHATA, et. al., 2003); (BITELLI, 2006).

Nas diversas interações possíveis dos fótons com os átomos de um atenuador, a probabilidade para cada interação depende da energia do fóton $(h v)$ e do número atômico $(Z)$ do material absorvedor.

Os processos responsáveis pela interação dos raios gama, completamente ou que podem produzir um espalhamento coerente ou incoerente são: efeito fotoelétrico, produção de pares, espalhamento Rayleigh ou efeito Compton, (PODGORSAK, 2005).

\subsubsection{Espalhamento Rayleigh}

O espalhamento Rayleigh (coerente) corresponde à absorção e a re-emissão da radiação pelo átomo. O fóton é espalhado por uma combinação de ações no átomo. O evento é elástico considerando que o átomo não perde, essencialmente, energia e move-se o suficiente para conservar o momento tendo um único ângulo pequeno de espalhamento. $\mathrm{O}$ fóton interage com um elétron orbital ligado, isto é, com a ação coulombiana do átomo inteiro.

O espalhamento Rayleigh possui importância relativamente pequena em comparação com outras interações dos fótons com a matéria. Sua contribuição representa uma ínfima porcentagem ao coeficiente de atenuação total em tecidos e materiais equivalentes ao tecido (PODGORSAK, 2005); (GREENING, 1985).

A ocorrência dessa interação da radiação com a matéria está sujeita a energias menores que $1 \mathrm{MeV}$ e é dependente de $Z^{2}$ para ângulos pequenos e $Z^{3}$ para ângulos grandes, aproximadamente (PECEQUILO, 2007). 


\subsubsection{Efeito Fotoelétrico}

No processo de absorção por efeito fotoelétrico, um fóton é totalmente absorvido por um átomo. No seu lugar, um fotoelétron rápido é ejetado do átomo. A interação acontece com o átomo como um todo e não pode ocorrer com elétrons livres, uma vez que um elétron livre não pode absorver um fóton sem o momento não seja conservado. O elétron orbital é ejetado do átomo como um fotoelétron (Figura 1 ) com uma energia cinética $(T)$ dada pela Eq. 1:

$$
T=E_{\gamma}-B_{e}
$$

onde $E_{\gamma}=h v$, sendo $E_{\gamma}$ a energia do fóton, $h$ a constante de Planck, $v$ a frequência da radiação e $B_{e}$ a energia de ligação do elétron no orbital (LILLEY, 2006).

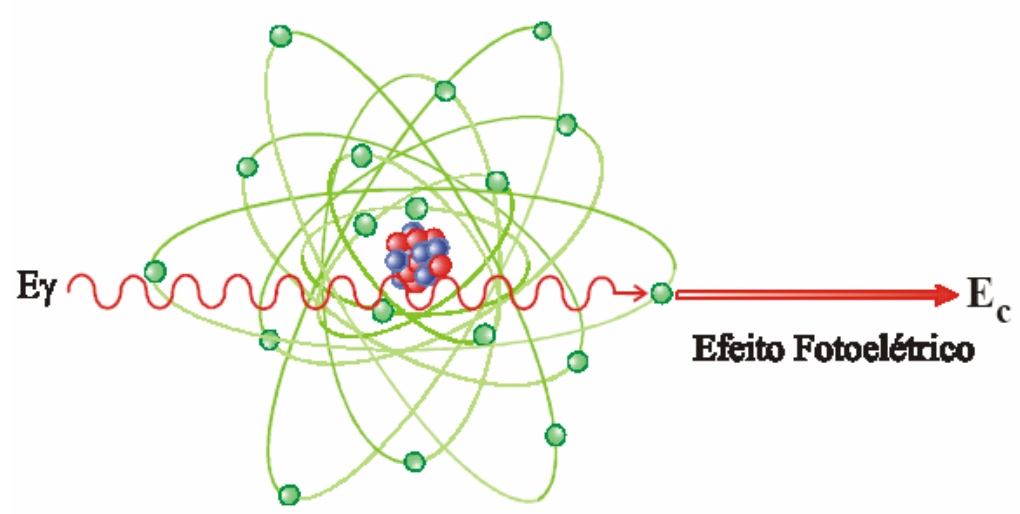

Figura 1. Representação do efeito fotoelétrico (TAHUATA, et. al., 2003).

O efeito fotoelétrico é predominantemente para baixas energias e para elementos químicos de números atômicos ( $Z$ ) elevados. A probabilidade de ocorrência aumenta com $(Z)^{4}$ e decresce rapidamente com o aumento da energia (TAUHATA, et. al., 2003).

A interação cria um íon excitado no material absorvedor com uma vacância em uma de suas camadas. Em geral, esta vacância é rapidamente preenchida com a captura de um elétron livre do meio e/ou por rearranjo de outros elétrons do átomo. Então, um ou mais fótons de raios $X$ característicos 
podem ser produzidos. Na maioria dos casos, os fótons de raios $X$ são reabsorvidos pelo meio (KNOLL, 1999).

A probabilidade de produzir um fotoelétron quando atinge um átomo é fortemente dependente de numero atômico (Z) e da energia $h v$ dos fótons. A probabilidade varia com $Z^{4} /(h v)^{3}$ (TURNER, 2007). Provavelmente ocorra com elétrons de camadas internas, com elétrons fortemente ligados ao núcleo ou quando a energia do fóton incidente é superior à energia de ligação eletrônica.

\subsubsection{Efeito Compton}

O efeito Compton, ao lado do efeito Fotoelétrico, é mais uma manifestação da natureza corpuscular da radiação. Com efeito, ao incidir sobre um elétron de um átomo, a radiação eletromagnética se comporta como se fosse uma partícula e tudo se passa como se fosse uma colisão elástica entre o fóton e o elétron (na primeira aproximação, admitindo livre), com conservação de energia e momento (COHEN, 1971).

A interpretação mais comum para o efeito Compton é que o fóton incidente transfere parte de sua energia para um elétron orbital essencial (livre e estacionário), também chamado de elétron de recuo. Então, o fóton perde parte de sua energia ao elétron recuado e é como fóton, $h v^{\prime}$, espalhado em um ângulo $\theta$ em relação a sua direção inicial (Figura 2). A energia do fóton incidente, $h v$, é muito maior que a energia de ligação do elétron orbital.

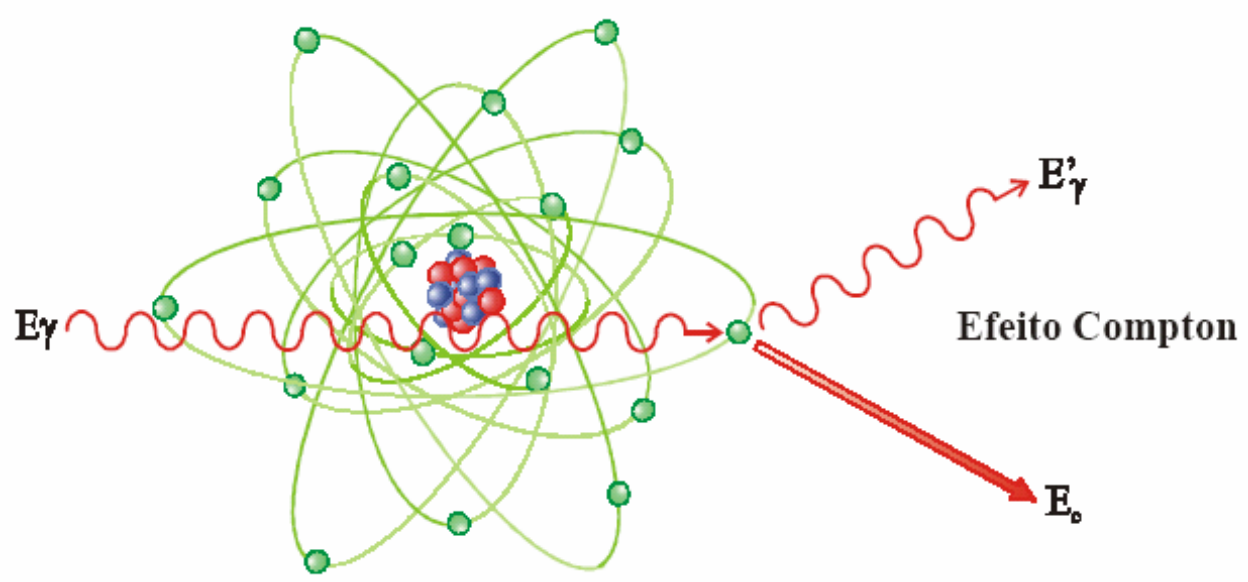

Figura 2. Representação do efeito Compton (TAHUATA, et. al., 2003). 
A energia do fóton após o espalhamento é dada pela Eq. 2 (LILLEY, 2006):

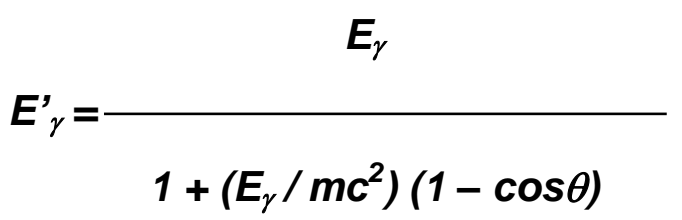

onde $\mathrm{m}_{0} \mathrm{c}^{2}$ é a energia de repouso do elétron (511 keV), $E_{\gamma}$ a energia do fóton incidente e $\boldsymbol{\theta}$ o ângulo de saída do fóton. Para ângulos pequenos a energia transferida, também, é muito pequena (STABIN, 2007).

$\mathrm{O}$ efeito Compton pode ocorrer sob energias de $\approx 1 \mathrm{MeV}$, com diminuição da probabilidade de ocorrência em função do aumento da energia, e é dependente de $Z$, aproximadamente (KNOLL, 1999). Provavelmente ocorrerá com elétrons de camadas mais externas ou fracamente ligadas ao núcleo, dependendo da energia do fóton incidente.

\subsubsection{Produção de Pares}

Um fóton com uma energia de pelo menos duas vezes a energia de repouso do elétron, $h v \geq 2 m c^{2}$, pode ser convertido em um par de elétronpósitron no campo de um núcleo atômico. O fóton é absorvido e toda sua energia é convertida em massa de repouso e energia cinética de um par de elétron-pósitron. A produção de pares pode, também, ocorrer no campo de um elétron atômico, mas há uma pequena probabilidade e o limiar de energia seria da ordem de $4 m_{o} c^{2}$. Quando o processo ocorre em um campo nuclear, o núcleo maciço recua com uma energia insignificante. Portanto, a energia $h v$ do fóton é convertida em $2 m c^{2}$ mais as energia cinéticas $T_{-}$e $T_{+}$dos parceiros (TURNER, 2007).

Nesse processo (Figura 3), a energia do fóton, em sua totalidade, é convertida no campo nuclear coulombiano para a criação de um elétronpósitron emparelhada com energia cinética total dada pela Eq. 3:

$$
T_{-}+T_{+}=h v-2 m c^{2}
$$


Assim como no efeito fotoelétrico, a produção de pares requer um corpo que tenha uma massa maciça mínima e suficiente para a conservação da energia e do momento. Pois, a massa é produzida totalmente da energia do fóton na forma de um par de elétron-pósitron.

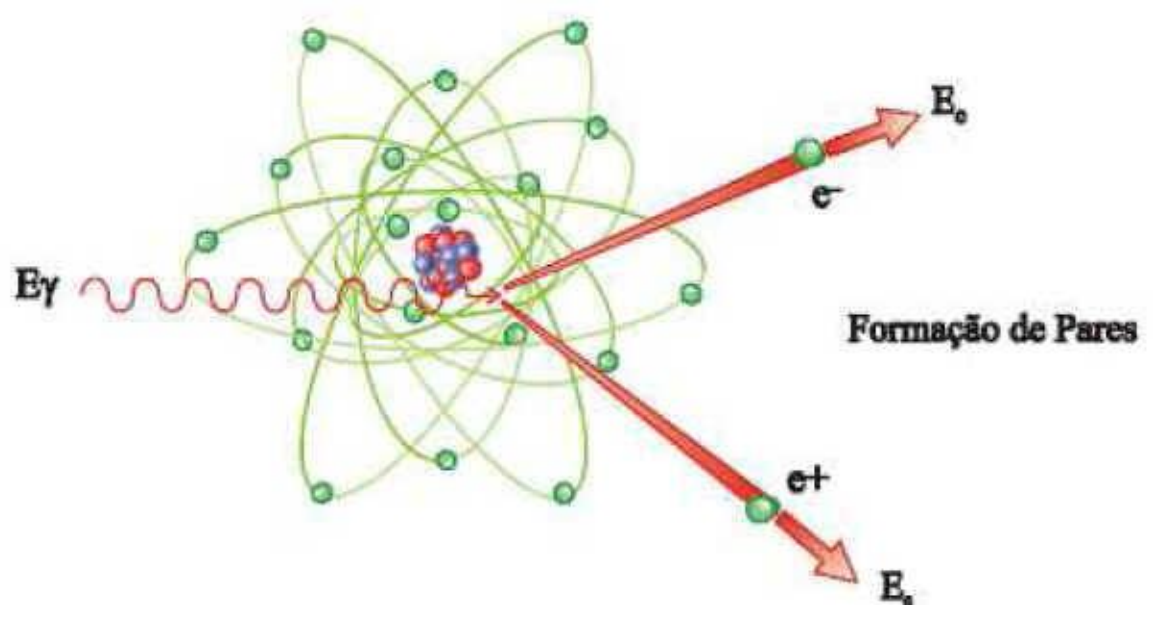

Figura 3. Representação da produção de pares (TAHUATA, et. al., 2003).

Existe uma energia limiar (energia mínima necessária do fóton para o efeito acontecer) de $2 m_{0} c^{2}=1,022 \mathrm{MeV}$ (LILLEY, 2006). No entanto a produção de pares torna-se mais provável com o aumento da energia do fóton. A probabilidade aumenta com a dependência de $Z^{2}$, aproximadamente, em energias maiores que 1,0 MeV , principalmente no intervalo de energia entre 5,0 e 10,0 MeV (PECEQUILO, 2007).

\subsubsection{Reações Fotonucleares}

A principal reação nuclear provocada por fótons é a reação fotonuclear ou reação de fotodesintegração. Um fóton de energia maior que a energia de ligação de nucleons é absorvido, excitando o núcleo, resultado na emissão de um próton [reação $(x, p)$ ] ou um nêutron [reação $(x, n)$ ] com energia cinética suficiente para abandonar o núcleo, que se transforma em um produto da reação radioativo (outra espécie nuclear).

A probabilidade para reações fotonucleares é da ordem de magnitude menor que as probabilidades combinadas do efeito Fotoelétrico, efeito Compton e produção de pares. Entretanto, ao contrário desses processos, 
reações fotonucleares podem produzir nêutrons, que poderia ocasionar, especialmente, problemas de radioproteção. Adicionalmente, núcleos residuais apresentam-se, muitas vezes, radioativos (TURNER, 2007).

O limiar para uma reação fotonuclear particular depende da reação e do núcleo. A energia para esse processo é da ordem de $10 \mathrm{MeV}$ ou superior para a maioria dos núcleos, exceto para os núcleos atômicos do deutério $\left({ }^{2} H\right)$ e do berílio $\left({ }^{9} \mathrm{Be}\right)$, nos quais o limiar é da ordem de $2 \mathrm{MeV}$ (PODGORSAK, 2005); (PECEQUILO, 2007).

\subsubsection{Predominâncias Relativas de Efeitos: Fotoelétrico, Compton e} Produção de Pares

Geralmente, as interações fotoelétricas predominam em energias baixas, mas à medida que energia aumenta, o efeito Fotoelétrico diminui mais rapidamente que o efeito Compton, onde este se torna predominante. Para energias acima de alguns MeV para o fóton a Produção de Pares torna-se a principal contribuição para as interações de fótons com a matéria.

A Figura 4 mostra claramente que o efeito Compton predomina para todos os elementos da tabela periódica para energias de fótons compreendidos entre algumas centenas de keV e alguns MeV. Se os números atômicos são baixos há predominância para todas as energias. Para números atômicos elevados existe maior probabilidade de ocorrência do efeito fotoelétrico para energias baixas e a para energias elevadas a produção de pares.

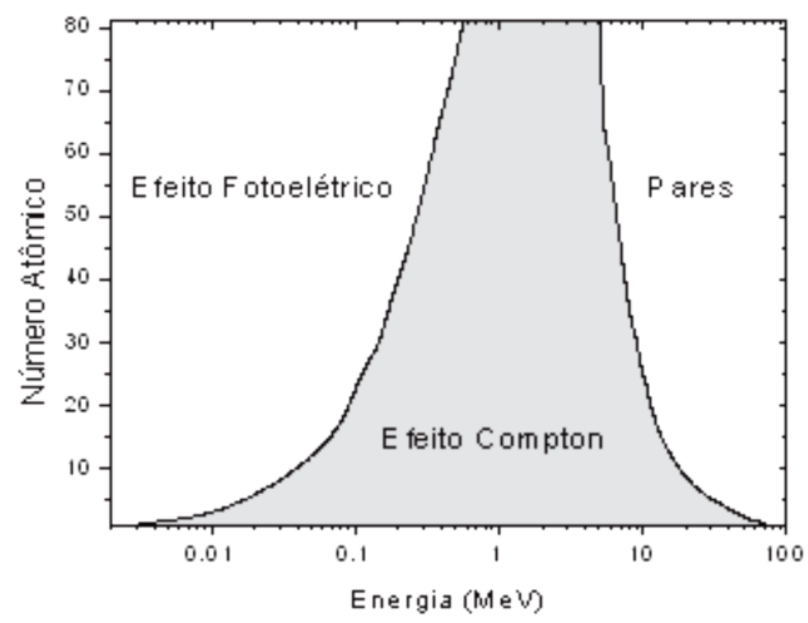

Figura 4. Regiões de predominância relativa das três principais formas de interação de fótons com a matéria (YOSHIMURA, 2009). 
No processo de irradiação de sangue com radiação gama de ${ }^{60} \mathrm{Co}$ ou ${ }^{137}$ Cs é a interação dominante.

\subsection{Dosimetria das Radiações}

A dosimetria das radiações (ou simplesmente "dosimetria") é o ramo da ciência que busca relacionar, através de tentativas, medidas de grandezas específicas feitas no campo das radiações ionizantes aplicadas em sistemas físicos, químicos e/ou relacionadas a efeitos biológicos que a radiação poderia produzir em um alvo (TURNER, 2007). Dosimetria é o ato de medir ou estimar as doses de radiação ionizante. O resultado da medição é o valor de uma grandeza dosimétrica expressa como o produto de um valor numérico e uma unidade de medida adequada.

A rigor, a dosimetria das radiações lida com a medição da taxa de dose absorvida ou da dose que resulta da interação da radiação ionizante com a matéria. De forma mais ampla, refere-se à determinação (por medição ou estimativa) dessas grandezas, assim como de algumas das grandezas radiologicamente relevantes tais como, exposição e kerma (ATTIX, 1986).

\subsubsection{Dosímetros}

O dispositivo, instrumento ou sistema que avalia as medições diretamente ou indiretamente das grandezas exposição, kerma, dose absorvida ou dose equivalente, ou suas derivadas do tempo (taxas), ou grandezas relativas à radiação ionizante é um dosímetro. Um sistema de dosimetria é composto pelo dosímetro e seu leitor (ATTIX, 1986).

Para um dispositivo funcionar como um dosímetro de radiação ionizante deve possuir, pelo menos, um efeito físico, que é uma função da quantidade da medição dosimétrica, que pode ser utilizado para uma calibração adequada. Para ser útil, dosímetros de radiação devem apresentar várias características desejáveis, por exemplo, na radioterapia, o conhecimento exato tanto da dose absorvida em água num ponto específico e a sua

distribuição espacial são importantes, bem como a possibilidade de obter a dose para um órgão de interesse no paciente. Neste contexto, as propriedades 
dosimétrica desejáveis serão caracterizadas pela exatidão e precisão, a dependência linear, com a dose ou taxa de dose, a dependência energética, a dependência direcional e a resolução espacial da resposta. Obviamente, nem todos os dosímetros podem satisfazer todas as características, por conseguinte, a escolha de um dosímetro de radiação e do seu leitor deve ser criteriosa, tendo em vista as exigências da situação de medição (IZEWSKA, 2005).

Os dosímetros são classificados em físicos ou químicos. Os dosímetros químicos podem se apresentar nos estados sólido, líquido ou gasoso. A Tabela 1 apresenta exemplos dos tipos de dosímetros existentes.

Tabela 1. Sistemas dosimétricos e exemplos de dosímetros utilizados (McLAUGHLIN, et al.,1989); (GALANTE, 2003); (SEHESTED, 1970)

\begin{tabular}{|c|c|}
\hline Sistema & Dosímetros \\
\hline \multirow{4}{*}{ Físico } & Calorímetros; \\
\hline & Câmaras de ionização; \\
\hline & Semicondutores. \\
\hline & Dosímetros Termoluminescentes (DTLs). \\
\hline \multirow{12}{*}{ Químico } & Líquidos \\
\hline & Dosímetro de sulfato ferroso (dosímetro Fricke); \\
\hline & Dosímetro de dicromato; \\
\hline & Soluções radiocrômicas coloridas; \\
\hline & Sólidos \\
\hline & Aminoácidos. \\
\hline & Ex.: alanina e vidros; Plásticos. \\
\hline & Ex.: CTA*, PMMA** e filmes radiocrômicos. \\
\hline & ( ${ }^{\star}$ Triacetato de celulose; ${ }^{* \star}$ Polimetilmetacrilato). \\
\hline & Gasosos \\
\hline & Óxido de nitrogênio (NO); \\
\hline & Dióxido de carbono $\left(\mathrm{CO}_{2}\right)$. \\
\hline
\end{tabular}

No ano de 1950, introduziu-se a indução da carga na forma de cores produzidas pela ação da radiação ionizante em corantes na investigação das doses em géis (DAY; STEIN, 1950). Em 1957 as profundidades de doses de 
fótons e elétrons em géis de ágar foram pesquisadas utilizando espectrofotometria (ANDREW et. al, 1957). Atualmente, esses dosímetros químicos vêm sendo bastante estudados na forma de gel e gel polímero, os quais permitem a avaliação tridimensional da dose. O dosímetro Fricke gel foi o primeiro dosímetro gel desenvolvido (1984) por Gore (GORE et. al, 1984). Os dosímetros gel poliméricos vêm sendo estudados para a avaliação tridimensional da dose por não apresentar difusão de íons propiciando a identificação de doses em diferentes regiões do objeto simulador. O uso desses dosímetros é realizado, principalmente, na área médica, uma vez que permite a obtenção objetos simuladores de diferentes formas e formatos.

A medição da dose absorvida envolve o uso de um sistema dosimétrico consistindo não somente de dosímetros físicos e químicos bem estabelecidos, mas também de instrumentos que meçam o efeito relevante induzido pela radiação ionizante no dosímetro e seus padrões de referência associados (tais como comprimento de onda e absorbância) e o procedimento para utilizar o sistema. O instrumento de medição deve ser caracterizado de modo a fornecer resultados precisos e reprodutíveis. Algum efeito induzido pela radiação (também chamado de resposta do dosímetro) o qual é reprodutível e mensurável pode, em princípio, ser utilizado para dosimetria (IAEA, 2002).

\subsubsection{Propriedades dos Dosímetros}

Os dosímetros devem apresentar propriedades e características desejáveis para utilização em processos que utilizam radiações ionizantes. Certamente, nem todos os dosímetros satisfazem todas as características descritas nas próximas subseções. A escolha de um dosímetro e de sua leitora deve ser feita considerando os requerimentos da situação de medição; por exemplo, em radioterapia as câmaras de ionização são recomendadas para calibração de feixes e os outros tipos de dosímetros, como os apresentados na Tabela 1, são apropriados para a avaliação da distribuição de dose (dosimetria relativa) ou verificação de dose (IZEWSK; RAJAN, 2005); (IAEA, 2002). 


\subsubsection{Precisão e Exatidão}

A precisão das medições em dosimetria específica e a repetitividade sob condições similares pode ser estimada a partir dos dados obtidos em repetidas medições. A precisão é associada a um pequeno desvio padrão da distribuição dos resultados da medição. A exatidão das medições dosimétricas é a proximidade de seu valor esperado ao valor convencional da grandeza medida. Os resultados das medições não podem ser absolutamente exatos e a inexatidão destes resultados é caracterizada como "incerteza". A incerteza é o parâmetro que descreve a dispersão do valor medido de uma grandeza, sendo avaliada por métodos estatísticos (tipo A) ou por outros métodos (tipo B). $O$ erro da medição é a diferença entre o valor medido de uma grandeza e o valor verdadeiro dessa grandeza. A literatura descreve que os erros das medições não são exatamente conhecidos, mas são estimados da melhor maneira possível introduzindo correções de compensação, quando possível (IZEWSKA; RAJAN, 2005); (IAEA, 2010).

\subsubsection{Linearidade}

A leitura de um dosímetro considerada ideal seria linearmente proporcional à grandeza dosimétrica. Todavia, depois de um determinado intervalo de dose uma não linearidade é verificada e a condição ideal não é mais satisfeita. O intervalo de linearidade e o comportamento da não linearidade dependem do tipo de dosímetro e de suas características. Dois exemplos típicos de respostas características de sistemas dosimétricos são apresentados na Figura 5. A curva $A$ apresenta inicialmente linearidade com a dose, em seguida, comportamento supralinear e logo após a saturação. A curva $B$ apresenta, primeiramente, linearidade e, logo em seguida, saturação em doses altas (IZEWSKA; RAJAN, 2005); (IAEA, 2002). 


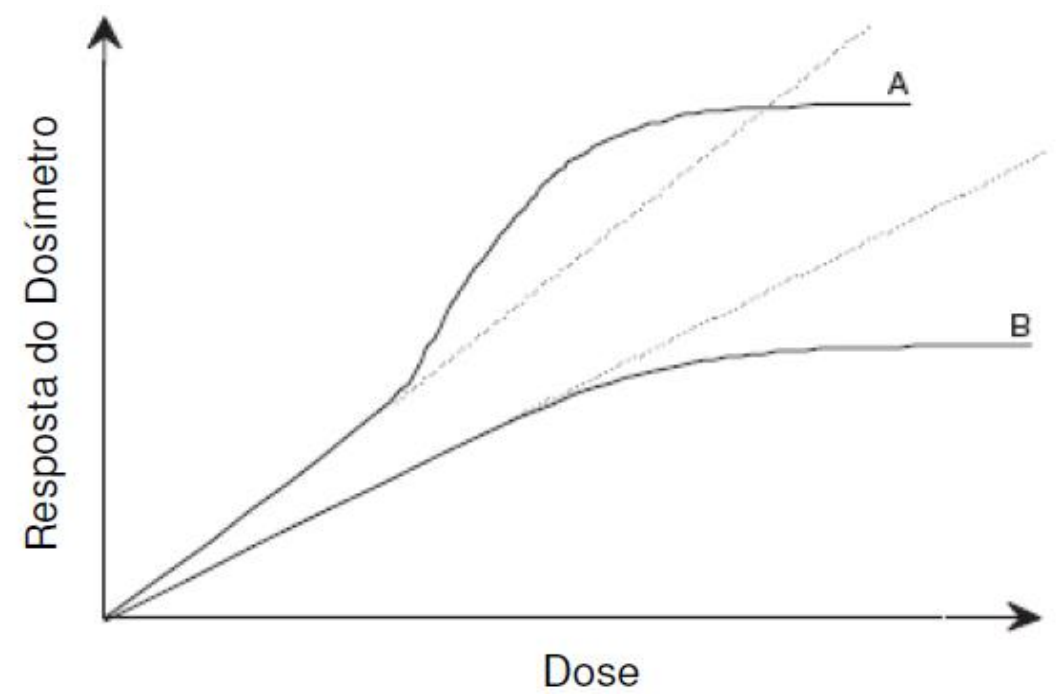

Figura 5. Respostas características de dois sistemas dosimétricos diferentes (IZEWSKA; RAJAN, 2005).

\subsubsection{Sensibilidade}

Um dosímetro pode ser útil quando apresenta sensibilidade à dose adequada do começo ao fim do intervalo de dose a ser medido, ou ao que se propõe a medir. Uma sensibilidade constante dentro deste intervalo fornece uma resposta linear. A leitura de um dosímetro $(\bar{r})$ versus dose média no meio $\left(D_{g}\right)$ contido no volume sensível do dosímetro, ou $\bar{r}$ versus $D_{g}$, que é desejável para a facilidade de calibração e interpretação (ATTIX, 1986); (IAEA, 2002).

\subsubsection{Limites Inferior e Superior de Detecção}

\subsection{Limite Inferior do Intervalo de Dose}

A leitura do dosímetro pode ser influenciada pelo ruído e/ou pela radiação de fundo. Essas influências devem ser subtraídas para que não ocorra adulteração na leitura apresentada pelo dosímetro.

Se $\sigma^{\prime}$ é o desvio padrão da média de um grupo de leituras de um dosímetro irradiado, $\bar{r}$ e $\sigma_{0}$ ' é o desvio padrão da média de leituras da radiação de fundo, $\overline{r_{0}}$, logo o desvio padrão da leitura do dosímetro adquirida, $\overline{r_{0}}-\bar{r}$, é 
dado pela Eq. 4, que não são desvios padrões percentuais (ATTIX, 1986); (IAEA, 2002):

$$
\sigma_{r-r_{0}}^{\prime}=\sqrt{\left(\sigma^{\prime}\right)^{2}+\left(\sigma^{\prime}{ }_{0}\right)^{2}}
$$

\subsection{Limite Superior do Intervalo de Dose}

As limitações instrumentais externas podem, simplesmente, impor 0 limite superior do intervalo de dose útil de um dosímetro, tais como escala fora de leitura no último intervalo sensível de um eletrômetro. Buscando solucionar essas limitações a alternativa mais viável seria impor uma espécie de limite próprio, levando em consideração as características do dosímetro. Por exemplo, reações de competição por produtos da radiação em dosímetros químicos. Normalmente, o limite superior do intervalo de doses é revelado por uma diminuição na sensibilidade a um valor inaceitável. A sensibilidade pode ser reduzida a um valor negativo, ou a zero, como apresentado na Figura 6, estimando duplamente a função dose-resposta. Em princípio, é possível fazer uso da parte inclinada negativa de uma curva de resposta em função da dose para propósitos de dosimetria, caso seja suficientemente reprodutível, como mostra a Figura 6 (ATTIX, 1986); (IAEA, 2002).

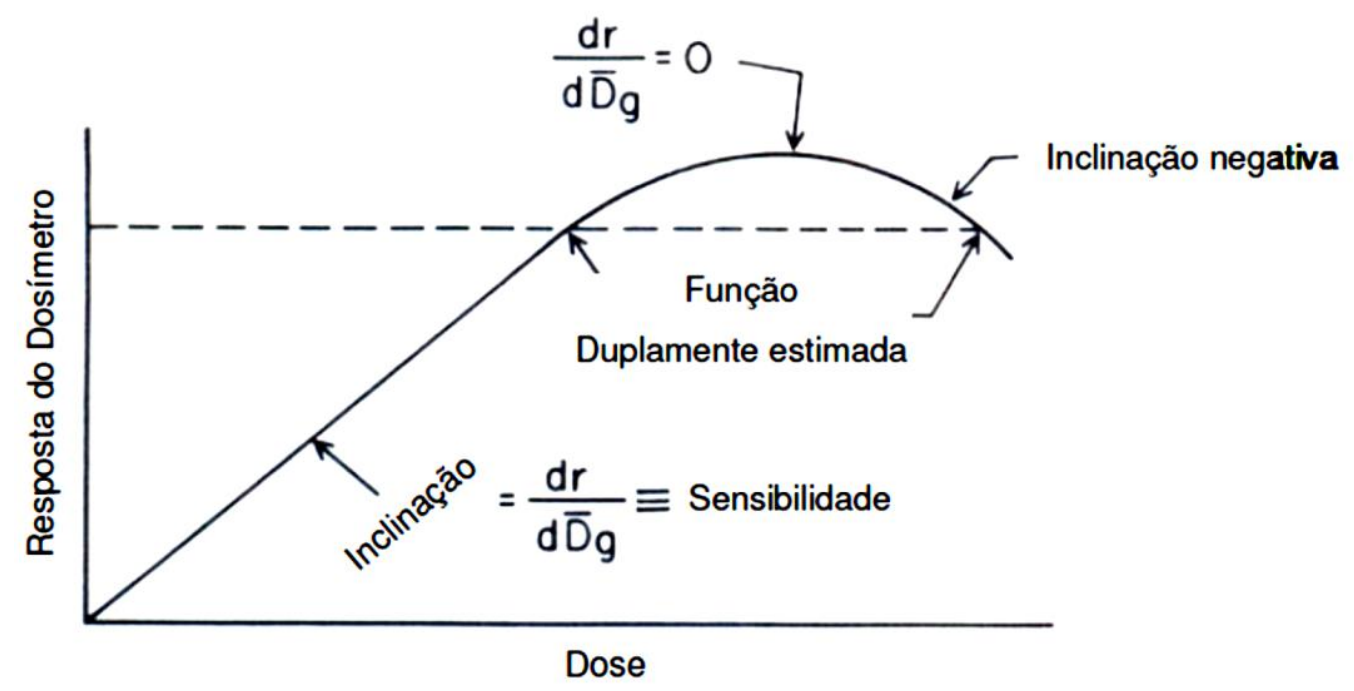

Figura 6. llustração de uma função dose-resposta duplamente estimada resultante de uma diminuição na sensibilidade de um dosímetro em doses altas (ATTIX, 1986). 


\subsubsection{Estabilidade}

\subsection{Antes da Irradiação}

Os dosímetros devem apresentar características estáveis com o tempo até a sua efetiva utilização. Os efeitos provocados pela temperatura, oxigênio atmosférico ou pela luz e a umidade do ar podem causar uma mudança gradual na sensibilidade à dose. Dosímetros de estado sólido, dosímetros fotográficos ou químicos estão geralmente mais sensíveis às estas influências comparados a contadores e câmaras de ionização (ATTIX, 1986); (IAEA, 2002). A solução Fricke gel apresenta estabilidade comum a todos os sistemas de dosimetria gel. Por exemplo, o dosímetro Fricke gel pode ser usado para demonstrar a sensibilidade dos dosímetros gel nas condições de preparação (pureza química, aditivos, temperatura, etc) e sua relação com os parâmetros de medição (SCHREINER, 2004).

\subsection{Depois da Irradiação}

A inconstância na leitura de alguns dosímetros integradores, como os de estado sólido, fotográficos e químicos, em alguma extensão do dosímetro, ocorrendo desvanecimento da imagem ou decaimento do sinal durante o intervalo de tempo entre a irradiação e a leitura poderá ser provocada por condições ambientais desfavoráveis de temperatura ou umidade elevadas, luz solar direta ou iluminação fluorescente brilhante podem agravar este efeito (ATTIX, 1986); (IAEA, 2002).

A solução Fricke gel dosimétrica, após a irradiação, se apresenta muito sensível às condições ambientais e ocorre a aceleração do processo químico ao qual se faz presente a partir do momento da sua produção em laboratório. Por ser uma solução biodegradável não mantém os íons em posição espacial inicial por intervalos de tempo superiores há duas horas, podendo ocorrer difusão iônica. 


\subsubsection{Dependência com a Taxa de Dose}

A resposta de um sistema dosimétrico a duas taxas de dose diferentes deve permanecer constante, em condições ideais. Naturalmente, a taxa de dose pode influenciar as leituras dos dosímetros e são apropriadas ou necessárias as devidas correções. (IZEWSKA; RAJAN, 2005); (IAEA, 2002).

\subsubsection{Dependência Energética}

Geralmente, a resposta de um sistema dosimétrico é função da qualidade do feixe de radiação. A variação da resposta de um sistema dosimétrico com a qualidade da radiação, também chamada de dependência energética, requer correção, pois os sistemas dosimétricos são calibrados em uma qualidade (ou qualidades) de feixe de radiação específica e utilizados sobre um intervalo de energia muito extenso. O sistema de calibração deve ser independente da energia sobre um determinado intervalo de qualidade de radiação, ou seja, a resposta energética deve ser horizontal. Ao fazer a correção de energia, esta correção deve ser incluída na determinação da grandeza para a maior parte das situações de medição.

Quando dispomos de um sistema dosimétrico equivalente ao tecido humano para todas as qualidades do feixe de radiação, a dependência energética é uma característica relevante desse sistema de dosimetria (IZEWSKA; RAJAN, 2005); (IAEA, 2002).

\subsubsection{Dependência Direcional ou Angular}

A dependência direcional ou angular do dosímetro é a variação na resposta de um dosímetro com o ângulo de incidência da radiação. Habitualmente, em virtude dos suas características estruturais, dimensões físicas e da energia da radiação incidente os dosímetros apresentam dependência direcional. A dependência direcional é importante em determinadas aplicações, como na dosimetria in vivo. Dosímetros empregados em terapia são geralmente utilizados na mesma geometria em que são calibrados (IZEWSKA; RAJAN, 2005); (IAEA, 2002). 


\subsubsection{Resolução Espacial}

Como a dose é uma grandeza pontual, e o dosímetro possui um volume muito pequeno para permitir a determinação da dose, a posição espacial da dose determinada deve ser bem definida em um sistema de referência coordenado. Os géis apresentam resolução tridimensional excelente e os filmes dosimétricos apresentam resolução bidimensional. Em ambos, o ponto de medição é limitado somente pela resolução do sistema de avaliação (IZEWSKA; RAJAN, 2005); (IAEA, 2002).

\subsubsection{Condição de Uso}

Alguns dosímetros medem a distribuição de dose em uma única exposição. Portanto, não são reutilizáveis. Os filmes dosimétricos, géis e alanina se encaixam nesse perfil. Mas, as câmaras de ionização mesmo com pequena mudança na sensibilidade e os semicondutores perdendo gradualmente sua sensibilidade, porém, dentro do seu tempo útil de vida são reutilizáveis (IZEWSKA; RAJAN, 2005); (IAEA, 2002).

\subsubsection{Homogeneidade do Lote}

Determinar a extensão de variabilidade da resposta dos dosímetros de um dado lote é essencialmente necessária. Obedecendo esta condição, 10 a 30 dosímetros são irradiados sob as mesmas condições de irradiação e com a mesma dose. Os dosímetros são submetidos a condições similares pela mesma técnica durante um período de tempo curto em que são analisados. Geralmente, isto é mencionado como condições de repetitividade. A medição da incerteza devida à não homogeneidade do lote de dosímetros é o desvio padrão da distribuição dos valores resultantes (IAEA, 2002). Também se faz necessário a verificação da reprodutibilidade do dosímetro, que é definida pelo grau de concordância dos resultados obtidos em diferentes condições de medição (TAHUATA, et. al., 2003). No caso de dosímetros químicos, a precisão aceitável está entre \pm 1\% e \pm 5\% (CHUNG, 1985). 


\subsubsection{Fatores de Influência}

A resposta de quase todos os tipos de dosímetros tem influência de parâmetros externos em uma proporção variada. Algumas das grandezas, tais como temperatura, umidade relacionada ao volume de água no dosímetro, volume de oxigênio no dosímetro e taxa de dose e luz são influências comuns. Os fatores geométricos, o tipo de radiação e a energia da radiação são fatores que podem afetar a resposta de um dosímetro em uma proporção menor. Se submetido a varias radiações a resposta do dosímetro pode variar completamente (IAEA, 2002).

\subsubsection{Dosimetria Química}

A dosimetria química está baseada na determinação da dose de radiação por meio da mudança química produzida em um meio sensível à radiação, que é o volume sensível do dosímetro químico. A mudança química é relacionada à energia absorvida no meio exposto à radiação ionizante (IZEWSKA; RAJAN, 2005); (CHUNG, 1985); (FIELDEN; HOLM, 1970).

Sendo $G$, também conhecido como rendimento químico da radiação, definido como o número de moléculas do produto formado ou reagente destruído por 100 eV de energia absorvida, a estimativa da dose em dosimetria química requer um conhecimento desse valor, no qual é estabelecido pela comparação de um sistema químico com um dosímetro físico absoluto. Portanto, os dosímetros químicos são secundários ou de referência (MCLAUGHLIN. et. al, 1989); (FIELDEN; HOLM, 1970).

O dosímetro Fricke é o padrão de dosimetria química mais amplamente utilizada. A solução Fricke é composta de $1,0 \mathrm{mM}$ de $\mathrm{FeSO}_{4}$ ou $\mathrm{Fe}(\mathrm{NH})_{2}\left(\mathrm{SO}_{4}\right)_{2}$ . $6 \mathrm{H}_{2} \mathrm{O}, 0,8 \mathrm{~N}$ de $\mathrm{H}_{2} \mathrm{SO}_{4}$ em ar saturado e $1 \mathrm{mM}$ de $\mathrm{NaCl}$. A irradiação de uma solução Fricke oxida os íons ferrosos $\left(\mathrm{Fe}^{2+}\right)$ em íons férricos $\left(\mathrm{Fe}^{3+}\right)$. Os íons férricos apresentam uma forte banda de absorção em um comprimento de onda $(\lambda)$ de $304 \mathrm{~nm}$. Já os íons ferrosos não apresentam qualquer absorção neste comprimento de onda (IZEWSKA; RAJAN, 2005); (SEHESTED, 1970).

A concentração de íons férricos induzida pela radiação pode ser determinada utilizando a técnica de espectrofotometria de Absorção Óptica 
(EAO). Esta técnica mede a absorbância da solução (IZEWSKA; RAJAN, 2005).

\subsubsection{O Dosímetro Fricke Gel}

A inovação da adição de um gel matriz para o dosímetro Fricke tradicional para estabilizar as informações geométricas estabeleceu o campo da dosimetria gel para a terapia de radiação. Uma discussão do gel tipo Fricke fornece uma visão geral das questões que determinam a dose-resposta de todos os dosímetros de gel em geral.

A moderna dosimetria gel nasceu da incorporação da solução Fricke (solução de sulfato ferroso) com uma matriz aquosa de gel. Partiu-se do dosímetro Fricke convencional para o gel de sulfato ferroso. Os dosímetros Fricke gel podem ser utilizados para demonstrar a sensibilidade dos dosímetros gel para condições de preparação (pureza química, aditivos, temperatura, etc.) e a relação de sensibilidade de um dosímetro para parâmetros de medição. Em seu próprio mérito, o Fricke gel têm algumas vantagens sobre outros sistemas de gel. Uma delas é que consistentes soluções Fricke gel são facilmente reproduzidas e preparadas para determinação da distribuição da dose espacial. Por outro lado, os dosímetros Fricke gel possuem limitações particulares que não são encontradas com dosímetros de gel polimérico, tais como restrições de tempo entre a irradiação e medida imposta pela difusão do íon que eventualmente destrói as informações de dose espacial. Assim como no Fricke convencional, no dosímetro Fricke gel ocorre a oxidação dos íons ferrosos $\left(\mathrm{Fe}^{2+}\right)$ a íons férricos $\left(\mathrm{Fe}^{3+}\right)$ induzida pela radiação ionizante. (GORE et. al., 1984 ).

A radiação gama, quando atinge os íons $\mathrm{Fe}^{2+}$ transforma-os em íons $\mathrm{Fe}^{3+}$. As principais reações envolvidas são:

$$
\begin{aligned}
& \mathrm{Fe}^{2+}+\mathrm{OH}^{\bullet} \rightarrow \mathrm{Fe}^{3+}+\mathrm{OH}^{-} \\
& \mathrm{H}^{\bullet}+\mathrm{O}_{2} \rightarrow \mathrm{HO}_{2}{ }^{-} \\
& \mathrm{Fe}^{2+}+\mathrm{HO}_{2} \rightarrow \mathrm{Fe}^{3+}+\mathrm{HO}_{2}^{-} \\
& \mathrm{HO}_{2}^{-}+\mathrm{H}^{+} \rightarrow \mathrm{H}_{2} \mathrm{O}_{2} \\
& \mathrm{Fe}^{+2}+\mathrm{H}_{2} \mathrm{O}_{2} \rightarrow \mathrm{Fe}^{3+}+\mathrm{OH}^{-}+\mathrm{OH}^{\bullet}
\end{aligned}
$$


Cada átomo de hidrogênio forma um radical hidroperóxido, $\mathrm{HO}_{2}$, e cada um destes radicais oxidam três íons de $\mathrm{Fe}^{2+}$, um através da reação (3) e dois através das reações (4), (5) e (1). Cada radical hidroxila oxida um íon de $\mathrm{Fe}^{2+} \mathrm{e}$ cada molécula de peróxido de hidrogênio oxida dois íons de $\mathrm{Fe}^{2+}$. Todas as reações, exceto a (5) são rápidas. A quantidade de $\mathrm{Fe}^{3+}$ produzida depende da energia absorvida pela solução. Especificamente, a alteração na concentração de íon férrico está relacionada com a dose de radiação (energia por unidade de massa) por Eq. 5:

$$
\Delta\left[F e^{3+}\right]=\frac{D \cdot G \cdot(F e)^{3+} 10 \rho}{N_{A} \cdot e}
$$

Onde:

$D$ é a dose absorvida,

$\mathbf{G}\left(\mathrm{Fe}^{3+}\right)$ é o rendimento químico de $\mathrm{Fe}^{3+}$ (expresso em íons produzidos por 100 $\mathrm{eV})$,

$\boldsymbol{\rho}$ é a densidade em $\mathrm{kg} / \mathrm{L}^{-1}$,

$\boldsymbol{N}_{\boldsymbol{A}}$ é o número de Avogadro e

e é o número de joules por elétron-volt.

A dose absorvida por um dosímetro Fricke irradiado pode ser determinada pela medição da alteração da concentração de $\mathrm{Fe}^{3+}$ (SCHREINER, 2004).

A avaliação da distribuição da dose em bolsas de sangue irradiadas pode ser feita utilizando objetos simuladores preenchidos com a solução gel e, avaliados pelas técnicas de Absorção Óptica (A.O.) e RMI.

\subsubsection{Ressonância Magnética por Imagem (RMI)}

As imagens obtidas por ressonância magnética por imagem (RMI) foram introduzidas nos anos 80 em rotinas clínicas, e amplamente utilizadas para a obtenção de imagens clínicas anatômicas devido a sua alta resolução espacial e a ótima capacidade de contraste em tecidos moles. Belliveau 
(BELLIVEAU et al., 1991), no ano de 1991 apresentou as primeiras imagens funcionais mapeando o córtex cerebral utilizando um contraste exógeno, contraste intravenoso paramagnético para obter alteração do sinal da área ativada, sendo esse o primeiro passo para obter imagens de ressonância magnética funcional. Dois anos depois um novo método foi proposto (OGAWA et. al, 1993). O método se baseia nas propriedades magnéticas dos dois estados de oxigenação da hemoglobina utilizando um mecanismo de contraste natural. O contraste usado nesse método é denominado BOLD (Blood Oxygen Level Dependent), sendo atualmente muito utilizado em imagens fMRI (functional Magnetic Resonance Imaging).

A imagem por ressonância magnética é hoje um método de diagnóstico por imagem estabelecido na prática clínica e em crescente desenvolvimento. Dada à alta capacidade de diferenciar tecidos, o espectro de aplicações se estende a todas as partes do corpo humano e explora aspectos anatômicos funcionais (MAZZOLA, 2009).

\subsubsection{Teoria Básica}

Ressonância Magnética é a propriedade física exibida por núcleos de determinados elementos que, quando submetidos a um campo magnético forte e excitados por ondas de radiofrequência (RF) em determinada frequência, (frequência de Larmor), emitem radio sinal, o qual pode ser captado por uma antena e transformada em imagem.

A técnica de Ressonância Magnética por Imagem (RMI) fundamenta-se na absorção seletiva de uma onda de rádio por amostras colocadas num campo magnético. A amostra assim excitada regressa ao estado inicial emitindo energia radiante no domínio das radiofrequências. A determinação precisa dos valores destas radiofrequências específicas emitidas e da velocidade com que a amostra regressa ao estado inicial de partida (relaxação) constituem a essência da informação pormenorizada que é possível obter tanto sobre a estrutura molecular da amostra como sobre a dinâmica interna e global das respectivas moléculas (GIL; GERALDES, 2002).

A RMI é, resumidamente, o resultado da interação do forte campo magnético produzido pelo equipamento com os prótons de hidrogênio do tecido 
humano, criando uma condição para que possamos enviar um pulso de radiofrequência e, após, coletar a radiofrequência modificada, através de uma bobina ou antena receptora. Porém, a obtenção da imagem no corpo humano se faz através da codificação espacial do sinal através do uso de gradientes do campo magnético. O acionamento de um gradiente de campo magnético altera, também, a fase dos spins. Esta alteração é proporcional ao tempo que o gradiente fica ligado e sua amplitude. Juntas, a fase e a frequência poderão fornecer informações espaciais do sinal. A codificação do sinal passa por três etapas para obter uma imagem de RMI: seleção de corte, codificação de fase e a codificação da frequência. Cada etapa representa o acionamento do gradiente em uma direção (MAZZOLA, 2009).

A magnetização, $\mathbf{M}$, é processada em torno do eixo $0 z$ com o ângulo $\alpha$, onde há uma divisão da componente longitudinal, e Mz a componente transversal, Mxy. O ângulo de fase da Mxy é dada por $\phi$. Uma bobina de RF é colocado na direção do eixo 0y para recolher o sinal RMI.

A ressonância ocorre quando um pulso de energia é aplicado na frequência de Larmor $\left(V=\omega_{0} / 2 \pi\right)$, lançando os momentos magnéticos individuais de seu estado de baixa rotação a energia de seu maior estado de spin energia. Para a maioria dos núcleos para intensidades de campo convencionais de 1,5 T esta energia está na faixa de radiofrequência e é chamado o campo B-1 ou o pulso de RF. A fim de produzir uma magnetização observável, este pulso de RF é aplicado transversalmente ao campo $\mathrm{B}_{0}, \mathrm{O}$ depósito do vetor no plano transversal, de acordo com a Figura 7. O ângulo desse é chamado de ângulo de inclinação de RF. O tamanho deste ângulo depende da magnitude e duração do impulso aplicado.

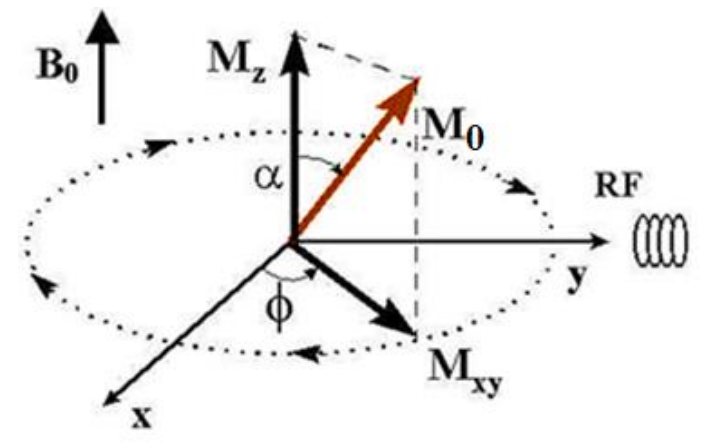

Figura 7. Magnetização longitudinal, $M_{z}$; Magnetização transversal, $M_{x y}$; Magnetização

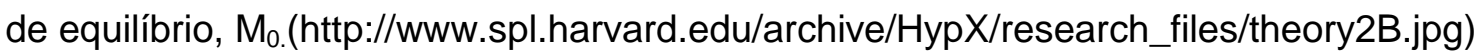




\subsubsection{O Espaço K}

Para auxiliar no entendimento de sequência de pulso e na metodologia de aquisição das imagens, o equipamento de RMI dispõe do espaço $\mathbf{K}$ que não é um espaço físico, mas um espaço abstrato. Podemos visualizar o espaço $\mathbf{K}$ na forma de uma matriz em tons de cinza. Cada ponto da matriz corresponde a uma intensidade de sinal e a uma posição no tempo, e representa a amplitude do sinal recebido pela bobina naquele dado instante. Os eixos de coordenadas $\left(\mathbf{x}, \mathbf{y}, \mathbf{k}_{\mathbf{x}}\right.$ e $\mathbf{k}_{\mathbf{y}}$ ) deste espaço são o gradiente de codificação de frequência e o gradiente de codificação de fase, respectivamente. O preenchimento do espaço K ocorrerá à medida que o gradiente de codificação de fase na sequência de pulso variar sua amplitude.

Uma característica importante do espaço $\mathbf{K}$ é que os extremos deste espaço serão preenchidos com sinal de baixa amplitude, pois o próprio acionamento do gradiente causa maior defasagem e redução de sinal ocorrendo, em alguns casos, perturbação no sinal. Nas regiões centrais ocorrerá o inverso e resultará em contraste (preto e branco).

Para a geração do pulso são usadas duas grandes famílias de sequências para a formação da imagem de RMI: spin eco (SE) e o gradiente eco (GRE).

A sequência de pulso spin eco (SE) se caracteriza pela aplicação de um pulso inicial de RF de $90^{\circ}$, seguido de um pulso de RF de $180^{\circ}$ e a coleta de um eco. Uma linha $\mathbf{K}$ é preenchida a cada tempo de repetição (TR). A ponderação da imagem é controlada pelo TR e tempo de eco (TE).

Uma variação da SE convencional é a multieco (spin eco multieco), onde, dentro de um mesmo TR, são selecionados dois tempo de eco diferentes. O primeiro TE é curto e o segundo TE é longo. Após a aplicação de cada um dos pulsos de RF de $180^{\circ}$, surgira um eco. Cada eco, em cada TE, é armazenado em um espaço $\mathbf{K}$ diferente. As imagens de RMI resultantes de cada um desses espaços K terão uma ponderação diferente.

O tempo de aquisição de uma imagem de RMI pode ser calculado na Eq. 6 da seguinte forma:

$$
\text { Tempo }_{\text {imagem }}=\operatorname{TR} \times N_{C F} \times N_{E X}
$$


Onde,

TR: tempo de repetição (em segundos)

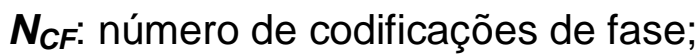

$N_{E X}$ : número de excitações ou número de espaços $\mathrm{K}$ coletados

As sequências de pulso do gradiente eco (GRE) são similares à SE, mas não se usa um pulso de RF de $180^{\circ}$ para refasar os spins. Utiliza-se um gradiente de campo magnético. Se os valores de TR, TE e ângulo de desvio do pulso de excitação forem semelhantes aos utilizados em sequência SE, a ponderação na imagem e o tempo de aquisição também serão semelhantes. Entretanto, o gradiente eco (GRE) é mais sensível a não homogeneidades do campo magnético e apresenta mais alterações no sinal da imagem devido a diferenças de susceptibilidade magnética (MAZZOLA, 2009).

Os parâmetros de relaxação de spin são de grande importância como fonte de informação sobre a dinâmica molecular e a estereoquímica (GIL; GERALDES, 2002).

\subsubsection{Relaxação Nuclear}

Após o desligamento do pulso de RF o vetor de magnetização retorna ao estado de equilíbrio inicial. Este processo é denominado relaxação devido às interações dos spins com a sua vizinhança e descrito pelos parâmetros $\mathbf{T}_{\mathbf{1}} \mathrm{e}$ $\mathbf{T}_{2}$.

O parâmetro $\mathbf{T}_{1}$, (tempo de relaxação longitudinal), ou tempo de relaxação spin-rede é associado com a interação dos spins com a rede, sendo responsável pelo retorno da magnetização a seu estado de equilíbrio térmico.

O parâmetro $\mathbf{T}_{2}$, (tempo de relaxação transversal), ou tempo de relaxação spin-spin é associado com a interação entre spins. Os momentos magnéticos perdem coerência de fase, nesse processo, devido à relaxação transversal. Isso leva os spins a precessionar com frequências ligeiramente diferentes. 


\subsection{Tempo de Relaxação Longitudinal $\left(\mathrm{T}_{1}\right)$}

A relaxação $\mathbf{T}_{1}$ é tempo que leva para a componente de magnetização longitudinal Mz retornar ao seu estado de equilíbrio.

Os métodos mais conhecidos na determinação de $\mathbf{T}_{1}$ são a saturação progressiva, a inversão-recuperação e a saturação-recuperação, os quais têm sido sujeitos a varias modificações. A escolha de um determinado método de medida depende de vários fatores como a ordem de grandeza da velocidade de relaxação, a precisão e o tempo requerido para a medida e as capacidades técnicas o instrumento (GIL; GERALDES, 2002).

\subsection{Tempo de Relaxação Transversal $\left(T_{2}\right)$}

Analogamente, relaxação $\mathbf{T}_{2}$ é o tempo para a componente $\mathbf{M x y}$, de magnetização transversal. Esses tempos de relaxação dependem de vários fatores como a intensidade da RF, campo magnético utilizado, uniformidade desses campos magnéticos, tipo de tecido orgânico, interação entre prótons, entre outros fatores. Imperfeições no campo magnético externo influenciam nos spins de cada próton, criando um desvio transverso para fora da direção esperada, alterando $\mathbf{T}_{2}$ para $\mathbf{T}_{2^{*}}$. Esse tipo de relaxação deve ser corrigido aplicando-se outro pulso RF para realinhar os prótons, invertendo o sentido dos spins. Esse tempo de realinhamento dos prótons é conhecido como eco time.

A medição do parâmetro $\mathbf{T}_{2}$ está sujeita a dificuldades experimentais superiores a $\mathbf{T}_{1}$, mesmo no caso de um único conjunto de spins idênticos. Isso decorre da necessidade de desenvolver técnicas que permitam descontar ou anular a contribuição da não homogeneidade do campo magnético para o decaimento do sinal ou, no espectro convencional para a largura a meia altura. $\mathrm{Na}$ presença de um campo magnético não homogêneo, o vetor de magnetização total pode considerar-se como a soma vetorial de vetores de magnetização elementares provenientes do volume da amostra, suficientemente pequenos para que neles o campo magnético, seja homogêneo (GIL; GERALDES, 2002). 
Na geração de imagens com dosímetro Fricke gel foi utilizado o tempo de relaxação $T_{1}$, onde temos a reações que resultam conversão de íon de $\mathrm{Fe}^{2+}$ em íons de $\mathrm{Fe}^{3+}$ tem como catalisador do processo a energia fornecida pela radiação gama.

\subsubsection{Dosimetria TL}

\subsubsection{Termoluminescência}

Certos cristais retêm parte da energia absorvida durante a irradiação em estados metaestáveis de energia; quando esta energia é perdida posteriormente na forma de luz ultravioleta (UV), infravermelha ou visível ocorre o fenômeno da luminescência (IAEA, 2004).

A luminescência se divide em fluorescência e fosforescência. A emissão de luz que se dá entre $10^{-10}$ e $10^{-8} \mathrm{~s}$ após a irradiação denomina-se fluorescência, e fosforescência, se a luminescência for estimulada pela luz ou pelo calor, recebe nome de luminescência opticamente estimulada (OSL) e termoluminescência, respectivamente.

Por meio do modelo de bandas para os níveis de energia dos elétrons nos sólidos é explicada a termoluminescência. Em geral, os materiais TLs são cristais iônicos onde a banda de valência (BV) se encontra repleta de elétrons e a banda de condução (BC) vazia. As bandas de valência estão separadas por uma faixa larga de estados energéticos não permitidos aos elétrons, conhecida como banda proibida (BP).

Geralmente, quando os elétrons de um sólido são excitados por absorção de radiação eletromagnética ou por outro processo qualquer, eles não permanecem por muito tempo nos respectivos níveis mais altos, decaindo por vários processos competitivos. Dizemos que existe luminescência, se o processo de decaimento mais provável envolve a emissão radiação eletromagnética na região visível do espectro.

Nos sólidos, a luminescência está ligada às impurezas e aos defeitos da estrutura cristalina. Quando um elétron da banda de valência é transferido para a banda de condução, deixa um nível incompleto. Se a estrutura cristalina 
do sólido em questão não contém defeitos nem impurezas, o elétron volta à banda de valência com a emissão de radiação eletromagnética com uma quantidade de energia muito alta para permanecer na região visível do espectro. Se a rede contiver algumas impurezas que originem níveis de energia entre as bandas de valência e de condução, um elétron de um nível de energia de impureza inferior pode preencher a lacuna na banda de valência, e um elétron da banda de condução pode preencher um dos níveis de energia de impureza superiores, com a emissão, nos dois casos, de radiação eletromagnética com energia muito baixa para ficar na região visível do espectro. Um elétron pode passar de um nível de energia de impureza superior para um nível de energia de impureza inferior que esteja vazio, com a emissão de radiação eletromagnética com energia que a situe na região visível do espectro, e isso é o que constitui a luminescência (CAMERON, 1968); (McKEEVER, 1995).

Uma explicação quantitativa simplificada para a termoluminescência (RANDALL e WILKINS, 1945) avalia a quantidade de elétrons que se recombinam admitindo que a probabilidade $P$ de um elétron capturado escapar da armadilha é uma distribuição maxwelliana da energia térmica dos elétrons (Eq. 7). (MATSUSHIMA, 2010).

$$
P=s \cdot \exp \left(\frac{E a}{K \cdot T}\right)
$$

Em que:

$s$ é o fator de frequência, relacionado à oscilação do elétron na armadilha;

$E_{a}$ é a profundidade (ou energia) da armadilha;

$\boldsymbol{k}$ é a constante de Boltzman;

$T$ é a temperatura.

Daniels e seus colaboradores foram os pioneiros na investigação das possíveis aplicações dos cristais TLs como detectores de radiação. Inicialmente, as características TLs do fluoreto de lítio (LiF:Mg,Ti) foram estudadas extensivamente na Universidade de Wisconsin (CAMERON et al.,1968; McKEEVER, 1995). 
No final dos anos 50 diversos outros grupos iniciaram trabalhos com dosimetria TL. O grupo de Schulman no Laboratório de Pesquisas Navais desenvolveu um dosímetro composto por fluoreto de cálcio dopado com manganês $\left(\mathrm{CaF}_{2}: \mathrm{Mn}\right)$. Outros trabalhos foram executados na Bélgica, na União Soviética e na Alemanha. A partir de 1960 o uso da dosimetria TL aumentou rapidamente devido às inúmeras vantagens da técnica e da disponibilidade de fósforos (cristais) comerciais e facilidade de instrumentação (CAMERON et. al, 1968).

\subsubsection{Filme Radiocrômico}

Desde 1965, estudos detalhados desenvolvidos por McLaughlin et al., 1985, e outros pesquisadores determinam as propriedades de varias formas de medidas radiocrômicas. Com a recente melhoria na exatidão e precisão de fabricação de filmes, bem como a robustez e facilidade de uso, dosímetros radiocrômicos tornaram-se cada vez mais popular em aplicações médicas e não médicas (BLACKWELL et al., 1998). Ao longo dos últimos anos as propriedades dosimétricas de dosímetros radiocrômicos foram avaliadas por muitos pesquisadores e produziu-se uma extensa literatura. Atualmente, existem vários dosímetros radiocrômicos na forma de filmes finos, filmes espessos e soluções líquidas são utilizados para a dosimetria de rotina de radiação ionizante através de uma ampla variedade de doses absorvidas entre $10^{-2}$ e $10^{6}$ Gy e taxa de dose absorvida com limite aproximado de $10^{12} \mathrm{~Gy} / \mathrm{s}$ (McLAUGHLIN et al., 1985). Os dosímetros radiocrômicos, também, têm sido utilizados para aplicações não clínicas, tais como irradiação de sangue e padrão de referência.

Os filmes radiocrômicos possuem vantagens como a não utilização de câmara escura, pois apresenta baixa sensibilidade a luz visível, e não há necessidade de revelação com uso de produtos químicos.

A dosimetria com filme radiocrômico é designada para a medição da absorção de fótons, elétrons e prótons de energias altas. A energia cinética da reação radiocrômica do produto GRAFCHROMIC ${ }^{\circledR}$ (MD-55) tem sido avaliada por MacLaughlin et al., 1991, usando fotólise e radiólise de pulso. 
Todas as formas atualmente disponíveis dos filmes radiocrômicos consistem basicamente na mesma emulsão sensível e diferem apenas na construção do filme e na espessura da emulsão.

A sensibilidade inerente ao filme é determinada pela mínima energia de absorção necessária para a formação do efeito de coloração produzido no cromóforo. Para os filmes Grafchromic a energia é de aproximadamente $50 \mathrm{~kJ} / \mathrm{mol}$ que corresponde a uma energia de ativação de aproximadamente 0,5 eV por cromóforo (SOARES, 2007). Para uma maior sensibilidade do GRAFCHROMIC ${ }^{\circledR}$ (MD-55), foi desenvolvido uma camada sensível côncava com espessura de $15 \mu \mathrm{m}$ para intervalo de dose compreendido entre 10 Gy e 100 Gy (BUTSON, 1996).

O limite absoluto da resolução admitido para o filme radiocrômico deve ser determinado pelo tamanho físico do cromóforo de 0,75 $\mu \mathrm{m}$. A resolução do filme Grafchormic frequentemente citado na literatura é de "1.200 pares de linhas por mm" (McLAUGHLIN et. al., 1991).

\subsubsection{Absorção Óptica}

Espectrofotometria na região UV-VIS do espectro eletromagnético é uma das técnicas analíticas mais empregadas, em função de robustez, custo relativamente baixo e grande número de aplicações desenvolvidas (LOBINSKI; MARCZENKO,1992). A técnica possui baixo custo operacional, fácil utilização e produz resultados de interpretação, geralmente, simples.

A espectrofotometria é fundamentada na lei de Lambert-Beer, que é a base matemática para medidas de absorção de radiação por amostras no estado sólido, líquido ou gasoso, nas regiões ultravioleta, visível e infravermelho do espectro eletromagnético. Para medidas de absorção de radiação em determinado comprimento de onda, tem-se:

$$
\mathrm{A}=\log \left(\frac{I_{0}}{I}\right)=\varepsilon \mathrm{bc}
$$

onde $\mathbf{A}$ é a absorvância, $\mathbf{I}_{0}$ é a intensidade da radiação monocromática que incide na amostra e I é a intensidade da radiação que emerge da amostra. A 
absortividade molar ( $\varepsilon$ ) é uma grandeza característica da espécie absorvente, cuja magnitude depende do comprimento de onda da radiação incidente. $O$ termo $\boldsymbol{c}$ é a concentração da espécie absorvente e $\boldsymbol{b}$, a distância percorrida pelo feixe através da amostra (PERKAMPUS, 1992). 


\section{MATERIAIS}

\subsection{Reagentes e Vidrarias}

A solução Fricke gel consiste de (Olsson et. al., 1989):

- Cloreto de sódio (1mM), NaCl, P.A. Merck ${ }^{\circledR}$;

○ Ácido sulfúrico, $\mathrm{H}_{2} \mathrm{SO}_{4}$; pró-análise (P.A.) Merck ${ }^{\circledR}$;

- Sulfato ferroso amoniacal $(1,0 \mathrm{mM}),\left[\mathrm{Fe}(\mathrm{NH})_{2}\left(\mathrm{SO}_{4}\right)_{2} \cdot 6 \mathrm{H}_{2} \mathrm{O}\right]$, P.A. Merck ${ }^{\circledR}$;

- Alaranjado de xilenol $(0,1 \mathrm{mM}), \mathrm{C}_{31} \mathrm{H}_{28} \mathrm{Na}_{4} \mathrm{O}_{13} \mathrm{~S}$, indicador de íons férricos, P.A. Merck ${ }^{\circledR}$;

○ Água ultrapura;

- Gelatina suína Bloom 270 (alimentícia); Gelita ${ }^{\circledR}$, Brasil.

Para a preparação de todas as soluções dosimétricas foram utilizadas vidrarias da rotina de um laboratório de análises químicas.

\subsection{Bolsa de Sangue de $300 \mathrm{~mL}$ para Transferência}

As bolsas de transferência são produtos especialmente desenvolvidos para transferência de sangue e seus hemocomponentes. Sua composição apresenta compatibilidade com todos os componentes do sangue. Possuem formato anatômico com cantos arredondados que facilitam o escoamento completo em todos os procedimentos e ótima resistência aos processos de congelamento e descongelamento. O material componente das bolsas é o policloreto de vinilo (PVC), largamente utilizado em dispositivos médicos (Figura 8). 


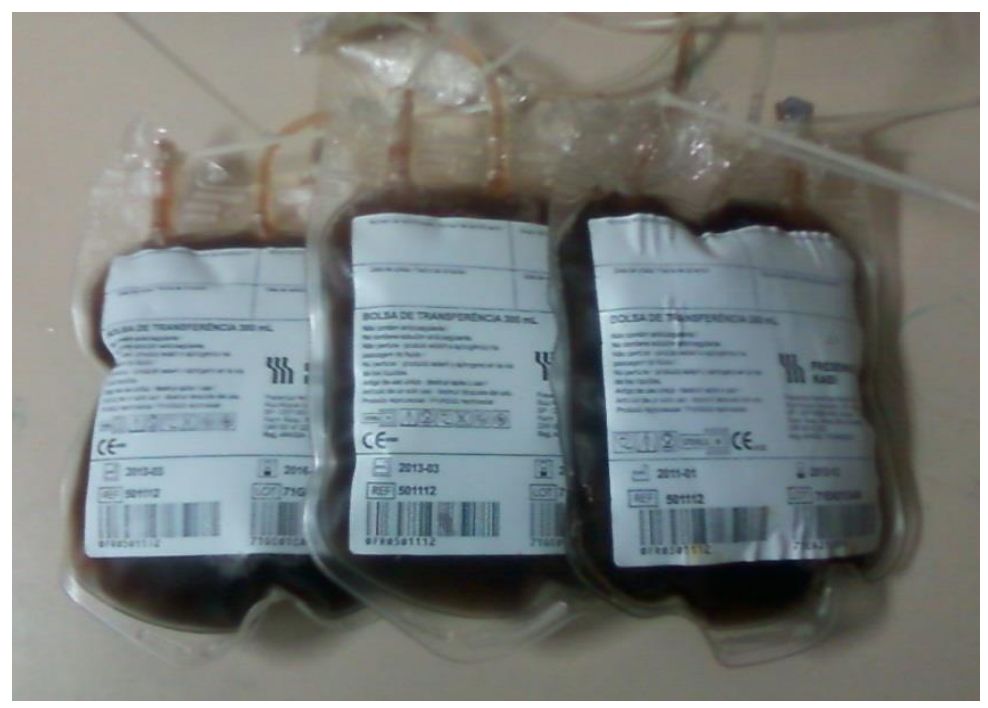

Figura 8. Bolsa de sangue de $300 \mathrm{~mL}$ para transferência.

\subsection{Filme Radiocrômico para Dosimetria de Fótons de Energia Alta - Grafchromic MD-55}

O filme radiocrômico Grafchromic MD-55 é projetado para a medição da dose absorvida de fótons de energia alta e possui dupla-face sensível à radiação ionizante e não-ionizante. De acordo com os parâmetros descritos pelo fabricante, a película apresenta resposta independente da energia para fótons acima de $0.2 \mathrm{MeV}$. O filme pode ser avaliado com densitômetros de transmissão, scanners de filme ou espectrofotômetros. Quando o componente ativo é exposto à radiação, reage para formar um polímero azul colorido com máximos de absorção próximos dos comprimentos de onda 615 nm e 675 nm. As propriedades do filme radiocrômico estão dispostas na Tabela 2. 
Tabela 2. Características do Grafchromic MD-55 descritas pelo fabricante

\begin{tabular}{|c|c|}
\hline Propriedades & Filme dosimétrico radiocrômico (Grafchromic MD-55) \\
\hline Configuração & $\begin{array}{l}\text { Duas camadas ativas em substratos de poliéster laminado } \\
\text { com fita adesiva. }\end{array}$ \\
\hline Tamanho & 5 "x 5 " (mínimo). \\
\hline Espessura (camada ativa) & Nominalmente $(2 \times 16) \mu \mathrm{m}^{2}$. \\
\hline Resposta sensitométrica & Densidade líquida de 0,90 a 25 Gy e 1,75 em 50 Gy. \\
\hline Dependência energética & $\begin{array}{l}<5 \% \text { de diferença em densidade liquida para exposições } \\
\text { de } 50 \text { Gy entre } 1 \text { e } 18 \mathrm{Mev.}\end{array}$ \\
\hline $\begin{array}{l}\text { Dose-resposta de } \\
\text { fracionamento }\end{array}$ & $\begin{array}{l}<5 \% \text { de Diferença na densidade para uma única dose } \\
40 \text { Gy e cinco doses cumulativas de } 8 \text { Gy em intervalos } \\
\text { de } 30 \text { minutos. }\end{array}$ \\
\hline Taxa de dose-resposta & $\begin{array}{l}\text { <5 \% de diferença em densidade liquida para exposições } \\
\text { de } 10 \text { Gy a taxas de } 3,4 \text { Gy/min e } \\
\text { 0,034 Gy/min. }\end{array}$ \\
\hline Estabilidade à luz & $\begin{array}{l}<0,005 \text { mudança na densidade por } 1000 \text { lux - entre } 2 \text { e } 4 \\
\text { dias. }\end{array}$ \\
\hline $\begin{array}{l}\text { Estabilidade em escuro } \\
\text { (pré-exposição) }\end{array}$ & $\begin{array}{l}<0,5 \times 10^{-3} \text { - mudança de densidade / dia a } 23{ }^{\circ} \mathrm{C} \\
<0,2 \times 10^{-3} \text { - mudança de densidade / dia sob } \\
\text { refrigeração. }\end{array}$ \\
\hline $\begin{array}{l}\text { Uniformidade uma única } \\
\text { folha }\end{array}$ & $<8 \%$ diferença (resposta sensitométrica). \\
\hline $\begin{array}{l}\text { Uniformidade folha -a- } \\
\text { folha }\end{array}$ & $<5 \%$ de diferença (resposta sensitométrica da média). \\
\hline
\end{tabular}




\subsection{Equipamentos de Medição}

- Preparação das Soluções Fricke Gel:

- Balança analítica eletrônica de alta resolução marca METTLER TOLEDO ${ }^{\circledR}$ modelo AB204-S;

○ Tri-destilador de água marca MARCONI ${ }^{\circledR}$ modelo MA-079;

- Purificador de água marca ELGA ${ }^{\circledR}$ modelo PURELAB Option-Q DV 25;

- Agitador magnético marca FISATOM ${ }^{\circledR}$ modelo 753A;

- Refrigerador compacto 80 marca CONSUL ${ }^{\circledR}$ modelo CRT08CBBNA;

○ Estufa de secagem e esterilização marca FANEM ${ }^{\circledR}$ modelo 315 SE.

- Medições Espectrofotométricas:

- Espectrofotômetro marca SHIMADZU ${ }^{\circledR}$ modelo UV-2101PC. Os parâmetros operacionais são apresentados na Tabela 3.

Tabela 3. Parâmetros operacionais do espectrofotômetro marca SHIMADZU ${ }^{\circledR}$

\begin{tabular}{lc}
\hline \multicolumn{1}{c}{ Descrição } & Parâmetros \\
\hline Modo de aquisição dos dados & Espectros de absorção óptica \\
Modo de medição & Absorbância \\
Intervalo de comprimento de onda $(\mathrm{nm})$ & $190-900$ \\
Velocidade de varredura Rápida & 2,0 \\
Largura da fenda $(\mathrm{nm})$ & Automático \\
Intervalo de amostragem $(\mathrm{nm})$ & Ar \\
Linha de base & Compartimentos de amostra e referência \\
Material de referência & Ar \\
\hline
\end{tabular}

○ Espectrofotômetro marca Agilent Technologies ${ }^{\circledR}$ Cary Series modelo UVVis-NIR. Os parâmetros operacionais são apresentados na Tabela 4. 
Tabela 4. Parâmetros operacionais do espectrofotômetro marca Agilent Technologies ${ }^{\circledR}$

\begin{tabular}{lc}
\hline \multicolumn{1}{c}{ Descrição } & Parâmetros \\
\hline Modo de aquisição dos dados & Espectros de absorção óptica \\
Modo de medição & Absorbância \\
Intervalo de comprimento de onda $(\mathrm{nm})$ & $200-800$ \\
Velocidade de varredura Rápida & 3,5 \\
Largura da fenda $(\mathrm{nm})$ & Automático \\
Intervalo de amostragem $(\mathrm{nm})$ & Ar \\
Linha de base & Compartimentos de amostra e referência \\
Material de referência & Ar \\
\hline
\end{tabular}

- Medições de Ressonância Magnética por Imagem (RMI):

○ Equipamento de RMI marca Siemens ${ }^{\circledR}$ modelo Magnetom Symphony Maestro Class (1,5 T), (Figura 9).

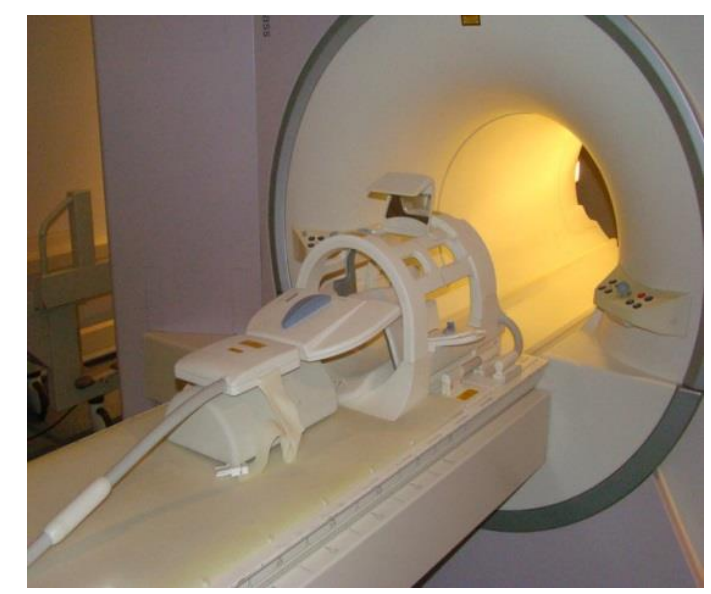

Figura 9. Equipamento de RMI modelo Siemens Magnetom Symphony Maestro Class (1,5 T).

Os parâmetros operacionais são apresentados na Tabela 5 . O equipamento de RMI pertence ao Departamento de Diagnostico por Imagem (DDI) da Universidade Federal de São Paulo (UNIFESP). 
Tabela 5. Parâmetros operacionais do equipamento de RMI marca Siemens ${ }^{\circledR}$

\begin{tabular}{cc}
\hline Descrição & Parâmetros \\
\hline Planos de aquisição de imagens & Sagital e axial \\
Sequencia & 8 canais \\
Tempo de repetição (TR) & 3D (tridimensional) Fast Spin Eco \\
Tempo de inversão (TI) & $2000 \mathrm{~ms}$ \\
Tempo de eco (TE) & $1100 \mathrm{~ms}$ \\
Espessura do corte & $3,42 \mathrm{~ms}$ \\
Tempo da sequência & $1,0 \mathrm{~mm}$ \\
\hline
\end{tabular}

\subsection{Sistemas de Irradiação}

- Radiação gama do Cobalto-60 $\left({ }^{60} \mathrm{Co}\right)$ :

- Irradiador do tipo Gammacell (fonte Gammacell):

- Marca: Atomic Energy of Canada ${ }^{\circledR}$;

- Modelo: 220;

- Atividade (novembro de 2013): 53,81 TBq;

- Taxa de dose sem atenuação (novembro de 2013) (IDAS-IAEA):

\section{1,23 kGy/h ;}

- Dose de trânsito (DT): 1,04 Gy.

- Irradiador do tipo Panorâmica (fonte Panorâmica):

- Marca: Yoshizawa Kiko ${ }^{\circledR}$;

- Modelo: FIS 60-04;

- $\quad$ Atividade (novembro de 2013): 9,88 TBq ;

- Taxas de dose sem atenuação (novembro de 2013) para as distâncias calibradas pelo Programa Internacional de Garantia de Dose da Agência Internacional de Energia Atômica (International Dose Assurance Service 
- International Atomic Energy Agency - IDASIAEA), com o dosímetro Fricke padrão:

- $10 \mathrm{~cm}: 1,08 \times 10^{-2} \mathrm{~Gy} / \mathrm{h}$; DT: $3,22 \times 10^{-1} \mathrm{~Gy}$;

- $20 \mathrm{~cm}: 4,3 \times 10^{-1} \mathrm{~Gy} / \mathrm{h}$; DT: $1,29 \times 10^{-1} \mathrm{~Gy}$;

- $30 \mathrm{~cm}: 2,5 \times 10^{-1} \mathrm{~Gy} / \mathrm{h}$; DT: $6,2 \times 10^{-2} \mathrm{~Gy}$;

- $40 \mathrm{~cm}: 1,51 \mathrm{~Gy} / \mathrm{h}$; DT: $4,10 \times 10^{-2} \mathrm{~Gy}$;

Os irradiadores apresentam incerteza expandida na taxa de dose de $\pm 1,7 \%$, com um nível de confiança de 95\% (IDAS-IAEA) e pertencem ao Laboratório de Fontes Intensas de Radiação (LFIR) do IPEN.

- Radiação gama do Césio-137 $\left({ }^{137} \mathrm{Cs}\right)$ :

- Irradiador Irradiador Gammacell Elan:

- Marca: Atomic Energy of Canada ${ }^{\circledR}$;

- Modelo: 3000;

- Atividade (novembro de 2013): 9,27 TBq;

- Taxa de dose sem atenuação (novembro de 2013) (IDAS-IAEA): $212 \mathrm{~Gy} / \mathrm{h}$;

O irradiador Gammacell Elan é um equipamento de uso exclusivo para a irradiação de bolsas de sangue e pertence a Universidade Federal de São Paulo (UNIFESP), (Figura 10a). Possui duas fontes de ${ }^{137} \mathrm{Cs}$ duplamente revestidas de aço inoxidável e permanentemente instaladas dentro de uma proteção contra irradiação (Figura 10b). O fabricante assegura que as fontes satisfazem os requisitos especiais de segurança da International Atomic Energy Agency (IAEA). Na parte frontal do irradiador existe um canister de aço inoxidável onde são depositadas as bolsas de sangue para irradiação. $O$ canister é acoplado a um rotor que produz uma rotação de 30 rpm, (Figura 9.ab). No momento do acionamento do irradiador uma blindagem móvel gira $180^{\circ}$, expondo o canister à irradiação gama e logo em seguida o equipamento faz um segundo movimento de rotação de $90^{\circ}$ de todo o sistema. Internamente 0 sistema é formado por uma blindagem cilíndrica (Figura 11). 


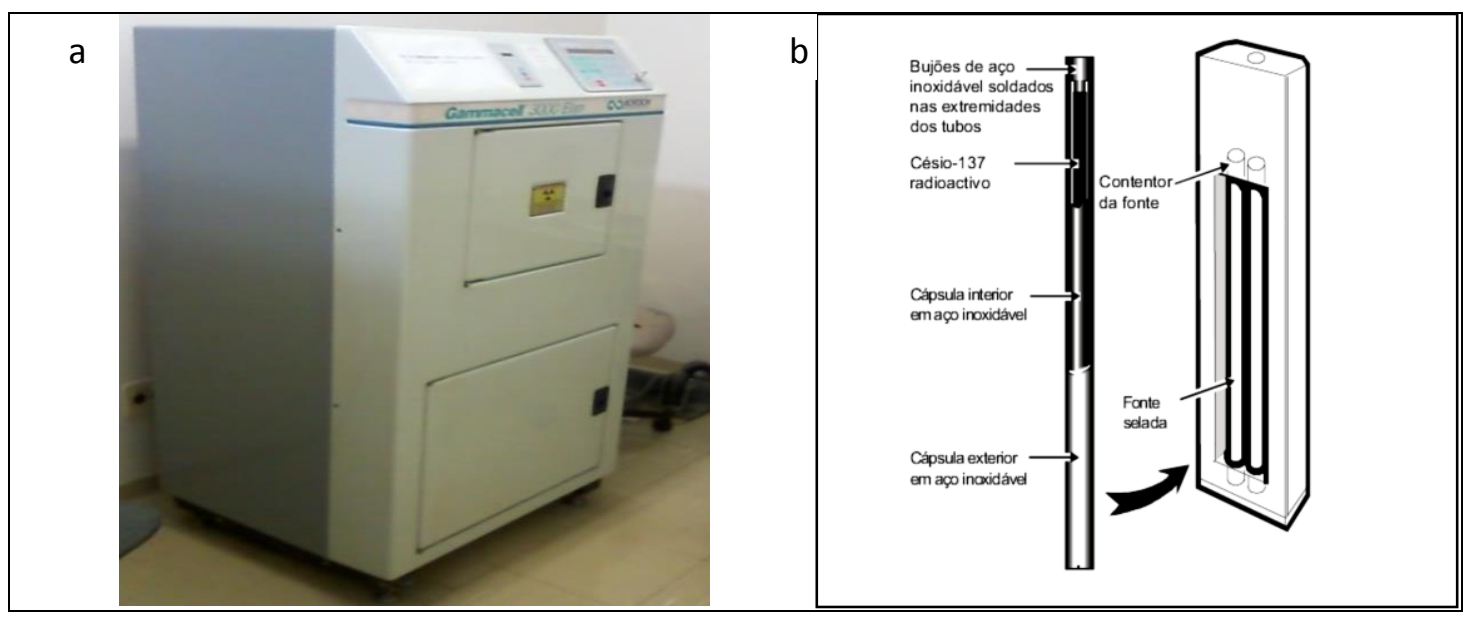

Figura 10. (a) Irradiador Gammacell Elan; (b) Conjunto de suporte das fontes do Gammacell Elan.

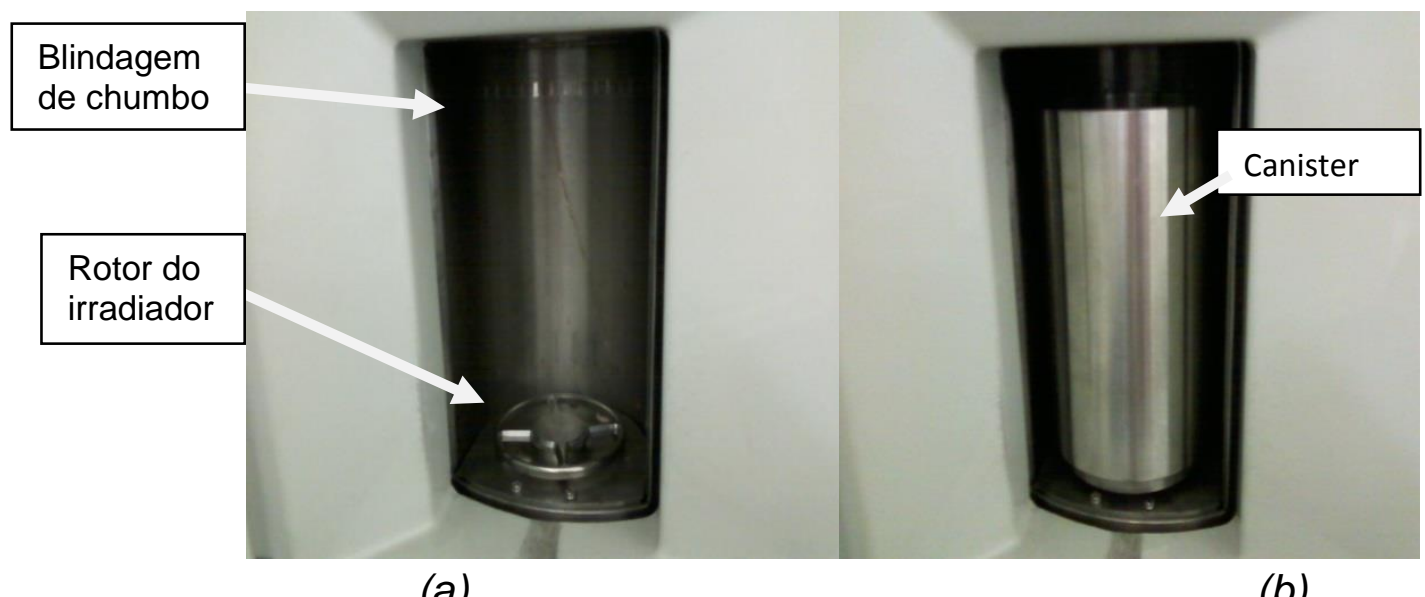

Figura 11. (a) Blindagem móvel e rotor do irradiador; (b) Posicionamento do canister no rotor.

O irradiador Gammacell Elan possui uma proteção externa e um sistema de blindagem cilíndrica fixa com uma porta móvel acionada através de um sistema pneumático, Figura 12. O sistema pneumático possui dois movimentos consecutivos, ambos com rotação de $180^{\circ}$ para a exposição das bolsas de sangue à fonte radioativa. 


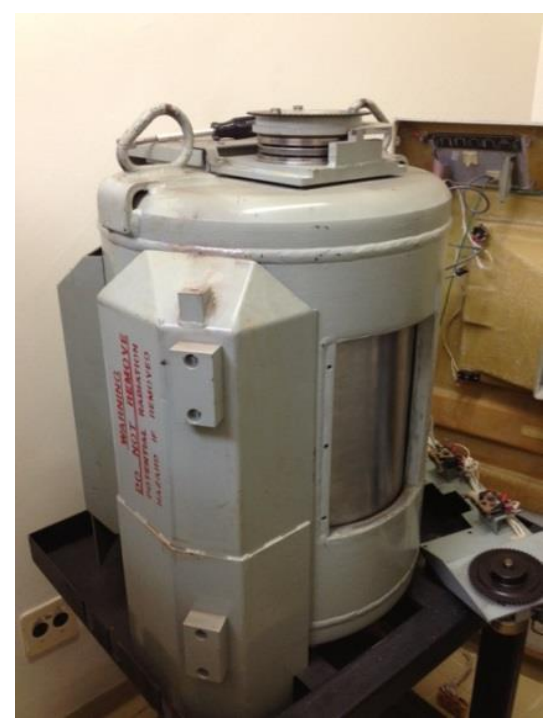

Figura 12. Equipamento sem proteção externa.

\subsection{Dosímetros Termoluminescentes (DTLs) - LiF:Mg,Ti (TLD-100)}

Foram utilizados 200 DTLs de LiF:Mg,Ti (TLD-100) produzidos pela Harshaw Chim. Co. de 3,15 $\mathrm{mm}$ de lado, 0,9 $\mathrm{mm}$ de espessura e massa de $2 \mathrm{mg}$. Os dosímetros foram selecionados criteriosamente de acordo com as sua repetibilidade e sensibilidade.

\subsection{Densitômetro Óptico}

Para a realização das medidas de densitometria óptica foi utilizado o densitômetro modelo Densoquick 2H fabricado pela Peha Med. Geräte $\mathrm{GmbH}$, (Figura 13), pertencente a Coordenadoria de Higiene das Radiações da Universidade Federal de São Paulo (UNIFESP).

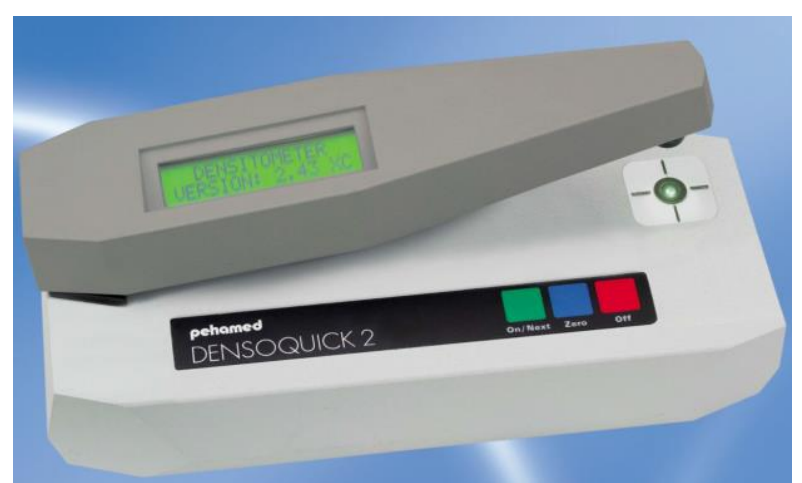

Figura 13. Densitômetro Densoquick 2H. 
$\mathrm{O}$ densitômetro Densoquick $2 \mathrm{H}$ realiza as medições de pontos do filme com funcionamento imediato, sem a necessidade de aquecimento. Os resultados das medições são apresentadas via display multi-linguagens. As especificações técnicas do Densoquick 2H constam na Tabela 6.

Tabela 6. Especificações técnicas do Densoquick 2H

\begin{tabular}{ll}
\hline Medida do comprimento do braço & $18 \mathrm{~cm}$ \\
\hline Temperatura de operação & $15^{\circ} \mathrm{C}$ a $35^{\circ} \mathrm{C}$ \\
\hline Medida do ponto & $7 \mathrm{~mm}^{2}$ \\
\hline Faixa de medição & $0 \leq \mathrm{D} \leq 5,0$ \\
\hline Incerteza da medida & $0 \leq 1: \Delta \mathrm{D}< \pm 0,02$ \\
\hline
\end{tabular}

\subsection{Programas Computacionais}

- Software Numaris ${ }^{\circledR}$ versão 4 Syngo-MR-A30, para a obtenção das intensidades de sinal de RMI;

- Software MatLab ${ }^{\circledR}$ (r2009a) versão 9.0, para a reconstrução tridimensional do simulador de bolsa de sangue;

- Software Microsoft ${ }^{\circledR}$ Excel versão 2010, para a efetuação de todos os cálculos necessários para a obtenção dos resultados;

- Software Microcal Origin ${ }^{\circledR}$ versão 8.0, para a confecção dos gráficos apresentados. 


\section{METODOLOGIA}

\subsection{Preparação da Solução Fricke Gel}

A gelatina é umedecida com água ultrapura à temperatura ambiente, em pequena quantidade. Após a total absorção, a gelatina é adicionada em $75 \%$ do volume total de água ultrapura previamente aquecida a $45^{\circ} \mathrm{C}$ e mantida nessas condições até a completa dissolução. Os $25 \%$ de água restante são utilizados para adição e dissolução dos demais compostos que são incorporados à solução no instante da completa dissolução da gelatina, a qual é previamente resfriada. A solução resultante é mantida sob agitação para a completa homogeneização. Imediatamente após a preparação as soluções foram acondicionadas nas cubetas de polimetil metacrilato (PMMA), com duas faces ópticas paralelas de $10 \mathrm{~mm}$ de comprimento e dimensões $10 \times 10 \times 45 \mathrm{~mm}^{3}$ para a irradiação e avaliação (Figura 14). Todas as amostras foram envolvidas e seladas com filme de policloreto de vinila (PVC), para minimizar a evaporação do solvente da solução.

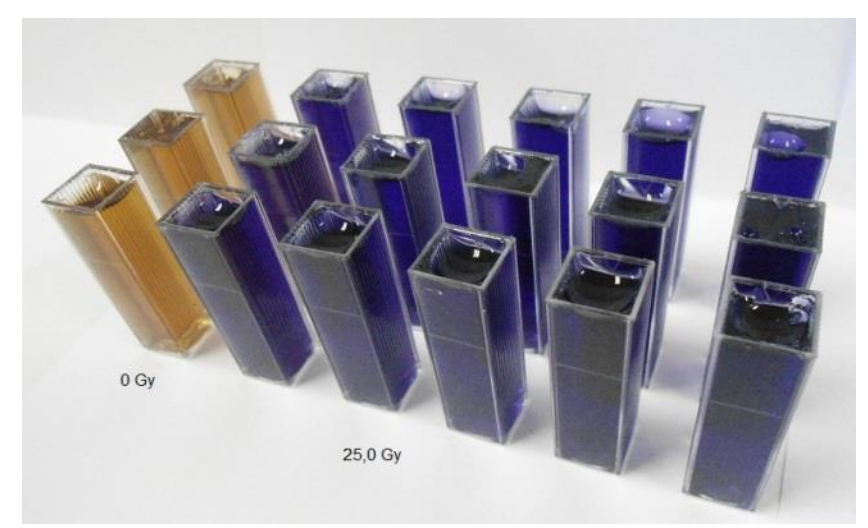

Figura 14. Cubetas preenchidas com Solução Fricke gel irradiadas e não irradiadas.

Todas as soluções dosimétricas estudadas foram preparadas com água produzida pelo purificador de água $(E L G A ®)$ utilizado na solução Fricke gel (5\% de gelatina 270 Bloom) e irradiadas nos irradiadores Gammacell 220, Gammacell Elan e Panorâmico com doses compreendidas entre 0,6 Gy e 45 Gy. 


\subsection{Bolsas de Sangue de $\mathbf{3 0 0} \mathrm{mL}$ para Transferência}

As bolsas de sangue foram preenchidas com uma solução Fricke gel, (Figura 15a), e irradiadas no irradiador Gammacell Elan, obedecendo a seu respectivo volume; foram mantidas em ambiente refrigerado, ((4 \pm 1$\left.)^{\circ} \mathrm{C}\right)$ e sob o abrigo da luz por aproximadamente 12 horas. As bolsas foram mantidas por 30 min a temperatura ambiente e ao abrigo da luz antes do procedimento de irradiação e, pelo menos, 5 min após irradiação sob as mesmas condições antes das avaliações de ressonância magnética por imagem (RMI).

As bolsas foram posicionadas no canister do irradiador Gammacell Elan, obedecendo ao mesmo protocolo de irradiação de bolsas de sangue para esterilização, e irradiadas com a dose de 25,0 Gy, formando conjuntos de uma única unidade, duas unidades e três unidades. O protocolo recomenda para a irradiação uma quantidade máxima de três unidades, (bolsas de sangue), por procedimento. Na esterilização do concentrado de plaquetas as bolsas utilizam, apenas, um volume de $100 \mathrm{~mL}$. Neste caso específico são esterilizados em um único procedimento o conjunto de dez bolsas contento plaquetas. A avaliação da dose foi realizada utilizando a técnica de ressonância magnética por imagem (RMI), executada antes e depois da irradiação.

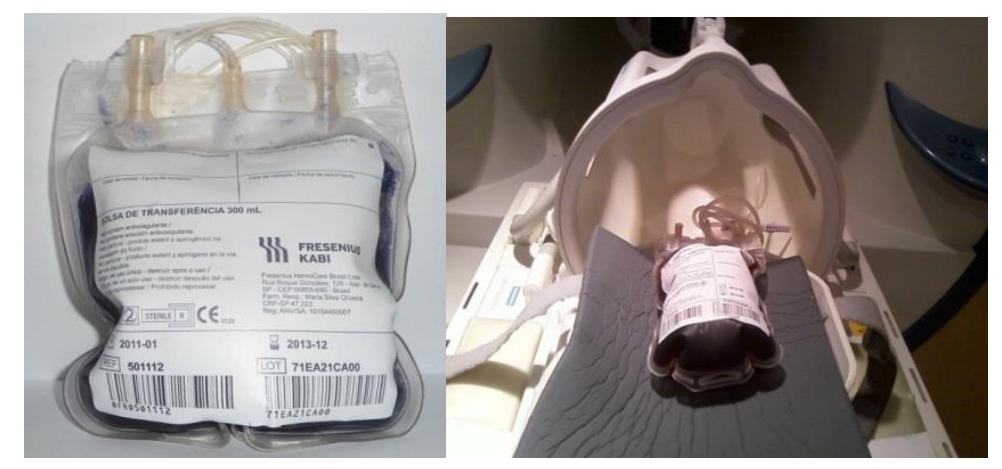

(a)

(b)

Figura 15. (a) Bolsa de sangue para transferência de $300 \mathrm{~mL}$ preenchida com solução

Fricke gel; (b) Bolsa de sangue para transferência de $300 \mathrm{~mL}$ preenchida com solução Fricke gel irradiada posicionada no equipamento de RMI. 


\subsection{Filme Radiocrômico para Dosimetria de Fótons de Energia Alta - Grafchromic MD-55}

O filme radiocrômico foi dimensionado em partes de $2 \times 2 \mathrm{~cm}^{2}$. As partes foram irradiadas no Gammacell 220 e no Gammacell Elan, expostas a doses entre 1,0 e 45,0 Gy para a construção da curva de resposta em função da dose (curva de calibração). A leitura do filme foi realizada num densitômetro óptico e no espectrofotômetro após $72( \pm 1)$ h após a irradiação. No Gammacell Elan as irradiações foram feitas com o filme em rotação. O filme radiocrômico foi posicionado no centro do canister e em condições de equilíbrio eletrônico.

\subsection{Dosímetros Termoluminescentes (DTLs) - LiF:Mg,Ti (TLD-100)}

Foram utilizadas 200 DTLs de LiF:Mg,Ti (TLD-100) produzidos pela Harshaw Chem. Co. de 3,15 mm de lado, 0,9 mm de espessura e massa de 2 mg. Os lotes iniciais dos dosímetros foram reduzidos a lotes de 25 DTLs, cujas sensibilidades individuais ao ${ }^{60} \mathrm{Co}$, com reprodutibilidade máxima de $0,5 \%$, variam, no máximo, $5 \%$ para cada fósforo.

- No tratamento térmico dos dosímetros foram utilizados os equipamentos:

- 1 Forno tipo mufla com aquecimento por microondas marca CEM modelo MAS 7000;

- 1 Forno tipo mufla marca VULCAN modelo 3-550 PD;

- 1 Pinça anatômica com ponta de Teflon;

- 4 Bandejas de aço inox.

- Para a embalagem dos dosímetros foram utilizados:

- Filme de policloreto de vinila (PVC);

- Folhas de plástico resistente;

- Seladora manual;

- Pinça anatômica;

- Papel alumínio. 
- Para a avaliação da resposta TL dos dosímetros foram utilizados:

- 1 Leitora TL marca Harshaw modelo 4500;

- 1 Leitora TL marca Harshaw modelo 4000;

- Programa de aquisição de dados TLDSHELL para ambiente DOS;

No processo de leitura, o dosímetro é posicionado no centro da prancheta metálica da leitora e aquecido de acordo com o tipo de protocolo de leitura selecionado. A temperatura e a umidade do ar da sala foram controladas, variando, respectivamente, de $15^{\circ} \mathrm{C}$ a $20^{\circ} \mathrm{C}$ e abaixo de $50 \%$. O ajuste da temperatura foi feito em três fases: o pré-aquecimento, a aquisição e o tratamento, cada um com tempos e temperaturas independentes e definidos pelo protocolo de leitura (MATSUSHIMA, 2010).

Os dosímetros DTLs foram utilizados no irradiador Gammacell Elan para a verificação do tempo de abertura e fechamento do equipamento.

\subsection{Espectrofotometria}

Foram utilizadas soluções Fricke gel dosimétricas armazenadas em cubetas de $5 \mathrm{~mL}$ e partes do filme radiocrômico Grafchromic ${ }^{\circledR}$ (MD-55) medindo $2 \times 2 \mathrm{~mm}^{2}$, ambos protegidos de uma exposição direta da radiação luminosa e submetidos a um feixe luminoso de diâmetro de $3 \mathrm{~mm}$ nos espectrofotômetros do Laboratório de Doses Altas (LDA) na Gerência de Metrologia das Radiações (GMR-IPEN).

\subsection{Irradiação das Amostras}

As soluções, após a preparação, foram mantidas em ambiente refrigerado $\left((4 \pm 1){ }^{\circ} \mathrm{C}\right)$ e sob o abrigo da luz por aproximadamente 12 horas (Olsson et. al., 1989), permanecendo por 30 minutos à temperatura ambiente e ao abrigo da luz antes da irradiação. As irradiações das amostras de solução Fricke gel foram realizadas nas próprias cubetas de leitura. As diferentes amostras de Fricke gel foram irradiadas com fontes de ${ }^{60} \mathrm{Co}$ usando os irradiadores Panorâmico (Yoshizawa Kiko ${ }^{\circledR}$ modelo FIS 60-04) e Gammacell 
(Atomic Energy of Canada $^{\circledR}$ modelo 220), no Centro de Tecnologia das Radiações (CTR) do IPEN. As amostras foram irradiadas com doses compreendidas entre 0,6 Gy e 45,0 Gy. As irradiações foram sempre realizadas livre no ar em condições de equilíbrio eletrônico. Seguindo o mesmo procedimento acima, mas com fontes de ${ }^{137} \mathrm{Cs}$ e utilizando o irradiador Gammacell Elan (Atomic Energy of Canada ${ }^{\circledR}$ modelo 3000), no Hemocentro do Hospital São Paulo (UNIFESP). As cubetas contendo solução Fricke gel foram irradiadas com doses compreendidas entre 2,0 Gy e 35,0 Gy livre no ar em condições de equilíbrio eletrônico, sendo posicionadas no ponto médio do volume do canister.

As amostras foram mantidas, pelo menos, 5 min. após irradiação à temperatura ambiente e ao abrigo da luz, antes das avaliações de ressonância magnética por imagem (RMI). As imagens das cubetas foram analisadas na estação de trabalho do equipamento de ressonância magnética por imagem (RMI), antes e após a irradiação, onde foram selecionadas regiões circunferências de área 1,0 × $10^{-4} \mathrm{~m}^{2}$ em pontos centrais das cubetas para a observação do sinal e identificação de dose em faixas compreendidas num conjunto de 100 imagens a cada conjunto de três cubetas por dose irradiada. A análise resultou na construção da curva de resposta em função da dose e que foi comparada com os resultados obtidos empregando a técnica de espectrofotometria, onde se utilizou o mesmo conjunto de cubetas. As imagens das cubetas, e seus respectivos sinais, foram reproduzidas no programa computacional MatLab ${ }^{\circledR}$, versão r2012a, licenciado pelo Centro de Computação Eletrônica da USP (CCE-USP), para construção de um diagrama de cores capaz de identificar regiões onda se possa visualizar homogeneidade na dose aplicada.

Os dosímetros DTLs formam posicionados no ponto central do volume do canister e submetidos a doses de 0,5 Gy, 1,0 Gy e 1,5 Gy no irradiador Gammacell Elan. As condições de equilíbrio eletrônico foram mantidas.

As amostras do filme radiocrômico (Grafchromic MD-55) foram irradiadas no irradiador Gammacell 220 e no irradiador Gammacell Elan com doses compreendidas entre 1,0 Gy e $40 \mathrm{~Gy}$, mantidas as condições de equilíbrio eletrônico. 


\subsection{Avaliação das Amostras}

A absorção óptica (OA), técnica bem estabelecida, avaliada por técnica de espectrofotometria, foi empregada usando os espectrofotômetros modelo SHIMADZU UV2101-PC e Agilent Technologies ${ }^{\circledR}$ Cary Series modelo UV-VisNIR para análise do dosímetro Fricke gel (Laboratório de Doses Alta do IPEN LDA).

$\mathrm{Na}$ análise do filme radiocrômico (Grafchromic ${ }^{\circledR}$ MD-55), foi empregada a mesma técnica, mas utilizando o espectrofotômetro Cary Series modelo UVVis-NIR, (Laboratório de Doses Alta do IPEN - LDA) e a técnica de absorção óptica utilizando o densitômetro óptico marca Peha Med. Geräte $\mathrm{GmbH}$ modelo Densoquick 2 (Coordenadoria de Higiene das Radiações da Unifesp).

As medições de absorção óptica no dosímetro Fricke gel foram realizadas imediatamente após a preparação das soluções e 30 minutos após a irradiação, no intervalo de comprimento de onda compreendido entre $190 \mathrm{~nm}$ e $900 \mathrm{~nm}$. $\mathrm{Na}$ análise dos espectros foram considerados os comprimentos de onda de $441 \mathrm{~nm}$ e $585 \mathrm{~nm}$, de acordo com a literatura vigente.

As imagens das bolsas de sangue de $300 \mathrm{~mL}$ para transferência foram geradas antes e após a irradiação, obedecendo a parâmetros previamente estabelecidos nos ensaios realizados em cubetas. Nas imagens das bolsas de sangue foram selecionadas quatro regiões para a observação do sinal produzido por RMI com os planos de aquisição ortogonal sagital e ortogonal coronal. As regiões circulares selecionadas obedeceram uma área de 1,25 $x$ $10^{-4} \mathrm{~m}^{2}$, compreendiam um conjunto de 100 imagens a partir do ponto central de cada circulo em ambos os planos de aquisição. O sinal gerado nessas regiões proporcionou a comparação com a curva de resposta em função da dose estabelecido nas cubetas. 


\section{RESULTADOS E DISCUSSÃO}

\subsection{Espectro de Absorção Óptica da Solução Fricke Gel}

As cubetas de $5 \mathrm{~mL}$ preenchidas com solução Fricke gel foram irradiadas nos irradiadores Gammacell 220 e Gammacell Elan com fontes de ${ }^{60} \mathrm{Co}$ e ${ }^{137} \mathrm{Cs}$, respectivamente, sendo respeitadas todas as recomendações técnicas contidas na literatura.

$\mathrm{Na}$ avaliação das cubetas irradiadas, utilizando a técnica de espectrofotometria, foram determinados dois comprimentos de onda relevantes entre os comprimentos de onda de $190 \mathrm{~nm}$ e $900 \mathrm{~nm}$. Podemos observar na Figura 16 duas bandas de absorção: $441 \mathrm{~nm}\left(\mathrm{Fe}^{2+}\right) 585 \mathrm{~nm}\left(\mathrm{Fe}^{3+}\right) . \mathrm{O}$ comportamento da resposta em função da dose é similar, tanto para a irradiação com ${ }^{60} \mathrm{Co}$ quanto para ${ }^{137} \mathrm{Cs}$ nos sistemas de irradiação. Assim, podemos verificar que não há dependência energética considerável na resposta a dose fornecida pela solução Fricke gel.

O dosímetro Fricke gel demonstrou-se confiável e não apresentou dependência energética ao ser irradiado com fontes de energias distintas. Isso possibilitou a construção de uma curva de calibração para o que este trabalho foi proposto.

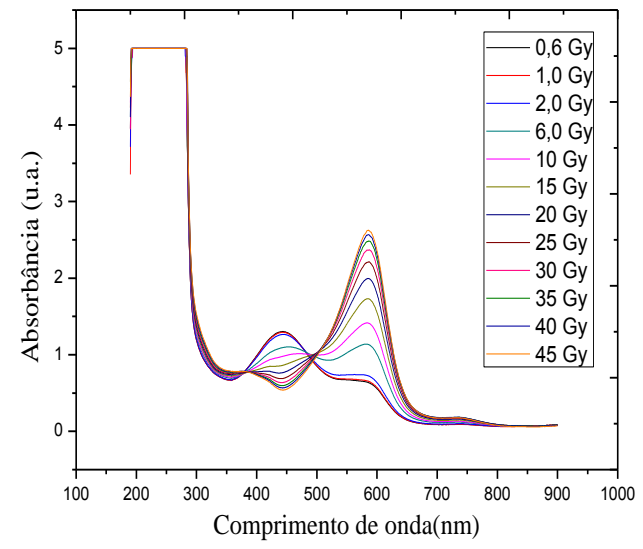

(a)

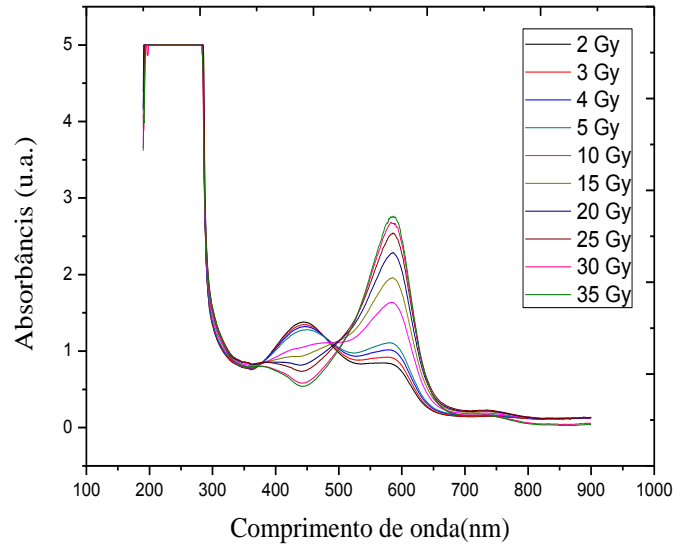

(b)

Figura 16. Espectro de absorção óptica da solução Fricke gel: irradiação gama com ${ }^{60} \mathrm{Co}$; (a) e irradiação gama com ${ }^{137} \mathrm{Cs}$; (b) para doses entre 0,6 e 45,0 Gy. 


\subsection{Resposta Espectrofotométrica da Solução Fricke Gel Irradiada no}

\section{Gammacell Elan}

Inicialmente a solução de Fricke gel foi utilizada nos sistemas de irradiação para a construção da curva-resposta em função da dose utilizando técnica espectrofotométrica na solução Fricke gel contida em cubetas de $5 \mathrm{~mL}$.

A curva de resposta em função da dose apresenta (Figura 17) comportamento linear no intervalo de dose estudado. O limite mínimo de detecção (LDL) se encontrou dentro dos limites estabelecidos pela literatura.

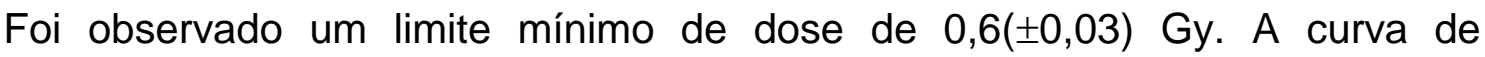
calibração demonstrou comportamento linear dentro do intervalo de dose proposto para a análise das doses que foram submetidas às bolsas de sangue, entre 20 Gy e 35 Gy.

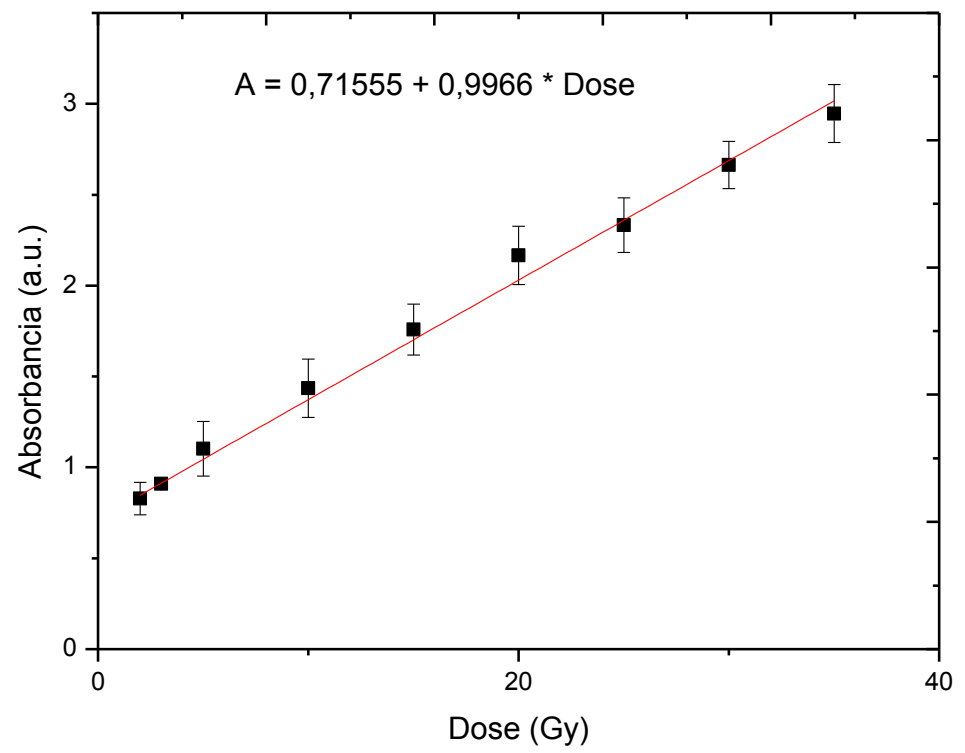

Figura 17. Resposta espectrofotométrica da solução Fricke gel irradiada com ${ }^{137}$ Cs. 


\subsection{Resposta da Solução Fricke Gel Avaliada por Técnica de RMI}

Para a análise das bolsas de sangue foi necessário a construção de uma curva de resposta em função do sinal gerado em função da dose pelas imagens produzidas no equipamento de RMI.

Cubetas de $5 \mathrm{~mL}$ preenchidas com solução Fricke gel foram irradiadas no irradiador Gammacell Elan com doses de 15 Gy, 20 Gy, 25 Gy e 30 Gy. As irradiações foram divididas em lotes e para cada lote havia a separação de três cubetas para uma respectiva dose. Os sinais gerados pelas imagens produzidas no equipamento de RMI foram analisados no ponto médio das cubetas e construindo uma curva-resposta estabelecida entre a dose e a intensidade de sinal gerado nas imagens, Figura 18. O comportamento do sinal em função da dose se apresentou linear dentro do intervalo de dose que as bolsas são submetidas para esterilização.

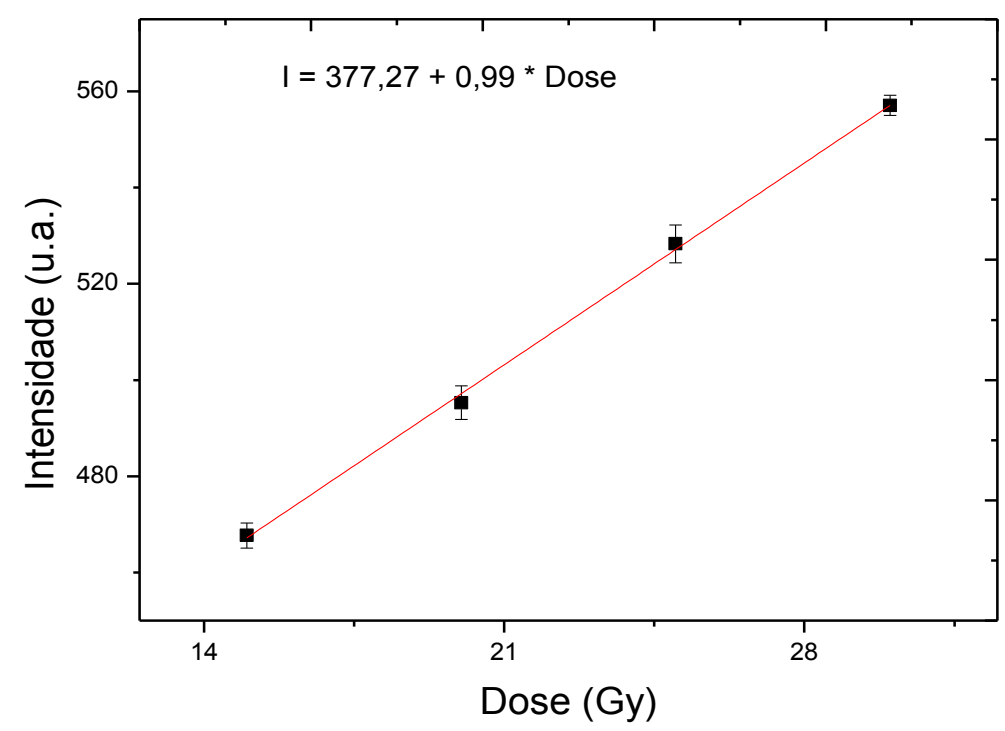

Figura 18. Curva de calibração da solução Fricke gel irradiada com ${ }^{137}$ Cs: técnica de RMI.

\subsection{Bolsas de Sangue de $300 \mathrm{~mL}$ para Transferência}

Respeitando todas as recomendações técnicas e reproduzindo o mesmo procedimento que foi adotado nas cubetas, as bolsas de sangue de $300 \mathrm{~mL}$ para transferência foram irradiadas no irradiador Gammacell Elan com 
dose de 25 Gy e produzidas imagens com equipamento de RMI.

Analisando o sinal gerado pelas imagens obtidas no equipamento de RMI foram selecionadas quatro regiões na bolsa de sangue preenchida com solução Fricke gel, Figura 19.

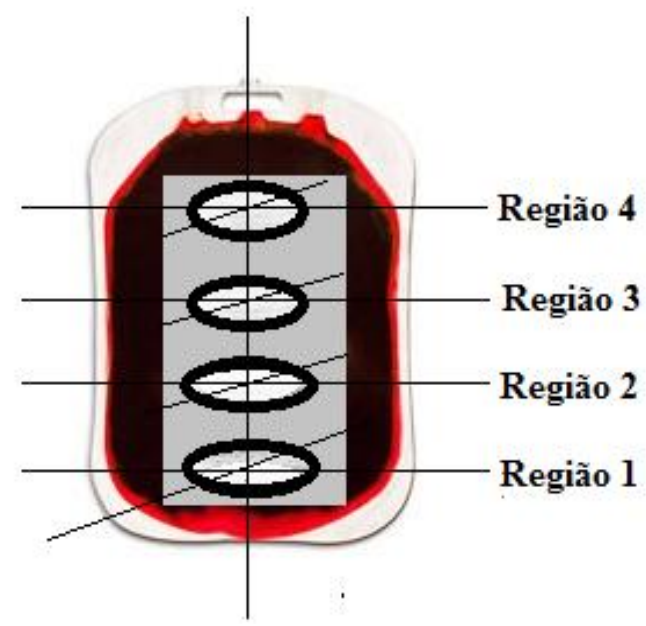

Figura 19. Regiões selecionadas nas bolsas de sangue para estudo do sinal da RMI.

Analisando a relação entre a dose entregue e a intensidade do sinal avaliado por RMI nas regiões selecionadas nas bolsas de sangue para uma única amostra, mostradas na Tabela 7 , pode ser obervado que não há homogeneidade da dose e a região 4 apresentou dose inferior aos 25 Gy recomendados para o procedimento de esterilização dos hemocomponentes do sangue. O intervalo de dose entre a região 1 (26,67 Gy) e a região 4 (24,23 Gy) demonstrou uma variação de $\pm 3,65 \%$.

Tabela 7. Relação entre a intensidade do sinal avaliado por RMI e as regiões selecionadas nas bolsas de sangue para uma bolsa.

\begin{tabular}{cccc}
\hline $\begin{array}{c}\text { Regiões } \\
\text { selecionadas } \\
\text { na bolsa de sangue }\end{array}$ & $\begin{array}{c}\text { RMI-intensidade do } \\
\text { sinal } \\
\text { (unidade arb.) }\end{array}$ & $\begin{array}{c}\text { Dose } \\
\text { absorvida } \\
\text { (Gy) }\end{array}$ & $\begin{array}{c}\text { Desvio } \\
\text { padrão } \\
\text { (\%) }\end{array}$ \\
\hline 1 & 563,6 & 26,67 & $\pm 6,68$ \\
2 & 556,7 & 26,34 & $\pm 5,38$ \\
3 & 549,5 & 26,00 & $\pm 4,01$ \\
4 & 512,0 & 24,23 & $\pm 3,08$ \\
\hline
\end{tabular}


A Resolução RDC 57 de 2010 da ANVISA recomenda que a dose mínima para o procedimento de esterilização dos hemocomponentes sanguíneos não seja inferior à dose de 25 Gy. Podemos verificar que uma das regiões da bolsa de sangue apresenta uma dose de radiação menor que a mínima dose determinada, Figura 20.

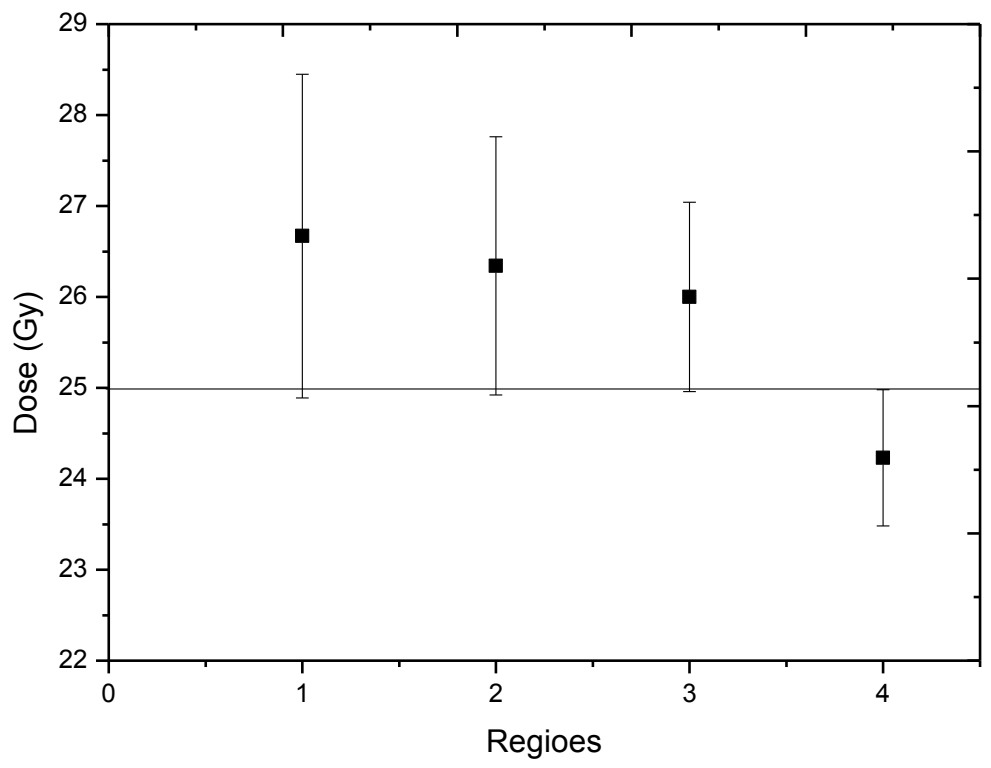

Figure 20. Relação entre as doses e as regiões selecionadas de uma bolsa de sangue irradiada com dose mínima de 25 Gy determinada pela Resolução RDC 57 de 2010 da ANVISA.

$\mathrm{Na}$ análise da relação entre a intensidade do sinal avaliado por RMI e a dose nas regiões selecionadas nas bolsas de sangue para irradiação de duas amostras, mostrada na Tabela 8, foi demonstrado também não há homogeneidade da dose e a região 4 apresentou dose inferior aos 25 Gy recomendados para o procedimento de esterilização dos hemocomponentes do sangue. O intervalo de dose entre a região 1 (26,46 Gy) e a região 4 (24,19 Gy) demonstrou uma variação de $\pm 2,65 \%$. 
Tabela 8. Relação entre a intensidade do sinal avaliado por RMI e as regiões selecionadas nas bolsas de sangue para irradiação de duas bolsas.

\begin{tabular}{cccc}
\hline $\begin{array}{c}\text { Regiões } \\
\text { selecionadas } \\
\text { na bolsa de sangue }\end{array}$ & $\begin{array}{c}\text { RMI-intensidade do } \\
\text { sinal } \\
\text { (unidade arb.) }\end{array}$ & $\begin{array}{c}\text { Dose } \\
\text { absorvida } \\
(\mathbf{G y})\end{array}$ & $\begin{array}{c}\text { Desvio } \\
\text { padrão } \\
\mathbf{( \% )}\end{array}$ \\
\hline 1 & 559,3 & 26,46 & $\pm 5,84$ \\
2 & 551,8 & 26,11 & $\pm 4,44$ \\
3 & 547,4 & 25,90 & $\pm 3,60$ \\
4 & 511,3 & 24,19 & $\pm 3,24$ \\
\hline
\end{tabular}

$\mathrm{Na}$ analise do sinal gerado nas imagens por RMI o comportamento se manteve regular quando comparado ao número de bolsas posicionadas no canister do irradiador Gammacell Elan. A região 4 continuou apresentando dose inferior à recomendação de dose mínima de 25 Gy e menor que a dose apresentada quando foi irradiada uma única bolsa de sangue, Figura 21.

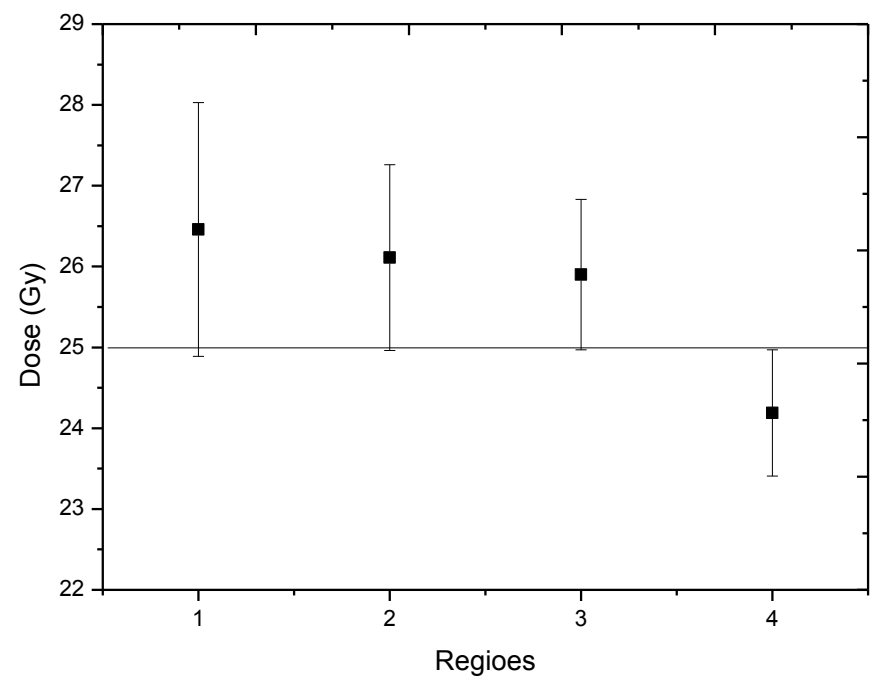

Figure 21. Relação entre as doses e as regiões selecionadas de duas bolsas de sangue irradiadas com dose mínima de 25 Gy determinada pela Resolução RDC 57 de 2010 da ANVISA.

Posicionado três bolsas no canister do irradiador Gammacell Elan e analisando o sinal gerado na imagem da bolsa intermediaria foram identificadas doses inferiores às bolsas periféricas e equidistantes da bolsa intermediária, Tabela 9. As regiões selecionadas demostram a não existência da 
homogeneidade na dose. A região 4 apresentou doses, ainda menores, quando o numero de bolsas se elevou ao número limite de bolsas recomendado pelo fabricante do irradiador Gammacell Elan. O intervalo de dose entre a região 1 (26,36 Gy) e a região 4 (24,11 Gy) demonstrou uma variação de $\pm 1,88$ \%.

Tabela 9. Relação entre a intensidade do sinal avaliado por RMI e as regiões selecionadas nas bolsas de sangue para três bolsas (bolsa intermediária).

\begin{tabular}{cccc}
\hline $\begin{array}{c}\text { Regiões } \\
\text { selecionadas } \\
\text { na bolsa de sangue }\end{array}$ & $\begin{array}{c}\text { RMl-intensidade do } \\
\text { sinal } \\
\text { (unidade arb.) }\end{array}$ & $\begin{array}{c}\text { Dose } \\
\text { absorvida } \\
\text { (Gy) }\end{array}$ & $\begin{array}{c}\text { Desvio } \\
\text { padrão } \\
\text { (\%) }\end{array}$ \\
\hline 1 & 557,2 & 26,36 & $\pm 5,44$ \\
2 & 550,4 & 26,04 & $\pm 4,16$ \\
3 & 546,2 & 25,85 & $\pm 3,04$ \\
4 & 510,6 & 24,11 & $\pm 3,56$ \\
\hline
\end{tabular}

Foi realizado o mesmo procedimento de análise da intensidade do sinal avaliado por RMI nas regiões selecionadas nas bolsas de sangue para as bolsas de sangue periféricas quando foram irradiadas três bolsas e foi demonstrada a não homogeneidade da dose, Tabela 10. A região 4, assim como nas medições anteriores, apresentou dose inferior os 25 Gy recomendados para o procedimento especificado. $\mathrm{O}$ intervalo de dose entre a região 1 (26,40 Gy) e a região 4 (24,17 Gy) demonstrou uma variação de $\pm 2,28 \%$.

Tabela 10. Relação entre a intensidade do sinal avaliado por RMI e as regiões selecionadas nas duas bolsas de sangue periféricas quando foram posicionadas três bolsas.

\begin{tabular}{cccc}
\hline $\begin{array}{c}\text { Regiões } \\
\text { selecionadas } \\
\text { na bolsa de sangue }\end{array}$ & $\begin{array}{c}\text { RMI-intensidade do } \\
\text { sinal } \\
\text { (unidade arb.) }\end{array}$ & $\begin{array}{c}\text { Dose } \\
\text { absorvida } \\
\text { (Gy) }\end{array}$ & $\begin{array}{c}\text { Desvio } \\
\text { padrão } \\
\text { (\%) }\end{array}$ \\
\hline 1 & 557,2 & 26,40 & $\pm 5,60$ \\
2 & 550,4 & 26,08 & $\pm 4,32$ \\
3 & 546,2 & 25,87 & $\pm 3,48$ \\
4 & 510,6 & 24,17 & $\pm 3,32$ \\
\hline
\end{tabular}


Podemos verificar que uma das regiões da bolsa de sangue, mais especificamente a região 4, continuou apresentando uma dose de radiação menor que a mínima dose de 25 Gy, Figura 22.

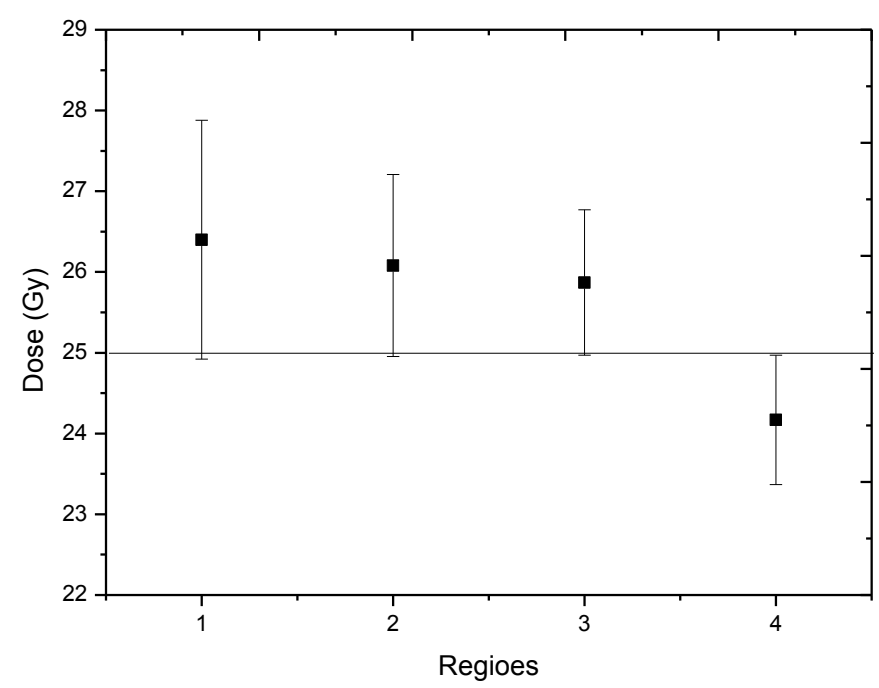

Figure 22. Relação entre as doses e as regiões selecionadas nas bolsas de sangue periféricas quando foram posicionadas três bolsas irradiadas com dose mínima de 25 Gy determinada pela Resolução RDC 57 de 2010 da ANVISA.

\subsection{Imagens de Corte das Cubetas de $5 \mathrm{~mL}$ e das Bolsas de Sangue} de $300 \mathrm{~mL}$ Geradas por RMI

A estação de trabalho do equipamento de RMI marca Siemens ${ }^{\circledR}$ modelo Magnetom Symphony Maestro Class (1,5 T) foi utilizada para a reconstrução das imagens e avaliação do sinal. A Figura 23 apresenta uma imagem em corte sagital das cubetas não irradiadas. O sinal da imagem foi tomado no ponto médio das cubetas de $5 \mathrm{~mL}$ preenchidas com solução Fricke gel, onde pode ser obervada a homogeneidade da imagem. 


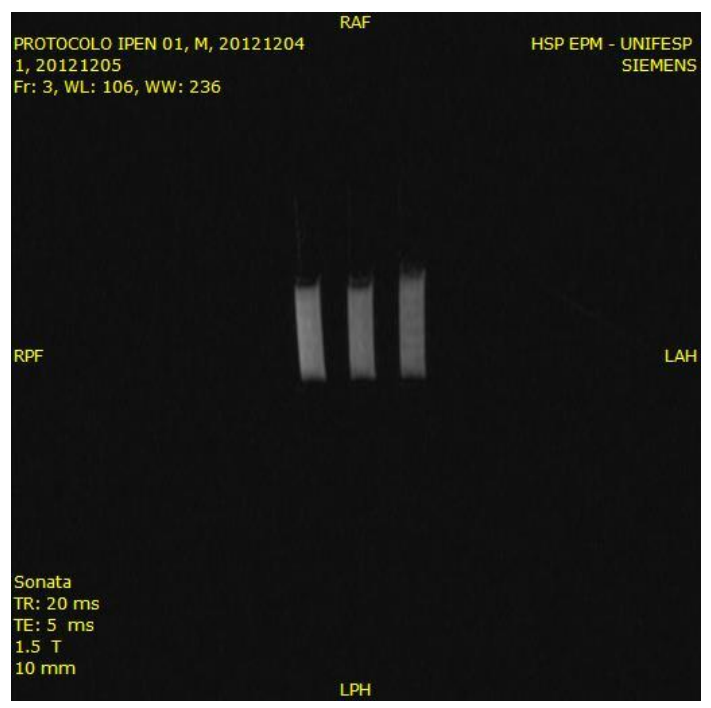

Figura 23. Corte sagital de uma Imagem obtida por RMI de um das um conjunto de cubetas de $5 \mathrm{~mL}$ não irradiadas.

A Figura 24 das cubetas de $5 \mathrm{~mL}$ irradiadas no Gammacell Elan com de 20 Gy, 25 Gy e 30 Gy apresenta uma imagem em corte sagital onde pode ser observada a variação em escala de cinza para doses distintas.

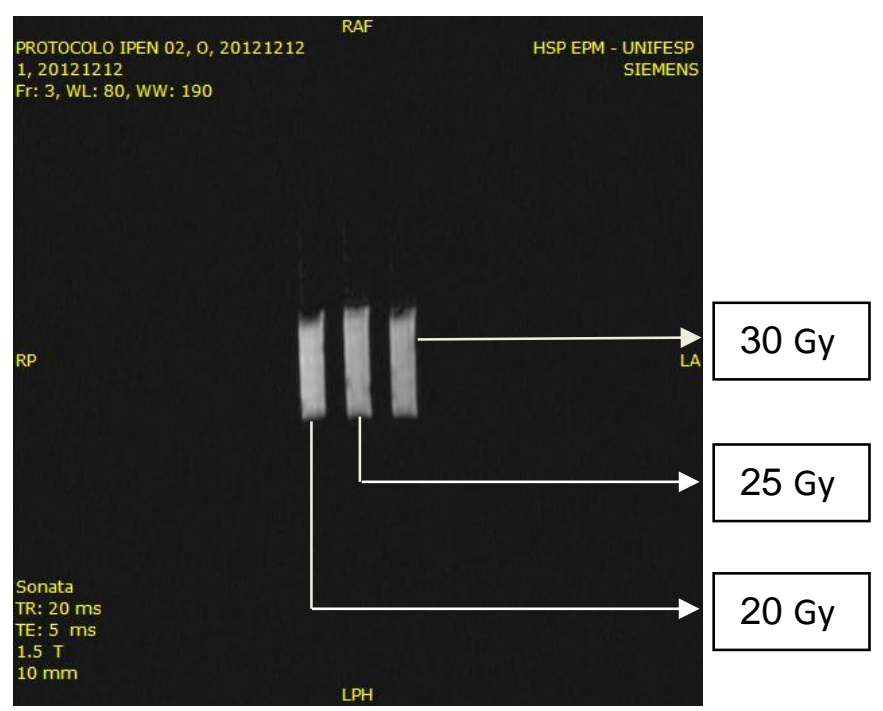

Figura 24. Corte sagital de uma imagem obtida por RMI de um conjunto de cubetas de $5 \mathrm{~mL}$ irradiadas com doses de $20 \mathrm{~Gy}, 25$ Gy e $30 \mathrm{~Gy}$.

A Figura 25(a,b,c) apresenta o cortes coronais de imagens obtidas por MRI de um conjunto de três bolsas de sangue posicionadas nas regiões periféricas (a e c) e intermediária (b) irradiadas com dose nominal de 25 Gy. 
As bolsas de sangue apresentaram não homogeneidade na distribuição da dose na região superior.

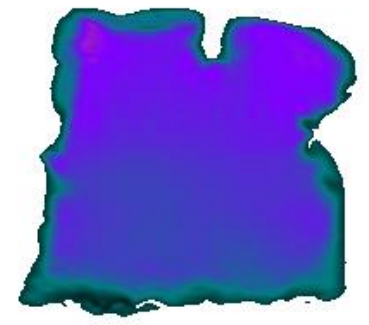

(a)

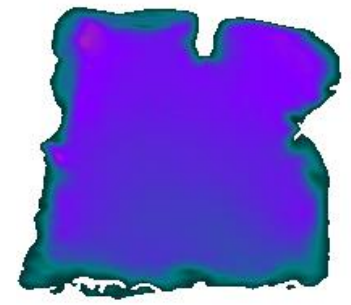

(b)

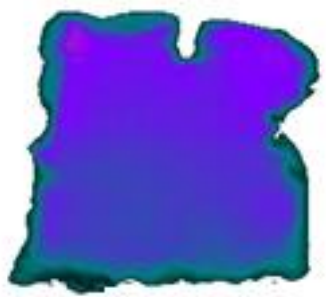

(c)

Figura 25. Corte coronal de uma imagem obtida por MRI de um conjunto de três bolsas de sangue irradiadas com dose de 25 Gy; (a) periférica 1; (b) intermediária; (c) periférica 2.

\subsection{Reconstrução da Imagem 3D das Bolsas de Sangue de $300 \mathrm{~mL}$ para Transferência}

A Figura $26(a ; b ; c ; d)$ mostram cortes de imagens de bolsas de sangue preenchidos com solução Fricke gel dosimétrica. As imagens são de bolsas de sangue irradiadas com uma dose de 25,0 Gy e não irradiadas. A aquisição de imagens foi realizada nos planos coronal e axial. As imagens foram geradas por ressonância magnética e reconstruídos com o uso de software MatLab ${ }^{\circledR}$ (r2009a). Na reconstrução adotamos um diagrama de cores para identificar regiões com diferentes doses, no caso de inexistência na uniformidade da dose.

A visualização do comportamento das bolsas de sangue em relação à dose aplicada foi possível através da construção de um diagrama de cores onde existe uma variação nas cores de acordo com a variação do sinal produzido em regiões distintas. A região da base das bolsas irradiadas apresentou uma coloração mais clara que variou do tom de vermelho ao tom de amarelo na extremidade posterior e a região central apresentou um tom de cor intermediária, considerado o diagrama de cores adotado. Através do diagrama de cores foi possível analisar que o sinal gerado pelas imagens de 
ressonância magnética que as bolsas de sangue irradiadas não apresentam homogeneidade na dose.

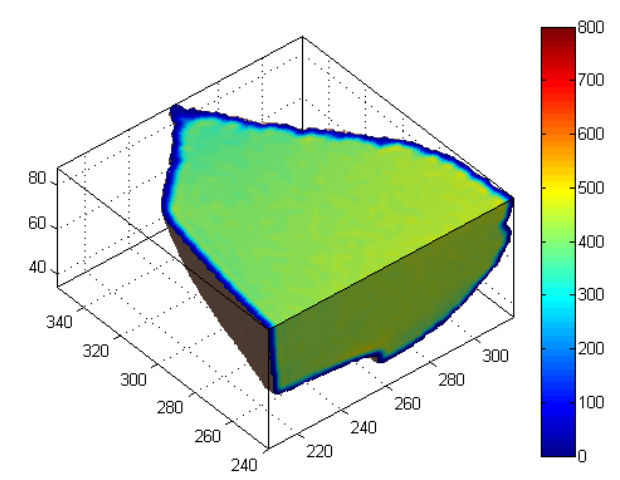

(a)

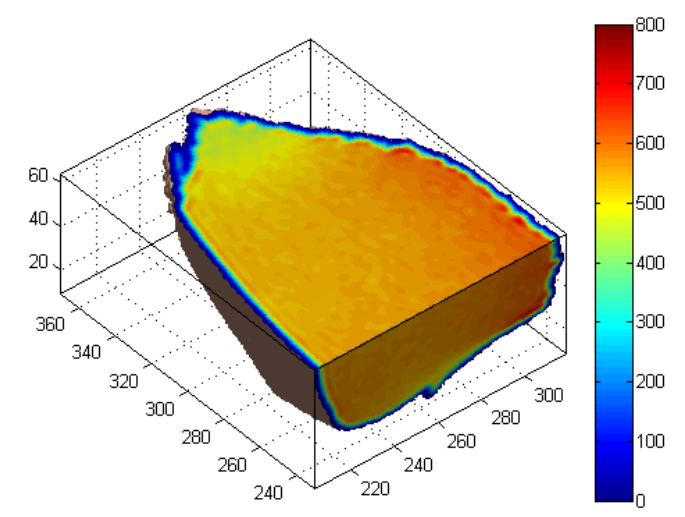

(c)

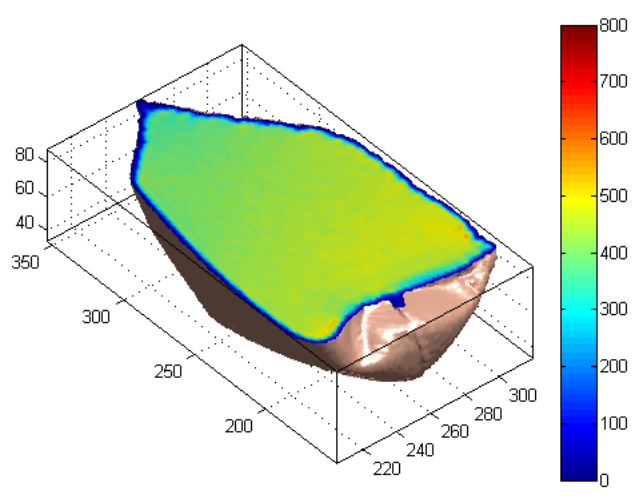

(b)

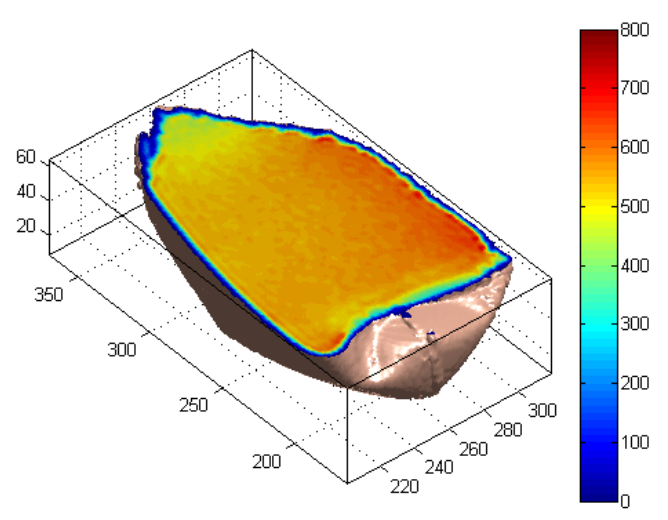

(d)

Figura 26. (a) Imagem reconstruída da RMI no plano coronal da aquisição da bolsa de sangue não irradiada; (b) Imagem reconstruída da RMI no plano axial da aquisição da bolsa de sangue não irradiada; (c) Imagem reconstruída da RMI no plano coronal da aquisição da bolsa de sangue irradiada com dose de 25,0 Gy $\left({ }^{137} \mathrm{Cs}\right)$; (d) Imagem reconstruída da RMI no plano axial da aquisição da bolsa de sangue irradiadas com dose de 25,0 Gy $\left({ }^{137} \mathrm{Cs}\right)$. 


\subsection{Filme Radiocrômico para Dosimetria de Fótons de Energia Alta -}

\section{Grafchromic MD-55}

As Figuras 27 e 28 demonstram as curvas de calibração do filme Grafchromic MD-55 irradiado com fontes de ${ }^{60}$ Co no irradiador Gammacell 220 e com fontes de ${ }^{137} \mathrm{Cs}$ no irradiador Gammacell Elan. A dependência energética e a pouca confiabilidade do filme para aplicação em rotinas devido á rotação produzida pelo equipamento pode ser claramente observada. No filme radiocrômico foi demonstrado que a distinção para doses com intervalos inferiores a 4,0 Gy não apresentou confiabilidade. Nos intervalos de dose compreendidos entre 1,0 Gy e 2,0 Gy apresentou densidade óptica semelhante, tornando-o insatisfatório para aplicação em rotinas que necessitem de precisão de dose dentro desse intervalo considerado. Além de possuir dependência energética quando irradiado com fontes de energias diferentes e limites mínimos de detecção (LDL) de dose distintas nas situações de irradiação descritas. Lembrado que o sistema de irradiação do Gammacell Elan possui dois estágios consecutivos de rotação.

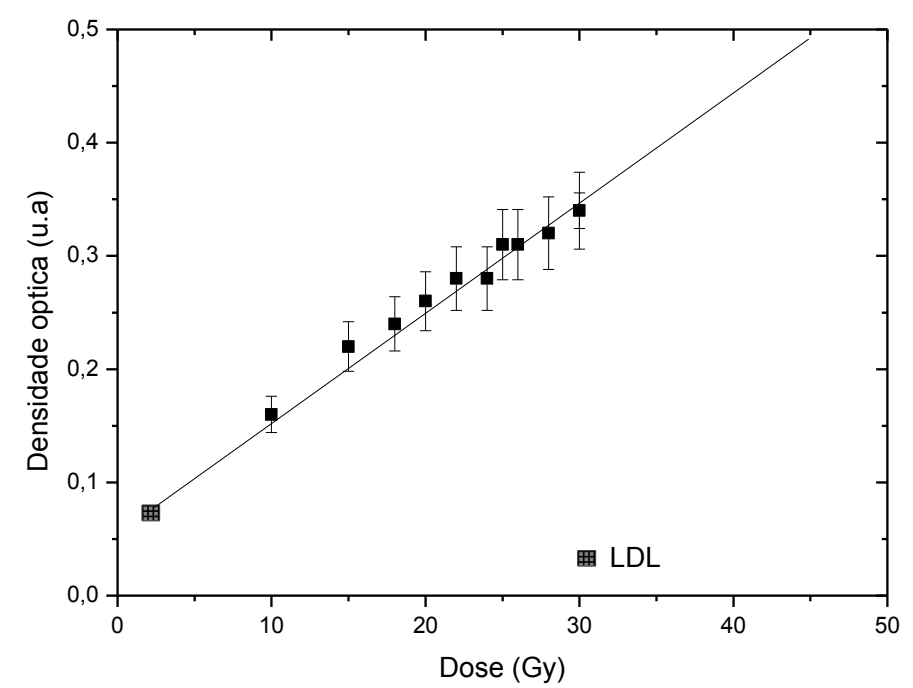

Figura 27. Resposta em função da dose do filme Grafchromic MD-55 irradiado com ${ }^{60} \mathrm{Co}$. 


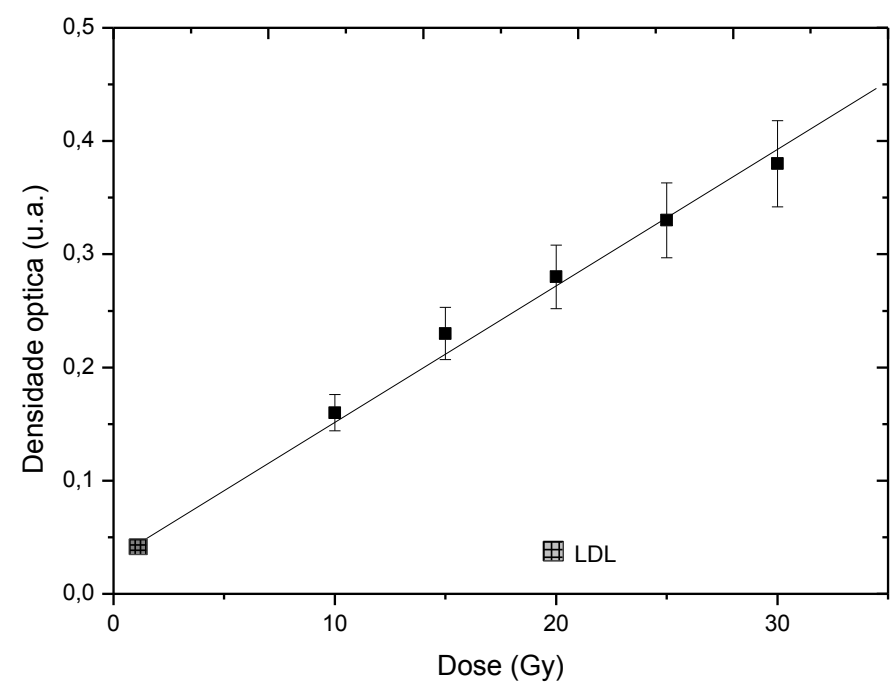

Figura 28. Resposta em função da dose do filme Grafchromic MD-55 irradiado com ${ }^{137}$ Cs.

A análise do filme Grafchromic MD-55 utilizando a técnica de densidade óptica, Figura 29, demonstrou dependência energética quando irradiado com fontes de ${ }^{137} \mathrm{Cs}$ e ${ }^{60} \mathrm{Co}$. O filme Grafchromic MD-55 demonstrou não ter boa precisão para intervalos de dose admitidos em rotina para o procedimento de irradiação de bolsas de sangue no irradiador Gammacell Elan.

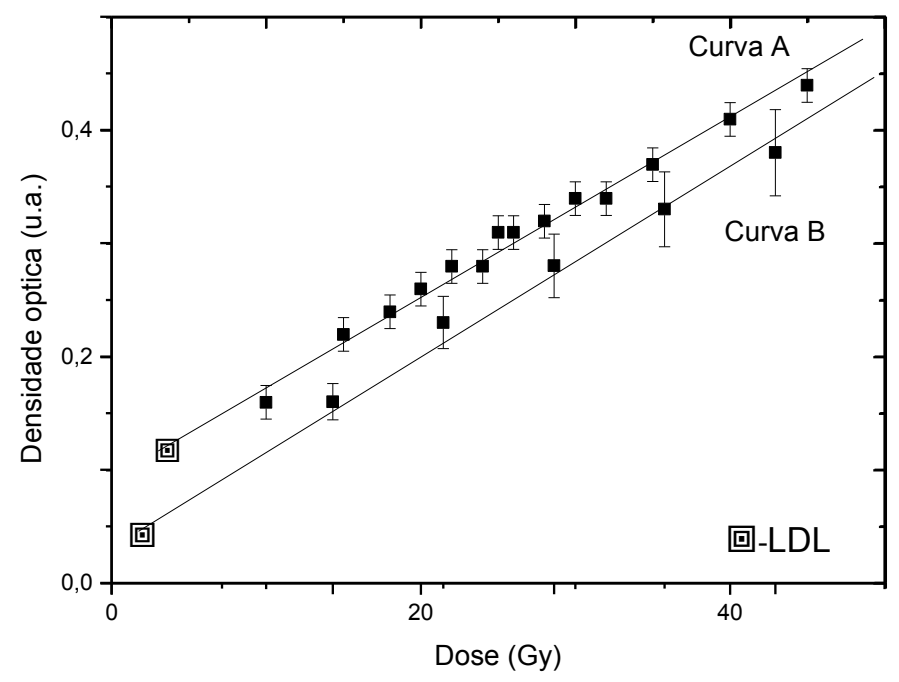

Figura 29. Curva de dose-resposta do filme Grafchromic MD-55 irradiado com ${ }^{60} \mathrm{Co}$ no irradiador Gammacell 220 (Curva A); e com ${ }^{137}$ Cs Gammacell Elan (Curva B).

Utilizando a técnica de absorção óptica o filme Grafchromic MD-55 foi irradiado no Gammacell Elan com doses compreendidas entre 1 Gy e 40 Gy. O espectro de absorção óptica apresentou um comportamento proporcional na região do comprimento de onda de 586 nm, mostrado na Figura 30. 


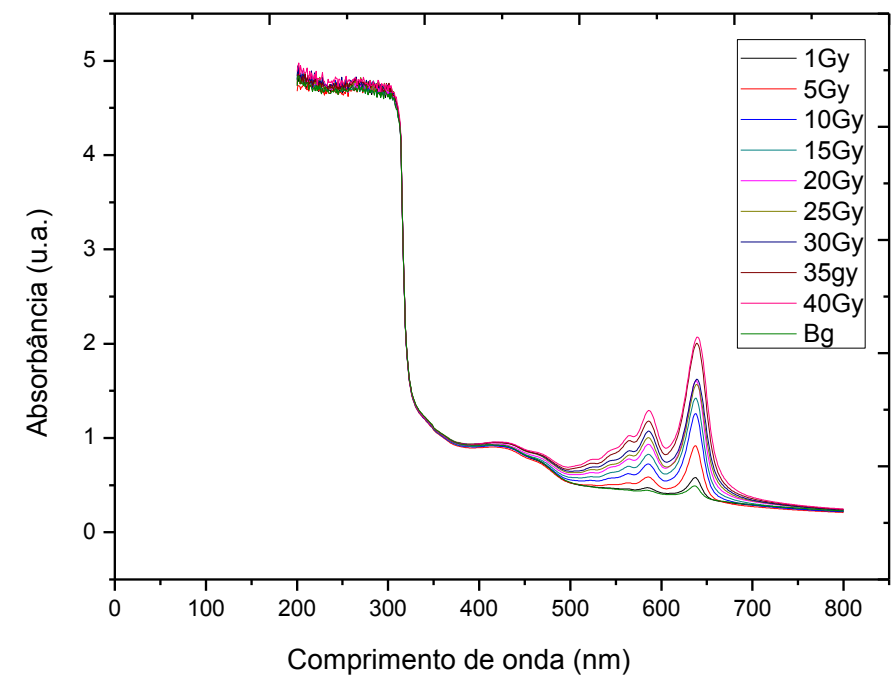

Figura 30. Espectro de absorção óptica do filme Grafchromic MD-55 irradiado com fonte de ${ }^{137} \mathrm{Cs}$ em rotação com doses entre 1,0 e 40,0 Gy.

A análise com espectrometria óptica, Figura 31, não apresentou resultados satisfatórios para doses de radiação superiores a 20,0 Gy. O filme radiocrômico demonstrou nos espectros uma região de interesse na faixa do comprimento de onda $(\lambda)$ de $586 \mathrm{~nm}$. Apesar de apresentar uma maior distinção entre as doses, o desvio padrão esteve sempre bem acima do recomendado. Não demonstrou aplicabilidade a rotinas dosimétricas, nas quais faz parte o nosso objeto de estudo.

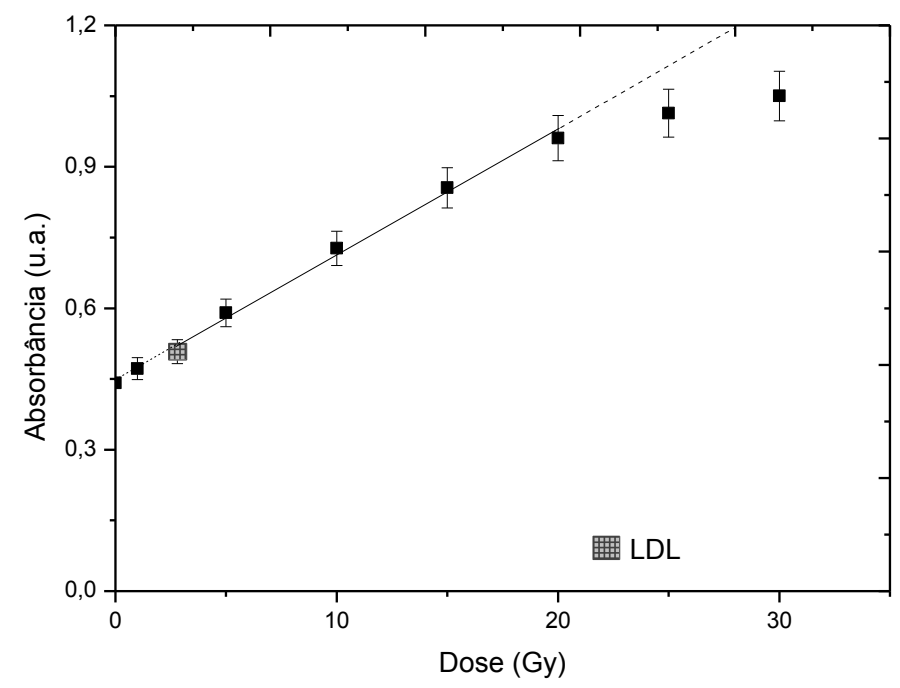

Figura 31. Curva de dose-resposta do filme Grafchromic MD-55 irradiado com ${ }^{137} \mathrm{Cs}$ analisado com técnica de espectrofotometria óptica. 


\subsection{Dosímetros Termoluminescentes (DTLs) - LiF:Mg,Ti}

Para a medição do tempo de abertura e fechamento do irradiador Gammacell Elan foram utilizados dosímetros de LiF:Mg,Ti (TLD-100). Os dosímetros foram irradiados com doses compreendidas entre 0,1 Gy e 1,0 Gy para a construção da curva-resposta. Na Figura 32 foi observado que ocorre linearidade na dose-resposta do dosímetro LiF:Mg,Ti .

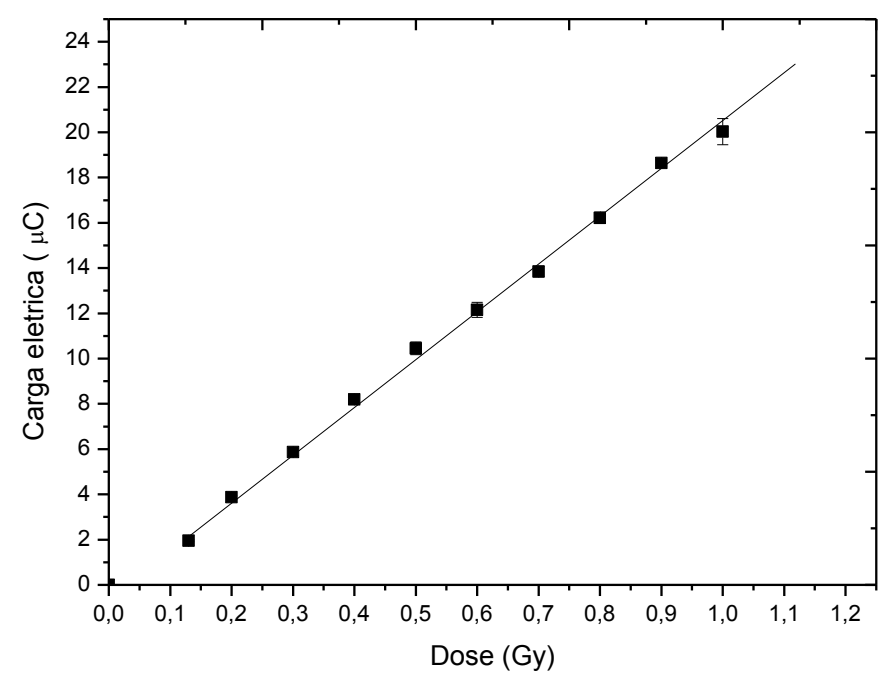

Figura 32. Curva de dose-resposta dosímetros LiF:Mg,Ti (TLD-100).

Os dosímetros foram posicionados no ponto médio do volume do canister do irradiador em condições de equilíbrio eletrônico e submetidos a doses de 0,5 Gy, 1,0 Gy e 1,5 Gy. As doses medidas nos dosímetros, Tabela 11, demonstraram que o desvio padrão assumiu valor máximo de 3,17\% quando submetido à dose de 1,5 Gy e 1,54 \% quando submetidos a doses de $1,0 \mathrm{~Gy}$. 


\section{CONCLUSÕES}

O estudo foi realizado depositando no canister do irradiador lotes com uma bolsa de sangue, duas bolsas e três bolsas e aplicando uma dose nominal de $25 \mathrm{~Gy}$. Os resultados obtidos indicam que o irradiador Gammacell Elan não demostrou homogeneidade na distribuição da dose. De acordo com os dados coletados a dose média avaliada foi 25,69 Gy. A dose mais elevada foi observada na região 1 , (variando entre 26,36 e Gy 26,67 Gy), e a menor dose na região 4, (variando entre 24,11 Gy e 24,23 Gy), mostrando que existe uma variação na dose efetiva aplicada na bolsa de sangue em relação a número de bolsas colocadas no canister do irradiador, ainda dentro dos limites da Agência Nacional de Vigilância Sanitária - ANVISA determina através da Resolução RDC 57 de 2010 que a dose mínima aplicada na esterilização de bolsas de sangue é de $25 \mathrm{~Gy}$. O Conselho Europeu de diretrizes do estado que recomenda que a dose mínima seja de $25 \mathrm{~Gy}$, mas não ultrapassando a dose de $50 \mathrm{~Gy}$.

As imagens produzidas por RMI e reconstruídas com uso do software MatLab $^{\circledR}$ (r2009a) e da estação de trabalho do equipamento de RMI demonstraram não homogeneidade na dose nominal de $25 \mathrm{~Gy}$ aplicada as bolsas de sangue de $300 \mathrm{~mL}$ para transferência.

A avaliação do tempo de abertura de fechamento do equipamento de irradiação Gammacell Elan demonstrou que, durante o procedimento de entrada e saída da amostra, existe uma diferença de dose em torno de 3,20\% acima da dose em que o equipamento é ajustado para realização das irradiações de bolsas de sangue.

O filme Grafchromic MD-55, apesar de ser produzido para irradiação em dupla-face, não apresentou resultado satisfatório para aplicação em rotinas de dosimetria no irradiador Gammacell Elan.

O irradiador Gammacell Elan demonstrou ser eficiente no processo de irradiação de bolsas de sangue para esterilização. O processo de irradiação não demonstrou homogeneidade na dose, porém o objetivo a que se propõe o equipamento foi atingido no que se refere ao intervalo de dose recomendado pela Anvisa e pelo Conselho Europeu de saúde. 


\section{REFERÊNCIAS BIBLIOGRÁFICAS}

- ANDREW, H. L., MURPHY, R. E., LEBRUN, E. J.. Gel dosimeter for depth dose measurements. Rev. Sci. Instrum., 28, 329-32, 1957.

- ATTIX, F.H.. Introduction to radiological physics and radiation dosimetry. New York, NY: John Wiley \& Sons. Cap. 11: Dosimetry fundamentals, 264-291, 1986.

- BUTSON, M.J., MATHUR, J.N., METCALFE, P.E.. Radiochromic film as a radiotherapy surface-doe detector. Phys. Med. Biol., 41, 10731087, 1996.

- BELLIVEAU, J. et al.. Functional mapping of the human visual cortex by magnetic resonance imaging. Science, 254, 716-719, 1991.

- BITELLI, T.. Física e dosimetria das radiações. $2^{\mathrm{a}}$ ed. São Paulo: Atheneu, 2006.

- BLACKWELL, C.R., COURSEY, B.M., GALL, K.P., GALVIN, J. M., MCLAUGHLIN, W.L., MEIGOONI, A.S., NATH, R., RODGERS, J.E., SOARES, C.G.. Radiochromic film dosimetry: Recommendations of AAPM RadiationTherapy Committee Task Group 55. American Association of Physicists in Medicine, 1998.

- BUShberG, J. T.; SEIBERT, J. A.; LeIDHOLFT JUNIOR, E. M.; BOONE, J. M. The essential physics of medical imaging. $2^{\mathrm{a}}$ ed. Philadelphia, PA: Lippincott Willians \& Wilkins, 2002.

- CAMERON, J.R.; SUNTHARALINGAM, N.; KENNEY, G.N. Thermoluminescent dosimetry. Londres: The Colonial Press, 1968. 
- CAVINATO, C.C.. Padronização do método de dosimetria Fricke gel e avaliação tridimensional de dose empregando a técnica de imageamento por ressonância magnética. 2009. Dissertação (Mestrado em Tecnologia Nuclear) - Instituto de Pesquisas Energéticas Nucleares - IPEN/USP, São Paulo, 2009.

- CAVINATO, C.C.. Dosimetria Tridimensional Aplicada a Tratamentos Radioterápicos e Radiocirúrgicos Utilizando Dosímetro Fricke Gel. 2013. Tese (Doutorado) - Instituto de Pesquisas Energéticas e Nucleares, São Paulo, 2013.

- CHUNG, W.H.. Chemical dosimetry. In: MAHESH, K.; VIJ, D.R. (Ed.). Techniques of radiation dosimetry. Índia: Wiley Eastern, 372-400, 1985.

- COHEN, B. L.. Concepts of Nuclear Physics, McGraw-Hill, 1971.

- SOARES, C.G.. Radiochromic film dosimetry. Radiation Measurements, 41, S100-S116, 2007.

- DAY, M. J., STEIN, G.. Chemical effects of ionizing radiation in some gels. Nature, 166, 146-147, 1950.

- FIELDEN, E.M.; HOLM, N.W.. Dosimetry in accelerator research and processing. In: HOLM, N.W.; BERRY, R.J. (Ed.). Manual on radiation dosimetry. New York, N.Y.: Marcel Dekker, 261-309, 1970.

- GALANTE, A.M.S.. Pesquisa, desenvolvimento e caracterização de materiais dosimétricos para monitoramento em processos de irradiação com doses altas. 2003. Tese (Doutorado) - Instituto de Pesquisas Energéticas e Nucleares, São Paulo, 2003. 
- GIL, V. M.S.; GERALDES, C. F. G. C.. Ressonância Magnetica Nuclear: Fundamentos, métodos e aplicações. Lisboa: Fundação Calouste Gulbenkian, 2002.

- GÓES, E.G., COVAS, D.T., HADDAD, R., PELÁ, C.A., FORMIGONE, C.E. et. J.C. BORGES. Quality control system for blood irradiation using a teletherapy unity. Vox Sanguinis, 86, 105-110, 2004.

- GÓES, E.G., OTTOBONI, M.A., P.V.B., et al.. Quality control of blood irradiation with a teleterapy unit: damage to stored red blood cells after cobalt-60 gamma radiation. Transfusion, 48, 332-340, 2008.

- GÓES, E.G., P. NICOLUCCI, I.C., NALI, C.A., PELÁ, J.L., BRUÇO, J.C., BORGES, D.T., COVAS.. Study of the spatial distribution of the absorbed dose in blood volumes irradiated using a teleterapy unit. Radiation Physics and Chemistry, 79, 673-677, 2010.

- GORE, J.C., KANG Y.S., SCHULZ R.J.. Measurement of radiation dose distributions by nuclear magnetic resonance (NMR) imaging. Phys. Med. Biol., 29(10), 1189-97, 1984.

- GREENING, J.R.. Fundamentals of radiation dosimetry. $2^{\mathrm{a}}$ ed. England: Adam Hilger. Cap. 2, interactions of ionising radiations with matter, 6-34, 1985.

- http://www.spl.harvard.edu/archive/HypX/theory1.html (acesso realizado em 31.03.2014 às 10h21min.)

- http://www.spl.harvard.edu/archive/HypX/research_files/theory2B.jpg(ace sso realizado em 31.03.2014 às 10h25min.)

- international ATOMIC ENERgy AGENCY. Dosimetry for food irradiation. Vienna, 2002. (Technical Report Series, 409). 
- INTERNATIONAl ATOMIC ENERgy AgENCy. Absorbed dose determination in external beam radiotherapy: an international code of practice for dosimetry based on standards of absorbed dose to water. Vienna, 2004. (Technical Report Series, 398).

- INTERNATIONAL COMMISSION ON RADIATION UNITS AND MEASUREMENTS. Prescribing, recording, and reporting photon beam therapy. Bethesda, MD, 1993. (ICRU Report 50).

- INTERNATIONAL COMMISSION ON RADIATION UNITS AND MEASUREMENTS. Prescribing, recording, and reporting photon beam therapy. Bethesda, MD, 1999. (ICRU Report 62).

- IZEWSKA, J.; RAJAN, G., ROSENBERG, I.H.. Review of Radiation Oncology Physics: A Handbook for Teachers and Students. International Atomic Energy Agency Publication., 3, 51-84, 2005.

- KAPLAN, I.. Física Nuclear. Rio de Janeiro: Editora Guanabara Dois S.A., 1978.

- KNOLL, G. F.. Radiation detection and measurement. John Wiley, N.Y., 4th ed., 1999.

- KRANE, K. S.. Introduction Nuclear Physics, John Wiley, N.Y., 1988.

- LANDI, E. P., OLIVEIRA, J. S. R. de. Doença do enxerto contra hospedeiro pós-transfusional- guia para irradiação gama de hemocomponentes. Rev. Ass. Med. Brasil, 45 (3), 261-72, 1999.

- LOBINSKI, R., MARCZENKO, Z.. Recent advances in ultravioletavisible spectrophotometry. Crit. Rev. Anal. Chem., 23, 55, 1992. 
- LILLEY, J. S.. Nuclear Physics: Principles and Applications. John Wiley \& Sons, N.Y., 2006.

- MANGUEIRA, T.F.. Avaliação dosimétrica da solução fricke gel usando a técnica de espectrofotometria para aplicação na dosimetria de elétrons e nêutrons. 2009. Dissertação (Mestrado) Instituto de Pesquisas Energéticas e Nucleares, São Paulo, 2009.

- McKeEVER, S.W.S.; MOSCOVITCH, M.; TOWNSEND, P.D. Thermoluminescence dosimetry materials: Properties and uses. Ashford, Kent: Nuclear Technology Publishing, 1995.

- MARGEN, C., KUNZEL, R., GÓIES, E. G., CÃS, E. V. da, ALVES, N. M. e BOTELHO, M. Z. Dosimetry of blood irradiation with cobalt teletherapy unit. Ciências Naturais e Tecnológicas, S. Maria, 6, 67-77, 2005.

- MATLAB $^{\text {TM }}$ v.9.0 - The MathWorks, Inc. MATLAB v.9.0 2010.

- MATSushima, L. C.. Avaliação da resposta de detectores termoluminescentes na dosimetria de feixes clínicos utilizando diferentes objetos simuladores. 2010. Dissertação (Mestrado em Tecnologia Nuclear) - Instituto de Pesquisas Energéticas Nucleares IPEN/USP, São Paulo, 2010.

- MAZZOLA, A. A.. Magnetic ressonance: principles of image formation and applications in funcional imaging. Revista Brasileira de Física Médica, 3(1). 117-29, 2009. 
- Mclaughlin, W. L., Miller, A., URIBE, R. M., KRONENBERG, S. and SIEBENTRITT, C. R. Energy dependence of radiochromic dosimeter response to $x$ - and rays. in High Dose Dosimetry, Proceedings of the International Symposium, Vienna, 1984, STI/PUB/671 (International Atomic Energy Agency, Vienna), pp. 397$424,1985$.

- MclaughliN, W. L., HUMPhReYS, J. C., HOCKEN, D. and CHAPPAS, W. J.. Radiochromic dosimetry for validation and commissioning of industrial radiation processes, in Progress in Radiation Processing, Proceedings of the Sixth International Meeting, Ottawa, 1987, edited by F. M. Fraser, Radiat. Phys. Chem., 31, 505-514, 1988.

- Mclaughlin, W.L., Yun-Dong, C., Soares, C.G., Miller, A., Van Dyk, G., LEWIS, D.F.. Sensitometry of the response of a new radiochromicfilm dosimeter to gamma radiation and electron beams. Nucl. Instrum. Methods Phys. Res., A 302, 165-176, 1991.

- Mclaughlin, W. L., PUHL, J. M., Al-ShEIKHLY, CHRISTOU, C. A., MILLER, A., KOVÁCS, A., WOJNÁROVITS, L. and LEWIS, D. F.. Novel radiochromic films for clinical dosimetry, in Proceedings of the 11th International Conference on Solid State Dosimetry, II, Budapest, July, 1995, edited by A. Peto and G. Uchrin @Radiat. Prot. Dosim., 66, 263268, 1996.

- McLAUGHLIN, W. L., Novel radiation dosimetry systems, invited aper in High Dose Dosimetry for Radiation Processing, Proceedings of Inter-2113, Niroomand-Rad et al.: Radiochromic film dosimetry 2113, Medical Physics, 25, No. 11, November, 1998. 
- MIZUNO, E.Y.. Desenvolvimento e caracterização de um gel Alanina para aplicação na medida da distribuição da dose de radiação usando a técnica de Espectrofotometria. 2007. Dissertação (Mestrado em Tecnologia Nuclear) - Instituto de Pesquisas Energéticas Nucleares - IPEN/USP, São Paulo, 2009.

- OGAWA, S. et al.. Brain magnetic resonance imaging with contrast dependent on blood oxygenation. In: NATIONAL ACADEMY OF SCIENCES. Proceedings. USA, 9868-9872, 1990.

- Olsson, L.E.; PETERSSON, S.; AHLGREN, L.; MATTSSON, S.. Ferrous sulphate gels for determination of absorbed dose distributions using RMI technique: basic studies. Phys. Med. Biol., 34, n. 1, 43-52, 1989.

- PATTON, G.A., SKOWRONK, M.G.. Implementation of a blood irradiation program at a community cancer center. Transfusion, 41, 2001.

- PECEQUILO, B.R.S.. Parte I: interação da radiação com a matéria. São Paulo: Instituto de Pesquisas Energéticas e Nucleares, 2007. Apostila da disciplina de pós-graduação TNA-5733: tópicos avançados de medidas nucleares, IPEN-USP, São Paulo, 2007.

- PERKAMPUS, H. H.; UV-VIS Spectroscopy and its Applications, Springer-Verlag: Berlin, 1992.

- PODGORSAK, E.B.. Radiation oncology physics: a handbook for teachers and students. Vienna: International Atomic Energy Agency. Cap. 1: Basic radiation physics, 1-43, 2010. 
- Resolução RDC no 57: Determina o Regulamento Sanitário para Serviços que desenvolvem atividades relacionadas ao ciclo produtivo do sangue humano e componentes e procedimentos transfusionais. Agência Nacional de Vigilância (ANVISA), Diário Oficial da União; Poder Executivo, 17 de dezembro de 2010.

- SILVA, C.F.. Avaliação dosimétrica da resposta Espectrofotométrica da solução gel de alanina para radiação gama, de fótons, de elétrons e de nêutrons térmicos. 2009. Dissertação (Mestrado em Tecnologia Nuclear) - Instituto de Pesquisas Energéticas Nucleares IPEN/USP, São Paulo, 2009.

- STABIN, M. G.. Radiation Protection and Dosimetry: An introduction to Health Physics. Springer, N.Y., 2008.

- SCHREINER, L.J.. Review of Fricke gel dosimeters. Phys:. Conf. Ser. 39, 2004.

- SEHESTED, K.. The Fricke dosimeter. In: HOLM, N.W.; BERRY, R.J. (Ed.). Manual on radiation dosimetry. New York, N.Y.: Marcel Dekker, 313-317, 1970.

- TAUHATA, L.; SALATI, I.P.A.; DI PRINZIO, R.; DI PRINZIO, M.A.R.R.. Radioproteção e dosimetria: fundamentos. $5^{\mathrm{a}} \mathrm{ed}$. rev. Rio de Janeiro: Instituto de Radioproteção e Dosimetria, 2003.

- TRINDADE, D.F; PUGLIESI, M.. Química básica teórica. São Paulo: Ícone, 1992.

- TURneR, J. E.. Atoms, Radiation, and Radiation Protection. WileyVCH, 2007. 
- YOSHIMURA, E. M.. Física das Radiações: interação da radiação com a matéria. Revista Brasileira de Física Médica, 3(1), 57-67, 2009. 